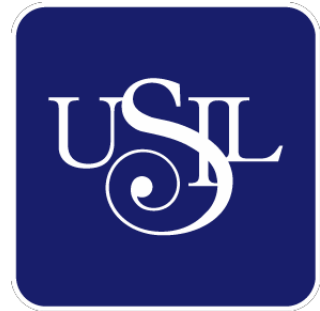

UNIVERSIDAD

SAN IGNACIO

DE LOYOLA

ESCUELA DE POSTGRADO

Maestría en Educación con Mención en Docencia en Educación Superior

\title{
ESTRATEGIA METODOLÓGICA PARA DESARROLLAR LA COMPETENCIA COMUNICATIVA ORAL EN LOS ESTUDIANTES DE INGLÉS DE NEGOCIOS INTERNACIONALES DE UNA UNIVERSIDAD PRIVADA DE LIMA
}

Tesis para optar el grado de Maestro en Educación con Mención en Docencia en Educación Superior

SUSAN JANNINA CUBAS CRUZ

Asesor:

Míriam Encarnación Velázquez Tejeda

Lima - Perú

2020 


\section{Dedicatoria}

A mi padre y a mi hermana que me apoyaron incondicionalmente en esta etapa profesional y de manera especial a mi madre que sentó en mí las bases de responsabilidad y deseos de superación. 


\section{Agradecimiento}

A mi asesora, Miriam Velázquez Tejeda por su apoyo y orientación permanente en la presente investigación.

A los docentes especialistas que con su experiencia y maestría pedagógica otorgaron un significativo aporte al trabajo investigativo.

A mis padres, por brindarme la motivación necesaria de seguir adelante con mi formación profesional. 


\section{Índice}

Carátula

Dedicatoria

Resumen

Abstract

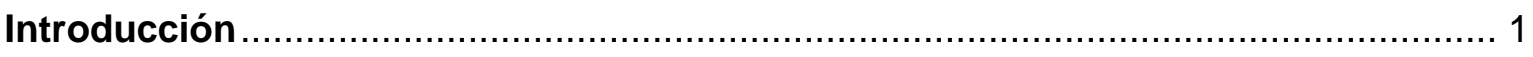

Planteamiento del problema de investigación ....................................................... 3

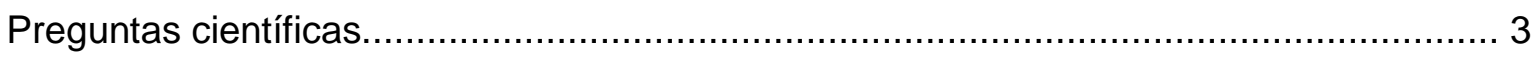

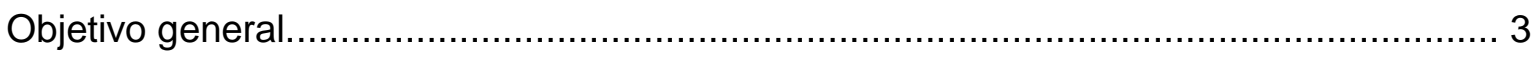

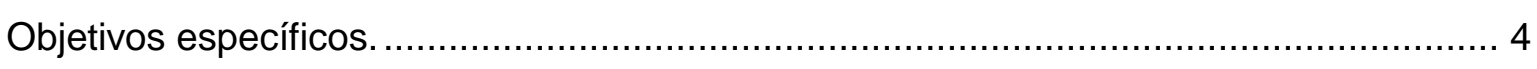

Categorías y subcategorías apriorísticas …....................................................... 4

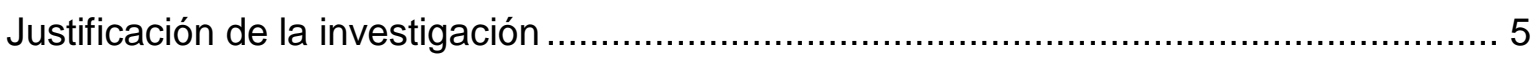

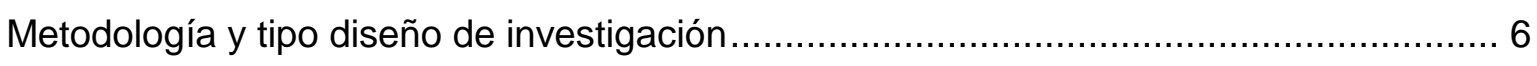

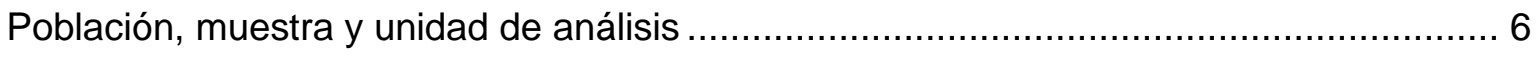

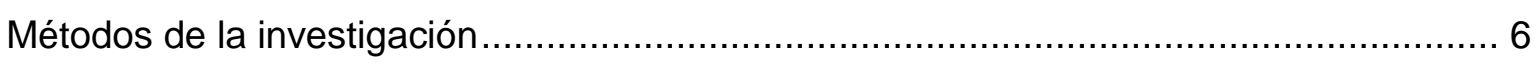

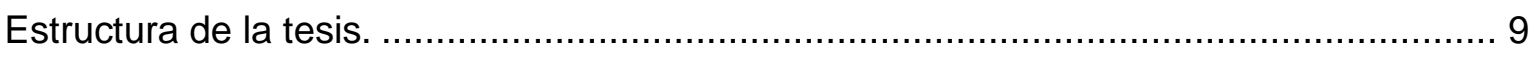

\section{Capítulo I}

\section{Marco Teórico}

Antecedentes internacionales y nacionales ...................................................... 10

Reflexiones teóricas sobre el aprendizaje como proceso psicológico ……......................13

Fundamentos teóricos sobre la expresión oral......................................................15

La competencia comunicativa, un acercamiento a su estudio....................................19

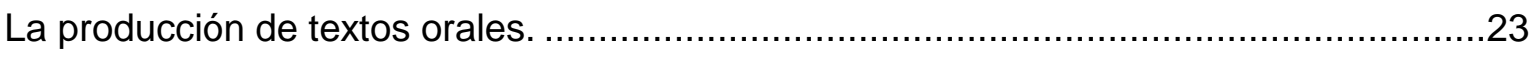

Especificidades del enfoque comunicativo y la enseñanza del idioma. .........................26

Métodos que contribuyen al desarrollo de la competencia comunicativa oral .................29

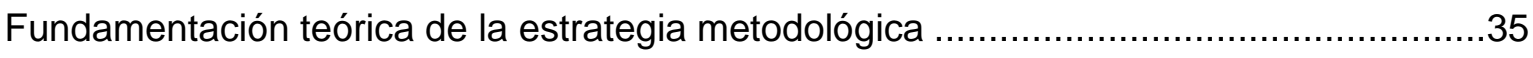




\section{Capítulo II}

\section{Diagnóstico o trabajo de campo}

Diseño y validación de los instrumentos .40

Procesamiento de la información, análisis, interpretación y discusión de los resultados...40

Relaciones analíticas e interpretativas de las categorías emergentes sustantivas...... .46

Contrastación teórica de las categorías emergentes incidentes en el problema .47

Conclusiones aproximativas del análisis realizado .49

\section{Capitulo III}

\section{Modelación, validación y aplicación de la propuesta}

Propósito de la estrategia metodológica .50

Fundamentación de la estrategia metodológica propuesta .50

Principios didácticos que rigen la enseñanza- aprendizaje de la propuesta .57

Estructura de la estrategia metodológica modelada .61

Concepción de la tarea de estudio en el proceso de enseñanza- aprendizaje .68

Orientaciones para la aplicación del método problémico en la estrategia .73

Validación de las potencialidades de la estrategia por consulta a especialistas. .79

Conclusiones .83

Recomendaciones .85

Referencias .86

Anexos . .94 


\section{Índice de Anexos}

Anexo 1 Matriz Metodologica

Anexo 2 Matriz de categorias, subcategorias e indicadores

Anexo 3 Instrumentos de investigación

Anexo 4 Fichas de validación de los instrumentos

Anexo 5 Resultados del analisis cualitativo de la entrevista a los docentes

Anexo 6 Resultados del analisis de la encuesta a los estudiantes

Anexo 7 Resultados del analisis de la prueba pedagogica

Anexo 8 Sesiones de aprendizaje

Anexo 9 Ficha de validación de la propuesta 


\section{Índice de tablas}

Tabla 1 Categorías y subcategorías apriorísticas

Tabla 2 Dosificación del sistema de clases de la unidad 1 de la asignatura Inglés II

Tabla 3 Diseño de talleres de capacitación docente

Tabla 4 Relación de expertos que validaron la propuesta

Tabla 5 Tabla de Valoración

Tabla 6 Sumatoria de la valoración interna y externa de los expertos

Tabla 7 Resultado de la valoración interna y externa de la estrategia por los expertos 


\section{Índice de figuras}

Figura 1 Categorías emergentes generales.

Figura 2 Categorías emergentes influyentes en el problema investigado.

Figura 3 Esquema teórico - funcional de la estrategia metodológica

Figura 4. Estructura de una unidad didáctica a través del enfoque por tareas.

Figura 5. Secuenciación de una unidad didáctica desde este enfoque. 


\section{Resumen}

La investigación se planteó como objetivo general diseñar una estrategia metodológica para contribuir al desarrollo de la competencia comunicativa oral en los estudiantes de primer año de la asignatura Inglés II de la carrera de Negocios Internacionales de una universidad privada de Lima. La metodología utilizada responde al paradigma sociocrítico interpretativo, el enfoque es cualitativo y el tipo de investigación es educacional de tipo aplicada. En este tipo de indagación el investigador reconoce el problema en su aula docente y lo analiza, profundiza en la teoría, explica por qué y busca soluciones para transformar la realidad educativa. En el estudio se utilizaron métodos cualitativos y cuantitativos que facilitaron argumentar desde distintas posiciones teóricas el problema científico. La muestra seleccionada por conveniencia la conforman docentes y estudiantes. Como parte del diagnóstico de campo se utilizaron métodos cualitativos y cuantitativos que permitieron analizar desde distintas posiciones teóricas el problema científico. Se aplicaron distintas técnicas e instrumentos como: entrevista semiestructurada y observación a clases a los docentes; un cuestionario y una prueba pedagógica a los estudiantes. Al triangular la información obtenida mediante el proceso investigativo se identificaron las fortalezas y las categorías emergentes que inciden en el problema investigado. Como parte del proceso de investigación se aporta a la práctica pedagógica una estrategia metodológica que dados sus fundamentos científicos y metodológicos sistematizados en el marco teórico orienta el desempeño del docente en el proceso de enseñanza- aprendizaje de la asignatura Inglés a fin de contribuir al desarrollo de la competencia comunicativa oral en los estudiantes de primer año

Palabras claves: estrategia metodológica, competencia comunicativa oral, aprendizaje. 


\begin{abstract}
The research proposes a methodological strategy in response to the deficiencies manifested in the performance of the oral communicative competence demonstrated both by a group of students and by the pedagogical practice of teachers in the development of this competence. Within this framework, the study is based on a set of theories, approaches, methods and procedures in order to carry out an analysis of analysis that supports the categories that influence the educational process. The research is in the context of the English subject at the International Business School of a private university in Lima, whose methodology is qualitative, educational and applied type and developed within a socioargumentative interpretative critical paradigm with the empirical method. The research sample was carried out by a non-probabilistic sampling for convenience and is composed of fifteen students and four teachers. Techniques and instruments were used such as teacher interview and observation of teachers; student survey and pedagogical test and expert criteria. In the theoretical framework, the aprioristic categories were systematized from holistic positions. The field diagnosis known the current state of the pedagogical process, teacher performance and the factors that affect the development of oral competence in students. The contrast of aprioristic categories with emerging categories allows the identification of emerging influential categories in the problem. As a general conclusion, a methodological strategy based on theoretical foundations and which gets a system of principles, activities, learning lessons and other pedagogical arguments that improve teacher performance by directing teaching - functionality learning with the proper development of oral proficiency in students.
\end{abstract}

Keywords: methodological strategy, oral communicative competence, pedagogical practice. 


\section{Introducción}

En el siglo XXI el mundo se enfrenta a diversos cambios, eventos y conflictos en todos los ámbitos del saber humano como parte del proceso de globalización. Este avance de las fuerzas productivas ha traído consigo un desarrollo vertiginoso en las ciencias y las tecnologías que han incidido notablemente en el volumen de información y las comunicaciones que se producen en todos los sectores del planeta.

Ante tales cambios abruptos, la sociedad demanda de los sistemas educativos la puesta en práctica del conocimiento científico, el uso de medios audiovisuales y la aplicación de métodos y procedimientos que promuevan en los estudiantes el pensamiento crítico, la formación de valores y la socialización para que puedan comunicarse amplia y acertadamente en el ámbito social en distintas lenguas, evidenciado el nivel cultural y la formación integral adquirida como un hablante de su época que debe enfrentar los retos culturales, como resalta Díaz Barriga (1995), Roméu (2007), Domínguez (2010) y Cassany (2016).

La Organización de las Naciones Unidas para la Educación, la Ciencia y la Cultura, (Unesco, 2012), refiere que el Inglés es un idioma universal debido a las dinámicas sociales, económicas y políticas. En consecuencia, su aprendizaje ha captado el interés de los jóvenes, estudiantes y la sociedad en su conjunto. Una de las motivaciones principales es poder acceder a la información internacional que, en su generalidad, aparece en esta lengua, otra para ampliar el nivel cultural y la competencia profesional de los egresados universitarios y tener mejor perfil ocupacional.

En ese sentido, el Marco Común de Referencia (Mcerl, 2017), documento que ha trascendido a través de los años como una herramienta de consulta en el campo de la lingüística aplicada, explica y contextualiza la realidad social del estudiante de este idioma. Su enseñanza no puede darse a través de un único método, por el contrario, deben aplicarse los métodos heurísticos, investigativos, creativos entre otros para logras asequibilidad en el aprendizaje y cumplimiento de los objetivos previstos.

Al respecto, Lujan (2012) expresa que dada la importancia de la enseñanza de la lengua inglesa es necesario sistematizar la realización de las investigaciones y publicar sus resultados en los eventos científicos y las revistas indexadas, a fin de divulgar las distintas problemática, las experiencias, el tratamiento metodológico y las propuestas de solución a la problemática. Se requiere estimular a los docentes en esa línea de acción para socializar 
el quehacer del aprendizaje de una segunda lengua en el aula y que el producto pueda llegar a los docentes y la población en general.

En América Latina, la enseñanza- aprendizaje de esta materia no ha tenido un notorio dinamismo y eficiencia, salvo algunas excepciones. En los últimos años se aprecia un nivel de concientización en los organismos responsables, directivos, docentes, estudiantado y las familias por el interés que ha suscitado esta lengua y como una respuesta para contrarrestar los resultados del estudio de Education First, (2018). Se reconocen una variedad de factores que dificultan la enseñanza y el desarrollo de los conocimientos y las habilidades idiomáticas en los educandos que son necesarios transformar.

Para enfrentar ese desafío se requiere que los docentes sean idóneos, que estén preparados en el dominio de los métodos y procedimientos que estimulen en los educandos las habilidades de observación, el pensamiento analítico, la escucha, el lenguaje, la comprensión y en general comunicarse adecuadamente a partir de los saberes previos, experiencias y vivencias socioculturales del contexto (Roméu, 2007; Harmer, 2015 y Pompilla et al., 2019).

En el Perú, el Ministerio de Educación (Minedu, 2012), ha perfeccionado el sistema educativo como es la reformulación de distintos objetivos orientados a provocar un cambio cualitativo superior en la enseñanza- aprendizaje de la disciplina Inglés. Se aplican una serie de programas y medidas para contribuir a la capacitación docente para lograr la eficiencia en la enseñanza- aprendizaje, entre ellas: El reordenamiento curricular de los programas de estudio del Inglés, nuevos planes de formación de profesores, capacitación docente en la didáctica universitaria, incremento de las horas clases por carreras profesionales como lo precisa la Ley Universitaria Nro. 30220 (2014).

A partir de esas exigencias, los docentes han recibido las capacitaciones para transformar la calidad del proceso de enseñanza- aprendizaje, aunque se hace necesario ahondar en los métodos heurísticos, dialógicos, colaborativos, comunicativos con el uso de las Tecnologías de la Información y las Comunicaciones y la didáctica del habla a fin de potenciar en el estudiantado el dominio del qué, cómo, para qué y cómo aplicar lo aprendido en la construcción de textos orales y escritos de esta materia ( Cassany, 2009 y Domínguez, 2010).

En el perfil de la carrera de Negocios Internacionales (2018), se indica en la asignatura de Inglés para el primer año, que los estudiantes deben desarrollar la competencia comunicativa oral: hablar, leer y producir textos; comprender lo escuchado, construir pequeños diálogos con coherencia y en general, desarrollar las habilidades comunicativas idiomáticas desde su experiencia y vivencias del entorno sociocultural. 
Sin embargo, en la enseñanza- aprendizaje de esa materia se observan deficiencias en los estudiantes, evidenciadas en el bajo nivel de los conocimientos y el desarrollo de las habilidades para expresarse, escuchar, comprender, realizar sencillos diálogos y leer; pobreza de vocabulario, dificultades en la pronunciación, fluidez y coherencia en las ideas al construir textos, lo cual provoca en ellos desinterés y desmotivación por el aprendizaje de esta materia.

\section{Planteamiento del problema de investigación}

¿Cómo desarrollar la competencia comunicativa oral en los estudiantes de Inglés II de la carrera de Negocios Internacionales de una universidad privada de Lima?

\section{Preguntas científicas.}

¿Cuáles son los fundamentos teóricos y metodológicos que sustentan el estudio del desarrollo de la competencia comunicativa oral en los estudiantes de primer año de la asignatura Inglés II de la carrera de Negocios Internacionales de una universidad privada de Lima?

¿Cuál es el estado actual del desarrollo de la competencia comunicativa oral en los estudiantes de primer año de la asignatura Inglés II de la carrera de Negocios Internacionales de una universidad privada de Lima?

¿Qué sustentos teóricos y metodológicos sirven de base a la modelación de la estrategia metodológica para contribuir al desarrollo de la competencia comunicativa oral en los estudiantes de primer año de la asignatura Inglés II de la carrera de Negocios Internacionales de una universidad privada de Lima?

¿Cómo validar por criterios de expertos la efectividad de la estrategia metodológica modelada para contribuir al desarrollo de la competencia comunicativa oral en los estudiantes de primer año de la asignatura Inglés II de la carrera de Negocios Internacionales de una universidad privada de Lima?

\section{Objetivo general.}

Diseñar una estrategia metodológica para contribuir al desarrollo de la competencia comunicativa oral en los estudiantes de primer año de la asignatura Inglés II de la carrera de Negocios Internacionales de una universidad privada de Lima. 


\section{Objetivos específicos.}

Argumentar los fundamentos teóricos y metodológicos que sustentan el estudio da la competencia comunicativa oral en los estudiantes de primer año de la asignatura Inglés II de la carrera de Negocios Internacionales de una universidad privada de Lima.

Diagnosticar el estado actual del desarrollo de la competencia comunicativa oral del idioma Inglés en los estudiantes de primer año de la asignatura Inglés II de la carrera de Negocios Internacionales de una universidad privada de Lima.

Determinar los sustentos teóricos y metodológicos que sirven de base a la modelación de la estrategia metodológica para contribuir al desarrollo de la competencia comunicativa oral en los estudiantes de primer año de la asignatura Inglés II de la carrera de Negocios Internacionales de una universidad privada de Lima

Validar por criterios de expertos la efectividad de la estrategia metodológica modelada para contribuir al desarrollo de la competencia comunicativa oral en los estudiantes de primer año de la asignatura Inglés II de la carrera de Negocios Internacionales de una universidad privada de Lima.

\section{Categorías y subcategorías apriorísticas}

En el estudio se definieron dos categorías apriorísticas y respectivas subcategorías Tabla 1

Categorías y subcategorías apriorísticas

\section{Categorías apriorísticas $\quad$ Subcategorías apriorísticas}

\section{Competencia comunicativa oral}

Es la correcta producción de la oralidad y percibir sin distorsionar el mensaje (implícito o explicito) para lograr el intercambio salomónico mediante recursos en situaciones de socialización (Llatas, 2017).

\section{Estrategia metodológica}

Es el conjunto de acciones y procedimientos, mediante el empleo de métodos, técnicas, medios y recursos que el docente emplea con el propósito de lograr eficazmente el proceso educativo en una situación de enseñanza aprendizaje especifica (Hernández 2017).

\section{Competencia semántica}

Competencia discursiva

Competencia sociolingüística

Determinación de necesidades y el objetivo general.

Sistema de métodos

Etapas y evaluación de la metodología

Fuente: Elaboración propia (2019). 


\section{Justificación de la investigación}

\section{Justificación teórica.}

La investigación se realiza con el fin de contribuir al desarrollo de la competencia comunicativa oral en los estudiantes de primer año de la asignatura Inglés II de la carrera de Negocios Internacionales de una universidad privada de Lima. De ahí que a través de la sistematización teórica de las categorías apriorísticas, la competencia comunicativa oral y su tratamiento en el proceso enseñanza- aprendizaje se ha podido ampliar la concepción científica del problema desde la perspectivas tratado desde los referentes de Vygotsky (1987), Canale,(1995), Font (1998), Machado (2009, Cassany (2006-2013), Domínguez (2010), Harmer (2015) y Pompilla (2019), entre otros, quienes fundamentan desde el enfoque comunicativo la necesidad de modelar una estrategia metodológica para estimular el desarrollo de las habilidades comunicativas en ambientes de asertividad y creatividad dialógica por los estudiantes. Línea de investigación: enseñanza - aprendizaje.

\section{Justificación metodológica.}

El estudio responde a la investigación educacional cualitativa de tipo aplicada, se sistematizan los referentes teóricos y se comprueba el estado actual del problema investigado con el propósito de modelar y proponer a la práctica pedagógica una estrategia metodológica que tiene en cuenta el rol del docente como mediador del proceso de enseñanza- aprendizaje, el empleo de los métodos que estimulan la comunicación, la reflexión y el diálogo que estimulan el rol protagónico de los estudiantes en la construcción del aprendizaje y el desarrollo de la competencia comunicativa oral del idioma Inglés.

\section{Justificación práctica.}

La investigación responde a la necesidad de mejorar el nivel de competencia comunicativa oral de los estudiantes de primer año universitarios y el desempeño de los docentes al guiar la enseñanza- aprendizaje del idioma Inglés para contribuir al desarrollo de las habilidades comunicativas en el estudiantado. El proceso de sistematización de los referentes teóricos contrastados con los resultados del diagnóstico de campo permitió modelar la estrategia metodológica, como medio factible de solución a la problemática investigada. El modelo teórico -práctico propuesto en las manos de los docentes, se convierte en una guía innovadora para guiar con eficiencia el proceso de enseñanza- aprendizaje con la finalidad de estimular el desarrollo de la competencia comunicativa oral en los estudiantes. 


\section{Metodología y tipo diseño de investigación}

El estudio responde al paradigma socio crítico -interpretativo, el enfoque cualitativo y se concreta en una investigación educacional de tipo aplicada. Esta se caracteriza por el tratamiento al problema científico desde un enfoque epistemológico crítico-social en el que se integran de forma lógica los métodos cualitativos en la sistematización, descripción e intervención para transformar la realidad. El carácter dialéctico de este tipo de investigación contribuya en la innovación estratégica en la metodología para desarrollar la competencia comunicativa oral. El autor determinó el problema investigado a partir de la práctica y observación pedagógica a través de la sistematización de referentes teóricos analizan el problema, causas y diseña la propuesta de orden metodológico que contribuye a transformar el proceso de enseñanza- aprendizaje de los estudiantes del primer año en el idioma de una universidad privada de Lima.

\section{Población, muestra y unidad de análisis}

\section{Población.}

La población objeto de investigación está integrada por 50 profesores de la especialidad de Inglés del Nivel Básico a tiempo completo, 120 estudiantes del idioma de primer año y tres directivos de la carrera de Negocios Internacionales de una universidad privada de Lima.

\section{Muestra.}

La muestra seleccionada por conveniencia, la integran cinco profesores de la especialidad de Inglés del Nivel Básico a tiempo completo, 15 estudiantes de primer año y tres directivos de la carrera de Negocios Internacionales de una universidad privada de Lima.

\section{Unidad de análisis.}

La unidades de análisis están constituida por los docentes de la especialidad de Inglés, los estudiantes de primer año, directivos, las fuentes científicas especializadas y los documentos normativos que rigen el trabajo docente metodológica de la Educación Universitaria.

\section{Métodos de la investigación}

Métodos teóricos.

Los métodos teóricos, permitieron obtener información con el fin de lograr una descripción integra y trascendente de la situación actual. Estos métodos fueron los siguientes. 


\section{Histórico- lógico.}

Gonzales y Sánchez (2012), refiere que este conduce al análisis de los antecedentes históricos de la investigación para conocer el origen, la evolución y el estado actual del objeto investigado en el tiempo. Se empleó para conocer cómo ha sido la enseñanzaaprendizaje del Inglés y el desarrollo de las habilidades comunicativas de los estudiantes universitario.

Análisis- síntesis.

Afirma Rodríguez (2002), el análisis implica la descomposición de un todo en sus partes, permitiendo el estudio de sus características, elementos, propiedades y relaciones, mientras que la síntesis se podría considerar como un método inverso. Se analizan las partes y se integran en un todo. Se empleó en el análisis y procesamiento de la información obtenida de los instrumentos aplicados.

Inductivo- deductivo.

según Bernal (2010), este método favorece el razonamiento mediante la lógica, lo inductivo se aprecia cuando el conocimiento pasa de aspectos particulares a lo general para establecer un sistema de formulaciones teóricas dirigidas a perfeccionar la base metodológica y epistemológica del desarrollo de la competencia comunicativa oral en los estudiantes. Se usó al procesar las fuentes teóricas y los resultados de los instrumentos aplicados.

Análisis documental.

Cerezal et al. (2002), considera que puede ser utilizado para analizar los documentos normativos que dieron soporte a la fundamentación de la investigación y a la elaboración de la propuesta metodológica. Se usó para analizar el perfil, el diseño curricular y el plan de estudio de la carrera y otros documentos normativos que rigen la docencia universitaria.

\section{Modelación.}

Según Gonzales (2007), es un proceso mediante el cual se crea una representación o modelo para transformar la realidad investigada, representando las características y relaciones fundamentales del objeto de estudio, proporcionando explicaciones y sirviendo de guía para generar hipótesis teóricas. Se empleó en el diseño y modelación de la estrategia metodológica para contribuir al desarrollo de la competencia comunicativa oral de los estudiantes en la asignatura Inglés.

\section{Técnicas e instrumentos de investigación}

Se emplean varios métodos del nivel empírico conocidos como técnicas y son los siguientes. 
Observación a clases de docentes.

Se usó con la finalidad de verificar el nivel de conocimientos teóricos y metodológicos de los docentes al guiar el proceso enseñanza-aprendizaje para analizar cómo se orienta la obtención de la competencia comunicativa y cómo reaccionan los discentes a este y al propio tratamiento de estas habilidades. Se utilizó como instrumento una guía de observación de clase.

Encuestas a los estudiantes.

Se aplicó para conocer el nivel de conocimientos y habilidades que poseen acerca de los contenidos y el grado de interés que muestran. Para tal fin se aplicó un cuestionario con veinte ítems.

Entrevista semiestructurada a docentes.

Se utilizó para constatar el nivel de conocimientos teóricos y metodológicos que poseen los docentes al orientar el proceso de enseñanza- aprendizaje en la expresión oral de la asignatura Inglés. Para ello se aplicó una guía de entrevista semiestructurada con distintos ítems.

Prueba pedagógica.

Se aplicó a los estudiantes para comprobar el nivel de conocimiento y las habilidades desarrolladas por los estudiantes en la competencia comunicativa oral. Se diseñó un cuestionario de cinco ejercicios de contenidos tratados en clases.

Criterio de expertos.

Se aplicó con el objetivo de que los especialistas validen la efectividad de la estrategia metodológica propuesta. Se emplearon como instrumentos dos rúbricas para la evaluación externa y la interna del producto final.

Métodos matemáticos.

Se empleó para realizar el análisis porcentual durante el procesamiento de los datos obtenidos mediante la aplicación de los instrumentos del diagnóstico.

\section{Métodos estadísticos.}

Se emplearon durante el procesamiento de la información mediante la estadística descriptiva que servirá para el procesamiento de los datos diagnóstico.

\section{Novedad científica}

La novedad científica de la investigación consiste en la sistematización de los fundamentos 
que sustentan las categorías apriorísticas desde posiciones holísticas, el tratamiento al diagnóstico de campo e identificación de las categorías emergentes influyentes en el objeto de estudio y la modelación de la estrategia metodológica que se aporta a la práctica pedagógica como producto de la investigación con el propósito de contribuir al desarrollo de la competencia comunicativa oral del idioma Inglés en los estudiantes.

\section{Estructura de la tesis.}

La tesis se inicia con la introducción que comprende los aspectos del diseño teórico metodológico que explica el proceso seguido en el proceso de la investigación. Esta investigación está estructurada en tres partes:

\section{Capítulo I.}

Comprende la fundamentación teórica a partir de la sistematización teórica realizada sobre las categorías y subcategorías apriorísticas tratadas desde posiciones integradoras y holísticas que dan sustento a la investigación desde distintitas perspectivas y que empoderaron al investigador para identificar las subcategorías y los indicadores de las categorías tratadas tanto desde el punto de vista teórico como didáctica

\section{Capítulo II.}

Comprende el diagnóstico o trabajo de campo que comprende el diseño, validación, aplicación e interpretación de las técnicas e instrumentos para constatar el estado actual del desarrollo de la competencia comunicativa oral de los estudiantes a través del proceso de enseñanza- aprendizaje de la asignatura inglés. Ello permitió e identificar las categorías emergentes sustantivas y los emergentes incidentes en el problema investigado.

\section{Capítulo III.}

A partir de la sistematización teórica y la identificación de las categorías emergentes influyentes negativamente en el problema, se modeló la estrategia metodológica desde los fundamentos científico y prácticos integradores que permiten al docente dirigir el proceso de enseñanza- aprendizaje a fin de desarrollar la competencia comunicativa oral en los estudiantes.

Se culmina el informe dando a conocer las conclusiones que son el resultado del proceso de investigación, las recomendaciones, las referencias y los anexos. 


\section{Capítulo I \\ Marco Teórico}

\section{Antecedentes internacionales y nacionales}

Al revisar el tema que sustenta el problema objeto de estudio se aprecia que ha sido motivo de investigación en el proceso enseñanza-aprendizaje por diferentes especialistas a nivel internacionales y nacionales

\section{Antecedentes internacionales.}

Al respecto Correa et al, (2017), desarrolló una investigación, cuyo objetivo se orientó a utilizar una relación entre la organización de sala de clases en grupos y la participación de los estudiantes en actividades en producción oral en clases de Inglés como lengua extranjera en Chile, este trabajo de investigación-acción busca conocer los efectos de cambiar esta distribución de filas a grupos, en la participación de los estudiantes en actividades de producción oral en clases de inglés. Este estudio fue llevado a cabo en dos fases: la primera, con la sala de clases organizada en filas, y la segunda, en grupos. Los resultados mostraron que la organización en grupos estimula la interacción entre los estudiantes, quienes muestran una actitud positiva hacia la nueva organización de la sala de clases y parecen motivados a participar, aun cuando mayoritariamente hablaron en español. No obstante, los participantes valoraron la oportunidad de interactuar con sus compañeros en un ambiente relajado y acogedor.

Aguilera et al. (2012), realizó una investigación titulada, La expresión oral como un componente de la competencia comunicativa en idioma Inglés. En el trabajo se presenta una concepción sobre el proceso de enseñanza - aprendizaje de la formación y desarrollo de la habilidad de expresión oral y su relación con el resto de las habilidades comunicativas: comprensión de textos y expresión escrita, además se exponen los aportes de investigadores nacionales y extranjeros. Se muestra ejemplos de tareas de aprendizaje para el tratamiento a la habilidad de expresión oral en idioma inglés de los estudiantes de primer año de la carrera de Ingeniería Geológica, como vía para contribuir a la formación y desarrollo de su competencia comunicativa atendiendo a las necesidades, intereses y motivaciones del futuro profesional geológico con énfasis en lo interactivo y colaborativo.

Pomposo (2016), llevó a cabo una investigación con el objetivo de analizar la evaluación de la competencia oral en segundas lenguas. El caso del inglés en el mundo profesional. En este documento se realizó un planteamiento teórico de la evaluación de la competencia oral en segundas lenguas, el proceso de evaluación y la importancia de las escalas de valoración. Se apreció las que son utilizadas por las instituciones más 
reconocidas en la enseñanza, la evaluación sus descriptores, ejemplos de esta en el mundo laboral y además se propone una rúbrica para evaluar de forma holística para utilizarla en el proceso de selección de candidatos a un trabajo.

Gonzales et al. (2013), desarrollaron una investigación titulada: Consideraciones metodológicas sobre la evaluación de la competencia oral en L2. Se realizó una revisión acerca de las consideraciones metodológicas para la evaluación de la competencia oral en el aprendizaje de una segunda lengua (L2). Se analizaron las características del constructor y su definición. En este caso, se refieren al ámbito competencial, que incluye la competencia en comprensión oral y la de expresión oral. Se analizan el modo en que diseñar instrumentos o técnicas evaluativas para la evaluación de las competencias que la integran y cuestiones respecto a fiabilidad, validez y establecimiento de puntos de corte.

Sanz (2010), realizó una tesis doctoral titulada: Aspectos regresivos en la retención de la competencia comunicativa oral del idioma en la Educación Obligatoria en el alumnado de segundo ciclo de ESO tras los períodos vacacionales. La muestra estuvo integrada por 22 estudiantes de los cuales 12 eran mujeres y 10 varones aplicándoles diversos métodos tales como test de medición y previo repaso practico. Se seleccionó aquellos estudiantes que corresponden al nivel facilitándoles grabaciones en formato vídeo y DVD para proceder a su aplicación. Los resultados evidenciaron la ausencia de la oralidad en todo el proceso de evaluación de la investigación previa, puesto que no se evalúa a los alumnos por su intervención oral, sino por la actividad escrita.

\section{Antecedentes nacionales.}

En el ámbito nacional, Fonseca (2016) escribió una tesis de maestría titulada, Through task-based interaction among basic level language learners at icpna, Cajamarca Branch. Su objetivo consistió en incrementar la producción oral de los estudiantes en la clase en un grupo experimental. Después de realizar las estadísticas descriptivas y las pruebas de hipótesis, se obtuvieron resultados positivos. En el grupo experimental se obtuvo el mayor porcentaje del tiempo de conversación de los estudiantes y el $48 \%$ con los maestros; mientras que en el grupo de control hubo un impacto poco menos de lo esperado. Esta evidencia puede afirmar que cuando queremos lograr un equilibrio entre el tiempo de conversación del maestro y el alumno, el TBL es definitivamente una buena opción.

Atiro et al (2017), en su tesis Competencia oral del idioma Inglés en los estudiantes del tercer grado de Secundaria de un institución educativa de Ventanilla. La investigación se desarrolló bajo el paradigma positivista con un tipo de muestreo no probabilístico y contó con una población igual a la muestra de cincuenta estudiantes, 30 pertenecieron al grupo 
experimental y 20 al grupo control. Se utilizó la técnica de la prueba oral de conocimientos para recolectar los datos y un módulo de 12 sesiones. Los resultados indicaron que la competencia comunicativa influyó significativamente en el desarrollo de la expresión oral en los estudiantes lo cual indica que la aplicación del módulo tuvo un resultado práctico en el desempeño de los estudiantes.

Briceño (2017), realizó una tesis de maestría titulada, Estrategias comunicativas del idioma inglés y nivel de expresión oral en los estudiantes del tercer ciclo de Educaciónespecialidad de Inglés de la Universidad Nacional de Cajamarca. La investigación se desarrolló en el paradigma positivista con un tipo de muestreo probabilístico que contó con una población conformada por 28 participantes de los cuales treinta pertenecieron al grupo experimental y veinte al grupo control. Se aplicó un Pre y Post test y se desarrolló un programa de aprendizaje con el grupo experimental, que consideró las estrategias comunicativas oral y del idioma inglés. Demostró un desarrollo en la expresión oral de los estudiantes del tercer ciclo.

Castañeda (2017), desarrolló una tesis de maestría: Actividades basadas en inteligencias múltiples para el mejoramiento de la habilidad de producción oral en idioma Inglés en los alumnos de la Universidad Nacional de Trujillo. Para alcanzar los objetivos propuestos se realizaron sesiones de aprendizaje con actividades basadas en las inteligencias más sobresalientes del grupo experimental, con la finalidad de que usarán los recursos cognitivos para su desenvolvimiento oral. Concluyó que el grupo experimental tuvo mejorías en la habilidad de producción oral.

Llatas (2016), realizó una tesis de maestría: Influencia del método oral situacional para las competencias comunicativas orales de inglés en 10 estudiantes de la especialidad de Primaria V ciclo del Instituto Octavio Matta Contreras- Cutervo. La aplicación de método oral situacional se desarrolló mediante sesiones de aprendizaje a través de ejercicios de memorización de significados con la correcta pronunciación (teoría conductista). Posteriormente se aplicaron situaciones de aprendizaje donde los estudiantes practicaban lo aprendido que los hacía tomar conciencia de la importancia del idioma inglés en diferentes contextos de la vida. Concluye que el grupo de estudio en el post test mejoró significativamente el nivel de competencia comunicativa oral.

Marquehua et al. (2017), en su tesis: Fortaleciendo la comunicación bilingüe: estrategia metodológica interactiva para desarrollar las habilidades comunicativas del Inglés en los estudiantes del cuarto grado de Secundaria de la Institución Educativa Ángel de la Guarda - Arequipa. El objetivo se orientó al desarrollo de las habilidades comunicativas en los estudiantes. La metodología, es cualitativa. Los resultados reflejan la mejora en la práctica pedagógica en la competencia de expresión y comprensión orales de 
los estudiantes, y el desarrollo de las habilidades comunicativas; aprendieron a expresar sus ideas, sentimientos, emociones e inquietudes de manera clara, fluida usando recursos verbales y no verbales, de manera clara y coherente, e interactuaron en equipos de manera heterogénea.

El análisis de las investigaciones revisadas le ha permitido a la investigadora conocer cómo se ha presentado y tratado el problema objeto de estudio a nivel nacional e internacional, los referentes teóricos asistidos, las metodologías aplicadas y las propuestas realizadas para transformar la realidad. En general se ha potenciado la perspectiva de la investigadora de la tesis acerca del desarrollo de la competencia oral del idioma.

\section{Reflexiones teóricas sobre el aprendizaje como proceso psicológico}

Al analizar las fuentes teóricas se aprecian distintas posiciones y definiciones sobre la categoría, aprendizaje tratado por las teorías del aprendizaje y las tendencias pedagógicas existentes, que permiten analizarlas y poder asumir las más integrales y su incidencia en la enseñanza- aprendizaje, a fin de alcanzar los objetivos previstos en los estudiantes.

Sobre el aprendizaje, Gagné (1965), refiere que este es un acto que provoca un cambio en la aptitud de las personas, el mismo que puede conservarse sin que sea necesario atribuírsele al fenómeno natural del crecimiento orgánico.

Por su parte, Hilgard (1979), afirma que el aprendizaje es un proceso en el cual se origina o cambia una estructura existente mediante la reacción a una situación dada, siempre que las características del cambio en curso no puedan ser explicadas con apoyo en tendencias, reacciones innatas, en la maduración por cambios corporales del organismo, por ejemplo, la fatiga o las drogas.

Es notorio que si bien estos autores consideran el aprendizaje como un proceso de cambio y transformaciones en la persona, no argumentan y hacen alusión a parte de la esfera cognitiva, qué otros componentes o esferas de la personalidad se integran intervienen en la adquisición del aprendizaje por el estudiante.

Otra posición aportó Piaget (1981), como un avance esencial a las teorías de aprendizaje de la época, al considerar el aprendizaje como un proceso personal activo, de construcción de conocimientos, a través de los procesos internos del sujeto (asimilación, desequilibrio, acomodación y organización) en el educando interacciona con la actividad, siempre que esté adecuadamente orientado en cómo realizar la tarea y cómo hacerla haciendo uso de las habilidades del pensamiento y la comunicación. 
Esta concepción significó un avance teórico a las concepciones del aprendizaje de la época, pues enfatizó en la esfera cognitiva al insistir que el aprendizaje es un acto de construcción del conocimiento. Enfatizó que cuando la materia a conocer se encuentra apartada de los dispositivos con que cuenta la persona, esta no podrá asignarle significado alguno y el acto de enseñanza - aprendizaje será imposible para él; aunque precisa que si el conocimiento no ofrece resistencias, el sujeto puede añadirlo a sus dispositivos si es que está orientado y podrá alcanzar los objetivos correctamente. Con este aporte resalta la madurez biológica y la enseñanza, aunque no deja explícito la función social en la producción del conocimiento y el desarrollo de las habilidades.

Sin embargo, es Ausubel (1983), quien enriqueció la psicología de su tiempo, al aportar la concepción teórica del aprendizaje significativo. Enfatizó que este es un proceso individual activo, en el que el sujeto aprende al relacionar los saberes previos con la nueva información, si está bien organizada para ser asimilada y entendida. En esa interacción el sujeto conoce qué es lo que aprende, cuál es su valor, su importancia, lo relaciona con la realidad, asume posiciones, lo aplica y le da sentido porque ha adquirido un aprendizaje significativo.

Como se aprecia, considera además de la esfera cognitiva, la afectiva en el aprendizaje, al destacar cómo en el proceso de aprendizaje, intervienen la importancia, la utilidad de lo que aprende, el sentido y el significado que le da el sujeto, estimulándose así el interés y motivación y por tanto mayor aprehensión y significatividad en lo que aprende.

Una posición teórica integral aporta Vygotsky (1978), al afirmar que el aprendizaje es un proceso social e individual (interpersonal) e individual (intrapersonal). A través del proceso de socialización, de la relación del sujeto con el objeto y con los otros al realizar la actividad, es donde se da la apropiación activa y consciente del conocimiento, se estimula el desarrollo de las capacidades, los conocimientos, las habilidades y las actitudes.

En tal sentido, refirió que en el aprendizaje es determinante la comunicación, la orientación del docente para promover el interés y la motivación de los educandos en el qué y cómo hacer según el tipo de actividad. Al realizarla en colaboración con otros compañeros, intercambian ideas, opiniones, vivencia, experiencias, actitudes; se ayudan mutuamente, autovaloran sus productos, se estimulan las formas de pensar, de hacer y las actitudes que conduce a la formación integral de los estudiantes.

En línea con los fundamentos sociocultural Castellanos et al. (2007), asevera que, el aprendizaje es un proceso dialéctico en el que como resultado de la práctica social, se producen cambios relativamente duraderos y generalizables, a través del cual el individuo 
se apropia de los contenidos y las formas de pensar, sentir y actuar construidas en la experiencia socio histórica con el fin de adaptarse a la realidad y transformarla.

Como se ha apreciado en el análisis de las posiciones teóricas expuestas por los especialistas, el aprendizaje es un proceso de apropiación de la cultura por el sujeto de manera social e individual, lo cual provoca modificaciones en las estructuras cognitivas y en las actitudes del sujeto al interactuar con el ambiente, y las demás personas en un contexto histórico concreto donde desarrolla su personalidad como sostienen los seguidores esta concepción social del aprendizaje (Vygotsky, 1987; Gonzáles, 2003; González, 2008; Ortiz, 2012 y Rico, Santos y Martín, 2013).

.En resumen, estos fundamentos teóricos tienen un valor heurístico esencial para el desempeño de los docentes al concientizar la necesidad de potencien la observación, el interés, la motivación y la socialización en la enseñanza - aprendizaje con la aplicación de métodos activos y problémicos que estimulen el diálogo, los saberes previos, el análisis, la crítica y se modele cómo realizar la actividad de aprendizaje en la clase en colaboración y socialización a partir de las necesidades y potencialidades de los estudiante.

\section{Fundamentos teóricos sobre la expresión oral}

Al analizar la actividad de la habilidad de la comprensión oral en la clase de idiomas conduce a referirse a un procesamiento complejo en donde se puede indagar y conocer el lenguaje hablado sin descuidar los diferentes aspectos relacionados con el estudio de la competencia comunicativa oral (Pompilla. et al. 2019).

Entre otros términos, comprender conlleva a saber escuchar para interpretar con facilidad lo dicho por el interlocutor, pero este evento no es exclusivo en el proceso de adquisición de una segunda lengua sino también afecta a la lengua materna ya sea en un aspecto social o académico. Ahora bien, para definir a la comprensión oral es necesario tener en cuenta los elementos esenciales en la actividad comprensiva como es la escucha activa que ayuda a construir significado (Sanz, 2010).

Por otro lado, hay quienes creen que escuchar es el equivalente a oír, pero de acuerdo con Widdowson (1989), es falso en el sentido que ambos procesos tienen una funcionalidad y valoración de significado con respecto al otro; pues el oír conlleva reconocer los fonemas, al escuchar el oyente recepciona lo sustancial y semántico del mensaje.

Para enriquecer el aprendizaje de una lengua se requiere ejercitar las destrezas pasivas y activas, en este sentido Peris (1996) puntualiza que la comprensión oral de un mensaje es menos atendida en comparación con las demás habilidades, lo cual califica de 
un grave error porque no es un proceso pasivo, para expresarse el hablante debe pensar para construir el texto y comunicarlo como parte de la relación pensamiento lenguaje y se logra a través del conocimiento y las destrezas comunicativas (López et al., 2019).

La comprensión oral no solo es escuchar el mensaje, involucra el saber interpretarlos en las diversas situaciones comunicativas. Por ello es preciso escuchar y comprender oralmente el mensaje para reaccionar ante él. Es un proceso que Sanz (2010), lo considera como una percepción crítica representativa de los contenidos orales que se logra en un contexto (Pompilla. et al., 2019).

La escucha, la expresión y la comprensión oral son procesos psicológicos que han evolucionado en el transcurrir del tiempo y las ciencias que inciden en la enseñanza en cuanto a los enfoques teóricos, didácticos, métodos y procedimientos de una lengua determinada. En ello interviene la habilidad comunicativa que Lynch y Mendelsohn (2002), califica como esencial en la comprensión, el intercambio de ideas y la competencia comunicativa oral.

En ese sentido, Sanz ( 2010), expresa que se debe tener en cuenta: Percepción del código lingüístico; Procesamiento secuenciada de la información; Interpretación y discernimiento del mensaje; Instauración de imágenes que corroboran la interpretación y comprensión; Discurso efímero y no permanente; Uso de la memoria para emisión de la respuesta espontánea; Uso de los elementos de la oralidad tales como énfasis, entonación, ritmo, volumen; Recurso de formas no gramaticales, reducciones, eliminaciones, repeticiones, pausas, correcciones, redundancia y otros fenómenos; y .Posibilidad de interferencias y distracciones en el proceso.

Desde esa óptica, es una capacidad lingüística que busca obtener información, procesarla y dar una respuesta sobre la en base de la interpretación, en la que influirá tanto los factores cognitivos, perceptivos, sociales, afectivos, actitudinales y de esa forma llegar al entendimiento y la interacción a través de las estrategias y las técnicas aplicadas (Quispe, 2017 y López, 2019).

La comprensión oral es un proceso activo en el cual el interlocutor se ayuda de recursos para entender lo dicho por el hablante utilizando su conocimiento lingüístico dándole un significado. El nivel de comprensión del mensaje se habrá logrado si lo predicho por el oyente es entendido con facilidad, por el contrario, el interlocutor por su parte se verá forzado a reformular el supuesto y empezar el proceso de nuevo. El éxito del proceso de comprensión y de expresión se concretan en los conocimientos y las habilidades de descodificación de la cadena fónica (fonemas, sílabas, palabras, oraciones entre otros) 
hasta la valoración personal a fin de construir el significado y comunicarse (Cassany, 20022013; Roméu, 2007 y Fuertes, 2017).

El análisis realizado, revela la importancia de la comprensión oral, su funcionalidad en el nivel cognitivo -afectivo- emocional del hablante y que se fortalece en un entorno de interacción social comunicativa como es: conversaciones, debates u otros, lo que a su vez sucederá inevitablemente es la adquisición de actitudes positivas para obtener el interés en lo que dice el interlocutor y responder a lo solicitado.

Un aspecto pobremente tratado en las investigaciones sobre la expresión oral es la escucha como precisa Cassany (2009) y Pompilla et al., (2019) quienes afirman que en el proceso de comprensión intervienen tres tipos de escucha: intensiva, selectiva e interactiva como se especifica a continuación.

Escucha intensiva: En este tipo de escucha los detalles es la base en donde el oyente analiza y pone toda su atención en el audio escuchado. Asimismo, para Wilson (2008), al hablar de la escucha intensiva comprende extraer una serie de palabras claves, los sonidos, frases y otras pistas para formar un nexo del lenguaje hablado con el significado.

Escucha selectiva: Esta escucha acerca a los estudiantes con la información necesaria que los oyentes esperan captar para dejar de lado el resto producto de una estrategia, al cual le presta la menor consideración para procesar todo el contenido

Escucha interactiva: Se desarrolla mediante la comunicación en la que el estudiante interactúa con sus pares entre sí, a partir de las situaciones comunicativas que se generen desde los saberes previos, experiencias y los entornos reales de la vida cotidiana como añade (Rost, 2002).Dicho esto, la comprensión oral como habilidad requiere de la escucha para poder asimilar el mensaje, procesarlo y reaccionar ante ello lo cual llevará al docente oriente con precisión el contenido de la expresión oral a ese sentido en las actividades de aprendizaje para lograr coherencia y concientización en el aprendiz sobre su desempeño en los actos comunicativos (Roméu, 2007; Cassany, 2013 y Pompilla. et al., 2019).

La expresión oral es una habilidad comunicativa que permite elaborar mensajes con al menos un interlocutor logrando efectividad y claridad al realizarlo. Al respecto Quispe (2017), postula que la capacidad de manifestarse oralmente por medio de palabras en el acto del discurso o conversación que, por su naturaleza guarda una relación directa con quien recibe y comprende el mensaje. Siguiendo esta línea se puede inferir la fundamental importancia que cumple en el ámbito comunicativo convirtiéndose en una necesidad primordial desarrollar la expresión oral de manera adecuada. 
Según Maquerhua y Quiroz (2017), la expresión oral es la capacidad de expresarse con fluidez y claridad, con optima pronunciación y entonación, y empleando con pertinencia y naturalidad" pues forma parte del proceso al interactuar oralmente nuestras ideas, emociones y sentimientos en diversos contextos en el día a día produciendo de esa manera la interpretación y negociación de información.

En esta perspectivas se aprecia que el autor subraya que el hablante no solo dependerá de estos factores, sino del saber en qué momento oportuno intervenir en un diálogo con el fin de lograr que el mensaje sea recibido y comprendido el oyente reacciona según sus intereses y de esa manera se desarrolla la comunicación interactiva.

Al respecto, Pérez, (2013) asevera que la lingüística precisa de distintos requisitos fonológicos y sociolingüísticos que interviene en la expresión oral: fonación, articulación, entonación, fluidez, timbre de voz, expresividad, coherencia, ajuste al tema y apoyo extraverbal (Roméu, 2007, Domínguez, (2010) y Maquerhua y Quiroz ,2017). Granda (2017).

Otro requisito de la comunicación oral es la fluidez que permite expresar de manera apropiada, coherente y con cierta espontaneidad un discurso sin fragmentar o intervalos de tiempo. En ese orden de ideas, Quispe (2017) asevera en su investigación que la fluidez le da más valor a la expresión oral y la gramática la asocia a su aplicación para mejorar lograr la cohesión del contenido del mensaje que se quiere comunicar (Baralo, 2000; Pinilla, 2000; Cestero, 2005 y Roméu, 2007).

Por su parte, Granda (2017) significa que la fluidez presenta tres elementos o áreas esenciales: área creativa (producción de ideas), área lingüística (sintaxis de las palabras) y área semántica (significado de las palabras)

La pronunciación es la habilidad que se refiere a la articulación en la producción de los fonemas en la cadena fónica que incluyen la entonación, tono de voz y el acento al emitir el texto esperado (Thornbury, 2006 citado por Granda, 2017). El sonido cumple un papel relevante en la interpretación significativa y adecuada conexión de palabras para que sean comprensibles y de fácil entender por los oyentes. De manera análoga, Fernández et al. (1995) resalta el valor fonético de las palabras, pues si surge una alteración en la pronunciación el sentido del mensaje cambiará (Pérez, 2013).

En cuanto al vocabulario o riqueza léxica de la palabra en su forma y significado Thornbury (2006), lo considera como un pilar para construir y comunicar palabras, frases, oraciones, textos orales o escritos es fundamental y revela la cultural del sujeto. El trabajo con el acto conversacional dependerá del dominio léxico en una estructura gramatical 
específica. Según la estructura lingüística del idioma inglés el léxico se establece en cuatro marcos: en el vocablo y el significado que reproduce el hablante (Granda, 2017).

Al respecto, Barrios (2019) refiere que en la expresión oral, es necesario relacionar el léxico o significado del vocablo que se usa con la estructura gramatical de la lengua, el contexto sociocultural y pragmático en el cual se desenvuelve el sujeto, a fin de contribuir al desarrollo desde los saberes previos y así ascender en una conversación. Es primordial recalcar el papel de los medios didácticos para estimular el conocimiento adquirido y las experiencias para producir la expresión oral desde las experiencias.

De acuerdo con ese argumento teórico, se resalta la valía de la conversación en la vida cotidiana y escolar, ya sea por ser espontanea o ser una modalidad formal y sencilla para lograr en la expresión oral. En esencia la escucha y el interés son requisitos indispensables para mantener un diálogo y la comunicación oral en general (Barrios ,2019).

El Minedu (2017), en sus documentos normativos, indica que la oralidad es un proceso donde se debe atender el sonido y su pronunciación en función del mensaje o texto a producir oral o escrito. Para ello la comunicación de fluir sobre el tema objeto de estudio en la que tanto el emisor como el receptor son protagonistas del acto comunicativo en un contexto interactivo en el que se ponen en práctica las habilidades dialógicas producir el mensaje oral (Quispe, 2017).

Desde esa óptica, la oralidad se concreta en el habla por el sonido producido por el aparato fonoarticulatorio mediante palabras que representan los códigos lingüísticos característicos de un idioma. En ese sentido se elabora el mensaje aplicando las habilidades comunicativas y de la oratoria. Para lograrlo se deben potencia la observación, el pensar, analizar, comparar y asumir posiciones por los hablantes en un acto comunicativo y que la meta es desarrollar la competencia comunicativa en los hablantes (Roméu, 2007; Domínguez, 2010 y Cordeiro, 2018).

\section{La competencia comunicativa, un acercamiento a su estudio.}

El origen del término competencia comunicativa empieza a generarse a fines de la década del 60, al calor de las teorías críticas a los métodos estructuralistas presentadas por Chomsky (1957), en las que explicaba la dependencia de las características fundamentales de la lengua (la creatividad y la singularidad) con sus propuestas radicales en cuanto a la naturaleza del lenguaje (García 2010).

Al respecto, Hymes (1972) sostiene que en la comunicación de una lengua determinada se pone de manifiesto el término de competencia lingüística acuñado por 
Chomsky (1967), que se tuvo en cuenta por tiempo en la didáctica de la lengua dándole de ese modo una perspectiva comunicativa a su teoría.

Para Chomsky, lo fundamental es estimular las habilidades abstractas en la producción de oraciones gramaticalmente correctas, a diferencia de Hymes (2003), quien describe la competencia concreta al integra la comunicación y la cultura. Dicho en otras palabras, se refiere a las habilidades del hablante de interpretar el contexto social para expresarse sobre él y destaca su importancia en el aprendizaje del idioma con el fin de expresar ideas, interpretarlas y dar solución a los problemas poniendo en funcionamiento una serie de recursos para lograr un propósito (García, 2010).

Por otro lado, Richards y Rodgers (2001) afirman que la función esencial de la lengua está en el acto de comunicarse e interactuar y no en su función estructural dejando al descubierto la expresión como significado, detalles que lo describen como un sistema. Desde esta postura se puede decir que entender, comunicarse y enseñar lengua son procesos de naturaleza social y compleja relacionada con el pensamiento, lenguaje y su interrelación (Roméu, 2007, Domínguez, 2010 y Castañeda, 2017).

Por esta razón, el proceso de enseñanza - aprendizaje de cualquier lengua se enfoca desde una perspectiva lingüístico- social y de contacto en el que se prioriza el desarrollo de la competencia comunicativa en el estudiante, que incluye las capacidades como el escuchar, comprender, hablar, leer y escribir. Ello se complementa con el conocimiento de los niveles de la lengua por la lingüística en cuanto a forma y contenido y su concreción en el habla, al desarrollarse en un contexto de entendimiento y contestación de preguntas siendo asumido por el sistema del idioma a aprender.

A continuación se conceptualizan las habilidades comunicativas que deben desarrollarse en los estudiantes para alcanzar la competencia comunicativa (Roméu, 2007; Ballesteros, 2012; Rojas, 2015, Cassany, 2016 y Castañeda 2017), entre otros.

Escuchar. Prestar atención de lo que comunica otros entes, sin modificar el mensaje con el fin de evitar malentendidos (Rojas, 2015).

Hablar. Sonidos producidos articuladamente y exteriorizados que permiten la capacidad de comunicarse (Velastegui, 2015).

Leer. Habilidad de distinguir y comprender la escritura que junto a las diversas destrezas que la acompañan, contribuye a la adquisición y desarrollo de la comunicación e iniciativa personal (Ballesteros, 2012).

Escribir. Habilidad para elaborar discursos coherentes y cohesivos, para exponer con propiedad y claridad de ideas con el fin de desarrollar un ideal que vaya acorde a la 
exigencia de la lengua en ser apropiada y dominada mediante el uso de las reglas semánticas y sintácticas propias del idioma.

Es importante aclarar que para el éxito del aprendizaje de L2 es primordial que puedan relacionarse las cuatro habilidades de forma integral entre sí en base a un enfoque de comunicación y elocuente. En este sentido los autores indicaron que para ser competentes en comunicación es importante desarrollar las destrezas lingüísticas que están orientadas al dominio expresivo y compresivo de la lengua de forma coherente, eficaz y correcta (Marquehua y Quiroz 2017).

A partir de estas premisas que caracterizan a la competencia comunicativa oral se puede afirmar que es una noción originada desde la lingüística que concibe su conceptualización en el desarrollo de las habilidades o aptitudes requeridas para desenvolverse en una sociedad interactiva a fin de estrechar relaciones sociales (interpersonales e intergrupales) a partir de niveles de análisis con fines comunicativos. Hoy en día, su concepción integradora y holística le permite integrar un conjunto de conocimientos de forma interdisciplinaria para lograr la interacción activa con los demás y aportar a su proceso de aprendizaje (Fábregas, 2015).

Al respecto, García (2010), define la competencia oral desde una perspectiva distinta, explica que es un mecanismo de producción - comprensión apropiada de lo expresado para lograr el intercambio y evitar de esa manera malas interpretaciones. Sin embargo, este proceso involucra el hacer uso de recursos orales y no orales en diversos contextos de socialización establecidos en un medio inductivo de interacción social y de lenguaje.

Esta posición teórica, destaca que el docente al dirigir la enseñanza- aprendizaje de la competencia oral, debe lograr que los estudiantes fundamenten los conocimientos lingüísticos, las habilidades comunicativa, el intercambio de mensajes orales desde los saberes, las experiencias del contexto y construya los texto aplicando el código de la lengua demostrando adecuada pronunciación, fluidez, comprensión, coherencia con dominio y así ejercitar las habilidades para convertirse en un comunicador eficiente y real (Quispe ,2017).

El Ministerio de Educación del Perú (2009), en el Diseño Curricular Nacional (DCN), indica que las competencias de expresión y comprensión oral, se desarrollan en las actividades interactivas orales, destaca el contexto comunicativo en un ámbito cercano o similar a la vida diaria planteando una proximidad a la realidad para el desenvolvimiento del aprendiz en lo social y familiar y la pertinencia (2017). 
Desde esa posición interactiva se requiere una comunicación con una identificación del hablante al codificar el mensaje para comunicarlo con un lenguaje que sea interpretado por el receptor. En ese sentido, Rodríguez (2010), denota la estrecha relación del pensamiento y el lenguaje para lograr la capacidad oral con los procesos involucrados tanto receptivos y productivos, denominados emisor (hablante) y receptor (oyente) en una comunicación.

De ese modo se comprende que la lengua oral es la capacidad que se adquiere y desarrolla gradualmente y es una necesidad del ser humano. Para tal efecto, el aprendizaje oral deba ser efectivo e interiorizado por los estudiantes, y de esa forma conquistar la comunicación mediante técnicas verbales y no verbales. El desarrollo de una comunicación real conlleva a mejorar su eficiencia en términos de estrechar una relación interpersonal (Quispe, 2017).

EL autor sostiene el lado humanístico y psicológico de la expresión oral que debe tenerse en cuenta en el aula. El docente debe garantizar un tratamiento adecuado a lo qué dice y cómo dice cada estudiante, proyectar la interacción comunicativa en el grupo en un ambiente de confianza, alegría y satisfacción por aprender a partir de actividades de aprendizaje atractivas que regule el comportamiento, respecto al compañerismo, los puntos de vistas, contextos culturales a fin de fortalecer las formas de pensar, la comprensión, los conocimientos, las habilidades expresivas y en general la competencia comunicativa (Quispe, 2017).

En síntesis, la importancia del entorno en la práctica oral es el espacio más cercano para el desenvolvimiento libre es y será el aula ya que cuenta con diferentes interlocutores que les facilitará las condiciones de aprendizaje y desarrollar su capacidad interactiva con sus compañeros y lograr la oralidad, en las Orientaciones para el trabajo pedagógico (Minedu, 2010).

En línea con ello, Páez (2003) sustenta que, todo acto comunicativo debe orientarse a impulsar las potencialidades expresivas y de comprensión hacia el dominio del lenguaje verbal y no verbal. En consonancia a este propósito Benavides (2013) resalta a la fluidez, pronunciación adecuada y el correcto uso de la gramática como elementos básicos para demostrar el dominio real de la competencia oral de un idioma (Quispe, 2017).

Estas observaciones se relacionan con las ideas expuestas por Zebadua y García (2011), quienes expresan la importancia de dos componentes esenciales en una situación comunicativa determinada: la lengua hablada y el lenguaje corporal o extraverbal como refiere (Roméu, 2007; Domínguez 2010 y Chávez, 2016). 
Acorde a los argumentos de Roméu (2007), Cassany (2009) y Zebadua y García (2011), la lengua hablada es un tipo de comunicación lingüística que se concreta en una situación comunicativa determinada que al ser asimilado el mensaje, procesado, comprendido e interpretada las ideas a partir del uso de los niveles de la lengua, se origina la expresión oral. Su realización requiere conocer y aplicar las características propias. En ello se distingue una lengua formal: para expresarse con conocimiento y coherencia según el contexto oficial científico; y el informal, utilizada frecuentemente en situaciones diarias de la práctica coloquial que encuentre el emisor o el receptor al comunicarse en la práctica social (Chávez, 2016).

Ese proceso comunicativo cotidiano o formal le permite al hablante alternar los roles de manera espontánea, ya sea de emisor o de receptor durante el acto comunicativo en un contexto específico. La interacción con el interlocutor es importante conocer y organizar detalladamente el pensamiento, las ideas lingüísticas, argumentos teóricos y prácticos a sustentar durante el acto comunicativo oral para facilitar la comprensión y el entendimiento (Cordeiro, 2018).

En ese orden de argumentos, Roméu (2007), Domínguez (2010) y Mercado (2014), señalan que esos argumentos pragmáticos se deben tener en cuenta en el tratamiento metodológico de la competencia oral de cualquier idioma, aplicar métodos que potencien el ejercicio de pensar, estimular la habilidad de escuchar (comprensión auditiva), la comprensión semántica del mensaje y la expresión oral propiamente dicha y en su conjunto propicia la producción de texto oral ajustada al contexto sociocultural (García, 1996 y Cassany, 2016).

\section{La producción de textos orales.}

La producción oral es una competencia que requiere de la comprensión y se concreta a través de la elaboración de diferentes tipos de textos orales de manera coherente y espontánea, utilizando recursos expresivos que faciliten la interacción de quienes lo recepciona (Cassany, 2009); Zebadua y García ,2011) y Llatas, 2017).

A tono con esa perspectiva, se resalta que además de atender los procesos cognitivos, metacognitivas, dominio de las estructuras discursivas y la actuación sociocultural es preciso atender en el educando la habilidad de la escucha, comprensión, vocabulario, pronunciación, fluidez y ajuste al tema para lograr la asimilación, procesamiento de la información, comprensión de los mensajes para interactuar oralmente (Castellanos, 2007; Díaz y Ávila ,2010; Guerrero, 2011 y Núñez, 2014). 
En ese orden, Fonseca (2010) manifiesta que para lograr la competencia comunicativa, debe estimularse la esfera cognitiva, profundizar en un tema, ejercitar las habilidades expresivas al realizar la actividad de aprendizaje de manera que comprendan los educando el tema objeto de estudio, qué hacer, cómo y cómo exponerlo ante el grupo.

La producción oral, refiere Brown y Yule (1983) es un proceso de interacción en el cual el hablante asimila, procesa, comprende e interactuar sobre un mensaje recibido al darle significado cuando lo comprende. En este sentido, se debe tener en cuenta cómo realizar el análisis de una parte de la situación comunicativa hasta lograr el todo para incidir en el desarrollo de la habilidad comunicativa interactiva que debe ejercitarse en el aprendiz de manera motivante y significativa.

Loa autores de referencia aseveran que la producción oral tiene tres funciones básicas que debe atenderse de forma integrada:

. Interacción, esencial procedimiento para lograr la comunicación entre las personas de manera natural y respondiendo a la función social.

- Transacción, alude a la asimilación y procesamiento del mensaje recibido, lo que permite que el oyente comprenda de manera clara y precisa y reaccione ante él para que se concrete la interacción comunicativa.

. Desempeño, es el proceso que tiene que ver con la ejercitación que estimula el desarrollo de la producción oral mediante distintas actividades orientadas desde el habla particular, la conversación, el monólogo, el diálogo, discurso, comentario, disertaciones, relato de historias, exposiciones entre otros.

Se reconoce a Harem (2007), como uno de los referentes de la producción oral desde el enfoque comunicativo en la enseñanza de un idioma extranjero. En ese sentido precisa que la producción oral es la capacidad de hablar fluido, que incluye recursos prosódicos y la habilidad de procesar información (Castañeda, 2017).

El autor considera la necesidad de atender distintos procedimientos en la enseñanza de la lengua para estimular la producción hablada en los estudiantes, como pueden ser:

Discurso en conexión, que hace mención a la habilidad de producir a través del manejo de discursos fluidos

- Mecanismo de expresión, relacionado al cambio de entonación, volumen, velocidad del discurso y emitir significados, emociones e intensidad. 
. Léxico y gramática, el discurso está conformado por el uso de expresiones léxicas y de uso gramatical en contextos en el cual desarrollarse.

. Lenguaje de negociación, primordial elemento para mantener un discurso efectivo y mostrar una organización del pensamiento y entendimiento de lo hablado.

Dimensión: lenguaje corporal (Chávez, 2016)

El lenguaje corporal es una forma de comunicación que puede realizarse de manera consciente o inconsciente para apoyar la comunicación o el discurso del hablante (Salas, 2004 y Roméu, 2007). El idioma del cuerpo suele ser influenciado por factores ambientales que no deben ser interpretados como una conclusión definitiva, pues es un apoyo a lo que se expresa concordante con lo que se expresa y el movimiento gestual o no verbal. Para lograrlo, refiere Navarro (2014) que los hablantes utilizan distintos recursos paralingüísticos.

Recursos no verbales. Llamados también, no lingüísticos, son aquellas formas de comunicación en las que se expresan con los movimientos del cuerpo en la que no es necesario el empleo de palabras para transmitir un mensaje. Pueden ser comunicados a través de gestos, lenguaje corporal, postura, expresión facial, entre otros. La comunicación no verbal forma una parte fundamental del sistema comunicativo y sirve como medio de interacción en las relaciones humanas que el discurso verbal no puede establecer (Aroni, 2019).

La expresión oral por su parte se manifiesta a través de la voz, tono, timbre, cadencia, expresividad, fluidez y se apoya en los movimientos somáticos y gestuales a fin de enfatizar y argumentar el mensaje que se expone; sin embargo, es necesario y conveniente utilizarlos de forma natural y oportuna para no caer en el ridículo (Barrios,2019).

De los recursos no verbales que intervienen en una exposición, la mirada es uno de los más notables, pues establece una conexión genuina en la exposición del mensaje y la comunicación entre el hablante y el oyente. Por otro lado, la elocuencia de la exposición e interacción dependerá del buen uso que se le dé a la expresividad de los ojos para lograr eficacia, quietud y simpatía durante el diálogo.

En resumen, el lenguaje gestual que acompaña a la producción oral del sujeto es esencial en las exposiciones o disertaciones públicas, pues no solo permite exteriorizar el argumento del mensaje con la voz, sino que se acompañar con el cuerpo, el rostro y las manos en concordancia con los argumentos que expresa o comunica el ponente. 
Esas habilidades o destrezas comunicativas se logran en las salas de clases si el docente crea un ambiente psicológico asertivo, aplica métodos de enseñanza que estimulen el desarrollo de los conocimientos y las habilidades de producción oral, a fin de usar las adecuadamente en los distintos actos comunicativos del contexto sociocultural. Las estrategias comunicativas deben ser empleadas en las distintas tareas de aprendizaje que deberán realizar en grupo para alcanzar un desarrollo ascendente (Domínguez, 2010; Cassany, 2013 y Briceño, 2017).

Acerca de ese argumento, Cassany (2000) indicó la necesidad de reivindicación la enseñanza de la comunicación oral, tanto en las situaciones formales como informales en los salones de clase de idiomas. El desarrollo de las capacidades orales permitirá que los estudiantes de apropien de las herramientas lingüísticas para expresar las ideas e interactuar con los demás con facilidad, y la mejor manera de lograrlo es mediante el trabajo grupal donde todos participan de forma oral con lo que estimula la motivación y la creatividad comunicativa (Marquehua y Quiroz,2017).

Partiendo de los supuestos anteriores, Nakatani (2006) relaciona las estrategias de comunicación oral con el acto de expresar los conceptos e ideas de forma interactiva y comunicativa. Al referirse a estas estrategias es conveniente hablar del enfoque aportado por Fernández (2017), al iniciar su análisis del acto comunicativo a partir de su desenvolvimiento en la ejecución propia de la estructura del proceso comunicativo que debe dominar el docente en el aula (Marquehua y Quiroz, 2017 y Barrios, 2019).

El análisis realizado permite redundar en lo expresado por, Cobas y López (2010) que, desarrollar la producción de textos orales forma parte de la competencia comunicativa a lograr en los estudiantes a través del proceso de enseñanza- aprendizaje. En tal sentido, el docente debe conocer que ese objetivo incluye la recepción-comprensión y la expresión de las ideas y los argumentos con ajuste a las reglas normativas de la lingüística, las características del hablante, los contextos y el tipo de texto que se dan en unidad dialéctica en el acto comunicativo.

\section{Especificidades del enfoque comunicativo y la enseñanza del idioma.}

Antes se impone la necesidad de analizar el término enfoque y para hacerlo y otros autores lo conceptualizan como la manera de tratar un asunto, determinado por las concepciones teóricas y epistemológicas que se asuman (Roméu 2007).

En ese sentido, Pompilla (2019), refiere que es una perspectiva en la que se visualiza la enseñanza - aprendizaje como dos procesos independientes y a la vez 
dependientes para lograr que los estudiantes conviertan la información asimilada y procesada, en conocimientos útiles y significativos para la vida.

Al aplicar el enfoque teórico y didáctico en la enseñanza de un idioma, es necesario analizar y conocer cómo ha sido tratado y potenciado el desarrollo de los conocimientos en los educandos para tomarlo como un principio pedagógico desde las teorías que lo anteceden. En esa línea, Harmer (2015), considera que el uso del lenguaje es una herramienta que entrelaza las condiciones de aprendizaje con el entendimiento ofreciendo un modelo de competencia lingüística (Pompilla. et al., 2019).

En ese sentido, existen diversos enfoques orientados al proceso de enseñanza aprendizaje de las lenguas. Si bien, la presente investigación asume el enfoque comunicativo o también llamado Communicative Language Teaching (CTL), el cual empezó a aplicarse entre la década del setenta y del ochenta se deberán tener en cuenta otras posiciones teóricas al respecto.

El enfoque comunicativo desde hace más de veinte años ha prevalecido en la didáctica de las segundas lenguas, ya sea por el enriquecimiento de los diversos modelos o por el conjunto de procedimientos y estrategias que aporta como vía para estimular el pensamiento, las habilidades y el desarrollo de una comunicación adecuada y efectiva entre los hablantes como precisa Luzón y Soria (1999).

La transcendencia del enfoque comunicativo aplicado en la enseñanza de una segunda lengua cambia, deja de lado el modelo estructuralista centrado en el código de la lengua, para ocuparse de la enseñanza y el desarrollo del habla. Ello requiere del docente renovar su práctica con la aplicación de los métodos dialógicos, heurísticos, creativos y comunicativos que partan de las perspectivas de los estudiantes, contextualización, socialización y la optimización del saber para desarrollar las habilidades comunicativas (Maati, 2000, Roméu 2007, Domínguez 2010).

Estas perspectivas exigen de métodos de enseñanza heurísticos y dialógicos que estimulen en el sujeto la asimilación y producción del conocimiento. Ello requiere de la didáctica del docente, para promueva el pensar y analizar como punto de partida con la realización de distintas actividades y procedimientos metodológicos que respondan a las necesidades del estudiante desde una base teórica propia de la lingüística social (Maati, 2000; Roméu, 2007 y Cassany 2013).

La lingüística considera que la vía esencial para lograr la comunicación humana es a través del lenguaje, lo cual resalta que su adquisición parta de situaciones reales comunicativas, facilitar la libre expresión de ideas, las opiniones diversas, estados de ánimos y emociones de forma coherente constructiva. Ello exige que el rol del profesor sea de negociador en el proceso de aprendizaje para que fluya la interacción comunicativa y la 
libre expresión de ideas al realizar las actividades en el aula (Salas, 2007; Domínguez, 2010 y Pompilla et al, 2019).

Las investigaciones afirman que, cuanto más implicado el estudiante esté en la actividad de aprendizaje, mejor será el alcance de su adquisición, comprensión, el dominio y desarrollo de las habilidades idiomática. Por otro lado, como complemento el docente debe ejercer un rol asertivo, facilitador y orientador para que el educando sea consciente de qué y cómo hacer y expresarse sus conocimientos, las habilidades y se forme integralmente (Gonzáles 2003, Gonzáles, 2008 y Ortiz, 2015).

Por lo tanto, convertir el aprendizaje de la lengua en una herramienta comunicativa útil para el hablante conlleva a no solo conocer las normas lingüísticas, sino de la capacidad de uso mediante recursos comunicativos que posibiliten el éxito del acto comunicativo tal como el pensar, en el qué decir y de qué manera hacerlo en distintas situaciones (García, Martinez et al., 2003, Roméu 2007 y Cassany 2013).

Desde esa posición teórica al centrar la actuación de los estudiantes como agentes socializadores de las tareas de aprendizaje, se estimula la esfera cognitiva, el pensamiento, lo emocional y la motivación, los moviliza a realizar las actividades. Así, el acto de enseñanza- aprendizaje se relacionan entre sí en su forma de uso y retroalimentación que va acorde a las dimensiones tales como las estrategias, competencias del usuario, actividades de la lengua en contextos reales (Mcrl, 2017).

De este modo se comprende que las situaciones comunicativas deben seleccionarse y tratadas de acuerdo con la realidad próxima del aprendiz y responder a sus necesidades asumiendo el componente sociocultural propio de la lengua como fenómeno social por ser imprescindible en el proceso de adquisición (García, Martínez et al., 2003; Roméu 2007 y Cassany, 2009).

Coherente con ello, el enfoque comunicativo propicia el engranaje del proceso de producción - recepción de la información del lenguaje con una estrategia que vaya en la línea con el aprendizaje significativo. Al respecto, Velázquez (2014) enfatiza que, esta concepción conlleva al desarrollo de la autonomía del estudiante por la variedad de métodos y procedimientos que aplica que hace atractivo el aprendizaje para los estudiantes (Cassany, 2009 y Briceño, 2017).

Conforme a lo expuesto, el estudiante es el protagonista central de este enfoque comunicativo, pues tiene como objetivos potenciar el desarrollo del pensamiento reflexivo, el lenguaje, la autonomía y satisfacer las necesidades comunicativas e interpersonales con responsabilidad de manera activa, metacognitiva y autorregulada (Sales 2007, De Corte 2015, Pompilla et al 2019). 
En ese sentido, para expresarse oralmente o comunicar un texto con efectividad en el plano oral es necesario poseer determinados conocimientos y habilidades por el sujeto al expresarse como refiere Bravo, (2013).

Mostrar habilidad de comunicarse lo que se quiere expresar sin caer en generalidades

. Cuidado en la manera y el cómo expresamos (mediar entre el intercambio verbal y no verbal).

. Acondicionar el contexto y rasgos de otras personas con la interacción

. Cerciorarse que el interlocutor haya oído, percibido y asumido la información.

. Descodificar la presunta respuesta de los demás receptores.

El análisis realizado sobre la comunicación oral reafirma que es un proceso socializador, que requiere del entrenamiento y la estimulación del estudiante para expresarse sus ideas a través de una situación comunicativa real y atractiva. Mientras más novedosa sea la actividad más necesidad y motivo tendrá para expresarse con fluidez, articulación, ajuste al tema, coherencia y comprensión de los mensajes para lograr la interacción comunicativa. La enseñanza- aprendizaje se debe asumir desde distintos enfoques didáctico en la búsqueda para alcanzar la eficiencia en desarrollo del pensamiento, la expresión, dominio lingüístico y en general la competencia comunicativa oral de los estudiantes y en interés comunicativo en los distintos contextos de actuación (Vence, 2012; Martínez, 2009 y Cruz y Velázquez, 2016).

\section{Métodos que contribuyen al desarrollo de la competencia comunicativa oral}

Acerca de la competencia comunicativa oral Rogoff (1993), Ortiz y Mariño (1996), Monereo, Castelló y otros (1999), Wells (2001), Álvarez (2005), Romeú (2007), Tolchinsky (2008) y García (2010), consideran que su desarrollo se logra al aplicarse distintos métodos en la clase que los motive a exponer sus ideas.

La categoría didáctica método, tiene raíces referidas a "camino"; el método comprende un proceso de orden, guía el pensamiento y el logro de un objetivo establecido. El método se caracteriza por garantizar un beneficio en los educandos en la enseñanzaaprendizaje (Quiroz, 2003).

La enseñanza de una segunda lengua requiere del uso de métodos que condicionen el aprendizaje con un accionar productivo e interacción del aprendiz junto a la naturaleza socializadora del proceso de aprendizaje. El estudiante se comunica siguiendo su pensamiento sobre la fuente de información. En ello el lenguaje es esencial en la formación 
y desarrollo del pensamiento y las actitudes del sujeto al intervenir valedera tanto de la actividad interna o externa del método y que impulsan en general el desarrollo de la competencia oral como porque entre pensamiento y lenguaje existe una unidad dialéctica (Vygotsky, 1987; Álvarez de Zayas, 1997, Roméu, 2007; Domínguez, 2010 y Usquiano, 2016).

En la formación del pensamiento lógico y dialéctico no solo se requiere del conocimiento del proceso y su estilo de pensar, sino deben ir acorde de una didáctica científica y crítica para garantizar la orientación y desarrollo eficiente de la enseñanzaaprendizaje (Álvarez de Zayas, 1997).

El método de CLIL se emplea en la enseñanza de idiomas y los contenidos empezó en los años 70 para consolidarse dos décadas después como el Aprendizaje Integrado de Contenidos y Lengua Extranjera (AICLE) o en su denominación en inglés Content and Language Integrated Learning (CLIL) siendo ideado por David Marsh, quien garantizo el éxito en el aprendizaje de una lengua en un contexto exclusivamente académico (Salgado, 2019).

Acorde con esta metodología, la lengua meta debe ser instruida como medio en la enseñanza de las asignaturas comunes recibidas en el aula de clase y de ese modo emplazar las horas de clase de idioma por el fortalecimiento del aprendizaje posterior por la ejercitación de las habilidades orales entre los estudiantes a partir de diversas situaciones comunicativas del contexto (Salgado, 2019).

Al aplicar el CLIL en el aula, el aprendiz fortalece las habilidades de fluidez y precisión al expresar ideas, la misma que se origina como producto de la interacción e interpretación de los mensajes que luego aplica en los entornos escolares y cotidiano con un notorio desarrollo del rango comunicativo de lo hablado y de lo escrito sobre asuntos conocidos, especializados y generales (Calderón, 2019).

En este sentido Marsh (1994), sugiere el método AICLE como el más apropiado para la enseñanza de una lengua extranjera, por su efectividad en el doble sentido de este enfoque que tiene al integrar los contenidos académicos o curriculares de cultura general con el contenido del idioma, permitiéndole al estudiante aprenderlo al mismo tiempo y utilizarlo de forma natural en la asignatura (Salgado, 2019).

En la actividad productiva del estudiante es determinante conservar y reproducir el modelo tecnología - producción en la actividad académica de la clase (Oxford, 1990). Eso supone formar en el docente una capacidad adaptativa, selectiva y aplicativa para llevar a cabo una metodología de trascendencia de los contenidos de manera que los estudiantes demuestren calidad en su aprendizaje integral frente a la L2, la cultura e interlocutores (Calderón, 2019). 
El método crítico o Thinking Based Learning (TBL), es un método que se basa en relacionar el conocimiento y la funcionalidad de las destrezas del pensamiento activas en el proceso ya sea en la toma de decisiones o la resolución de problemas; cumpliendo un papel significativo en la enseñanza que no solo constará en adquirir las capacidades y actitudes a fin de facilitar las estrategias que lleve a los estudiantes a pensar con eficacia (Barbarán, 2017).

El aprendizaje basado en el pensamiento, atribuye la labor hecha por Robert Swartz en los años 80, lo que motivo a Ennis (1985) conceptualizarlo como un acto cognitivo de dominio racional, válido y reflexivo, reconocido sobre las otras capacidades con carácter justo y verídico haciendo al humano un ser coherente; es así que el análisis crítico toma una posición distinta en el usuario donde cuestiona y argumenta las discordancias para rehusarse a la aceptación irreflexiva de la realidad (Delgado,2018).

Acorde con Delgado (2018), el pensamiento crítico por su parte es una actividad compleja que está mucho más encauzada en su funcionalidad hacia la interpretación de problemas que a formular las posibles soluciones. Dentro de este marco, la enseñanza mediante el TBL logra en sus estudiantes la construcción de "mapas de estrategia de pensamiento" que reflejan el producto de sus ideas frente a contextos otorgados por el docente a fin de expresar y desarrollar sus conclusiones de forma organizada, decisiva y consciente de su aprendizaje (Barbarán, 2017).

Atendiendo a esas consideraciones, el docente debe conseguir armonizar las destrezas del pensamiento con las estrategias para la solución de problemas y toma de decisiones a fin de lograr en sus estudiantes la adecuada recepción y aprendizaje del cómo y cuándo emplearlas asegurando de esa manera su efectividad ante una situación; un factor importante en lo antes mencionado es la manera colaborativa en que trabajan los estudiantes durante la ejecución del TBL a fin de enriquecer sus ideas y potenciar el pensamiento eficaz a través del aprendizaje introspectivo poniendo a la práctica hábitos de la mente de carácter productivo (Barbarán,2017).

Asimismo, López Aymes (2012) indica el rol investigativo que desempeña el estudiante en la práctica, le permite afianzar los conocimientos frente a cuestionamientos originados en un tiempo determinado. Este esfuerzo posibilita a los participantes (profesores y estudiantes) desarrollar estrategias investigativas de carácter cognitivo y la resolución de problemas en un entorno de seguridad para consolidar la construcción del pensamiento complejo a fin de instaurar el aprendizaje introspectivo (Cordero, 2012).

El método de aprendizaje basado en tareas (ABT) es un método que promueve en pensar y la comunicación y es de lo más actuales en la enseñanza de las lenguas extranjeras, pues sostiene el aprendizaje a base de la resolución e interpretación de tareas 
asignadas orientando al aprendiz a la acción donde el proceso de planificación y el diseño de las tareas cumplen un rol significativo en el acto comunicativo (Pompilla, 2019).

En este sentido, para alcanzar el aprendizaje de un idioma es preciso seguir un enfoque el cual impliquen actividades comunicativas relevantes y representativas que acerquen al aprendiz a imitar situaciones de la vida real a fin de proporcionar un ambiente natural de comunicación para el uso del idioma de modo espontaneo involucrándolos en el desarrollo de los principios básicos durante la realización de la tarea que los llevará a la comprensión e interacción con la lengua meta (Fuertes, 2017).

Por su parte, el docente presenta el tema a tratar y da las indicaciones sobre la tarea, que se conforma en grupos o en parejas. Sin duda el monitoreo de las tareas se ve limitado a la observación sin hacer correcciones o aclaraciones al aprendiz sobre el tema con el objeto de lograr su autonomía para confiar en sus capacidades para utilizar la L2. Pues el rol pasivo de éste es lo resaltante de este método ya que es quién verifica y evalúa las tareas certificando las debilidades o dudas que surgieron con respecto a lo trabajado (Pompilla, 2019).

Durante la aplicación de este método el estudiante planifica, organiza, coordina y ejecuta la actividad asignada lo cual le permite externalizar sus capacidades de orden superior sin restricción alguna viendo un incremento significativo y motivándolo a utilizar al lenguaje como herramienta frente al cumplimiento de la tarea planteada. Los profesores deben dirigir esta metodología con elocuencia y de esa manera evitar recibir una orientación al producto en lugar de poner la atención al proceso (Fuertes, 2017).

El método del ABT proporciona a los docentes una alternativa metodológica para orientar el aprendizaje de forma activo, superando las dificultades originadas en la enseñanza de lenguas en contextos exolingües donde el contacto directo es escaso para tal efecto las tareas conceden a los estudiantes la oportunidad de emplear las dimensiones del lenguaje (fonológicos, gramaticales, léxicos y contextuales) que son complementados de forma estratégica con las destrezas propios de la lengua (Manrique, 2014).

Dentro del marco de la enseñanza de idiomas la principal finalidad es alcanzar en el estudiante una comunicación genuina y real utilizando la L2 como un mecanismo al cual acudir sujeto a pautas de integridad y presión frente a una tarea más específica; pues este método otorga una libertad de dominio del lenguaje (Guamán,2019).

Método basado en proyectos (ABP), se origina a por las demandas surgidas en la Escuela Nueva, donde se enfatiza en las necesidades de los estudiantes, razón por la cual esta estrategia se impone por su carácter innovador sin representar una carga en la labor docente (Caravedo,2018). 
Si bien es cierto existen diversos conceptos, en general lo fundamentan como un proceso organizador del aprendizaje que gira en torno a proyectos que años más tarde cambio en su denominación a el aprendizaje basado en proyectos (Pompilla,2019).El aprendizaje basado en proyectos está dirigido al desenvolvimiento del estudiante en el campo de estudio, centra su actividad en el análisis, la asimilación de la información, comprensión, procesamiento a través de la ejecución de tareas complejas para emular el día a día en el área de trabajo empleando una serie de actividades para alcanzar con satisfacción de los objetivos trazados (1997).

Desde esta concepción, el estudiante forma parte del diseño de la clase, al señalar los problemas, desarrollarlo a través de un proyecto auténtico, de su interés personal y colectivo a fin de involucrarse a profundidad en la investigación atractiva, proponer posibles soluciones y de esa manera se ejercita la autonomía durante un lapso de tiempo en el que busca información para analizarla y culminar su proceso y socializar los resultados en su aula (Pompilla et al., 2019).

El docente en su papel de mentor, agente transformador y guía no solo se encargará de dar las orientaciones necesarias y las disposiciones requeridas para llevar a cabo el proyecto, sino de estimular una actitud de emprendimiento, de crítica e independencia en sus estudiantes, que influye en ellos el nivel de responsabilidad, autoaprendizaje, colaboración y organizar las acciones de indagación durante el desarrollo del proyecto (Pompilla et al., 2019).

Por ello se hace necesario diseñar un proyecto práctico y eficiente, para tal efecto Vergara (2015), señala la necesidad de aplicar diferentes procedimientos y metodología efectiva que ayuden a consolidación las habilidades de búsqueda de información sobre el problema identificado de manera que todos los estudiantes ejerzan la crítica constructiva y para la presentación del producto final (Buck Institute for Education, 2015).

Métodos de aprendizaje socializado en el ámbito educativo existe alguna polémica en la utilización de los vocablos de socialización y cooperación pues la desorientación causal se da a nivel conceptual por su naturaleza complementaria donde el aprendizaje cooperativo apunta a ejercer una función específica a cada integrante, mientras que en el aprendizaje socializado o también conocido como colaborativo crea una estructura cognitiva y de interacción con cada uno de los miembros del grupo (Manrique,2014).

En el aprendizaje socializado se fomenta la interacción en un contexto comunicativo y social para alcanzar un objetivo en conjunto. Sin lugar a dudas este método proporciona al estudiante la integración social sin perjuicio de lo personal mediante actividades intelectuales que enlacen sus intereses y capacidades para alcanzar objetivos complejos 
y altos. Es de consideración que la enseñanza socializadora fomente el aprendizaje a través de las dinámicas de trabajo grupal (Álvarez de Zayas, 1997).

En este contexto, el aprendizaje colaborativo resalta ciertos rasgos característicos que se distinguen notablemente en el aprendiz como la auto determinación, estrategia, intelectual y de empatía obteniendo el éxito de su aprendizaje en adquirir una segunda lengua teniendo implicancias de una interacción natural resultante como aprendiz contexto educativo - docente (Manrique, 2014).

Motivo por el cual Nérici (1989) explica el surgimiento de la propia energía por el intercambio mutuo existente entre sus miembros que llevan al aprendizaje mediante la interacción con la lengua extranjera en los contextos sociales y de identidad con otros hablantes en una situación reflexiva. En consonancia a lo dicho por O'Malley y Chamot (1990) al manifestar la importancia de la valoración empática y la cooperación (Álvarez de Zayas, 1999).

El proceso de aprendizaje se basa en la lógica generalizadora para la organización, asimilación y consolidación de la información, por una parte; y por la otra interiorizarlo y aplicar lo aprendido. Los objetivos de este método es transformar los conocimientos cualitativos del estudiante en un aprendizaje activo que despertó el interés y actitud.

Según, Álvarez (1997) este método orienta al educando al conocimiento del objeto de estudio, sistematizar la información para convertirla en conocimiento, programar las actividades y aplicar el conocimiento en la solución de los problemas.

En ese sentido, Pinilla (2008) sugiere un listado de estrategias comunicativas que pueden llevarse a cabo en el proceso de enseñanza - aprendizaje del idioma Inglés para estimular la comunicación oral, las cuales son.

Paráfrasis.- Producto del análisis conceptual en donde el aprendiz reorganiza los procesos lingüísticos con la finalidad de reemplazar la palabra que se desconoce. La manera de poner en marcha es utilizando dos tipos de estrategias de paráfrasis que puede incluir a las Aproximaciones y descripciones (Briceño, 2017).

Acuñaciones léxicas.- Es la creación de una palabra independientemente que exista o no en la interlingua del estudiante", en donde el análisis y la elaboración funcional del código suponen la aplicación de características morfológicas de la L2. Este tipo de estrategias se dividen en función de la lengua sobre la que se realiza para que después se transforme en léxico (Briceño, 2017).

Transferencia lingüística. Estrategia de prestación directa producto de las similitudes y diferencias que subyace a partir de enunciados propios de la lengua meta y la que previamente ha sido aprendida (Orlin, 1989). Aplicado en el estudio de la casuística, 
el estudiante al desconocer la expresión de un idioma recurre a su homólogo en su lengua materna (L1) y de esa formar realiza una conexión en cuanto a significado (Briceño, 2017). Peticiones de ayuda al interlocutor. Respuesta de una estrategia control del código y una clara muestra de la falta de conducción durante la comunicación que puede surgir por diversos factores que no soluciono en el proceso de aprendizaje. Esta petición evidencia la necesidad del estudiante en el recibimiento de la información o de certeza de quien la facilitó (Briceño, 2017).

Al concluir la sistematización teórica de la categoría competencia comunicativa oral, se asume como autor de base a Llatas (2017), por considerar que se ajusta su posición teórica a los objetivos de la investigación. Desde esta posición se identificaron las subcategorías apriorísticas y los indicadores que se presentan en la matriz de categorización (Anexo Nro. 1).

Subcategorías e indicadores:

Competencia semántica: Capacidad de identificar, organizar y utilizar los significados del léxico de acuerdo con el entorno comunicativo (Consejo Europeo, 2002)

Indicadores: Dominio del nivel semántico de la lengua y la estructura en la comunicación oral; dominio del vocabulario y comprensión de los fonemas y grafemas en el plano oral.

Competencia discursiva: Capacidad del aprendiz para expresarse en una lengua de manera activa y adecuada, mediante la articulación de las estructuras gramaticales y su significado alcanzando de ese modo un texto oral o escrito unificado (Consejo Europeo, 2002).

Indicadores: Uso de técnicas en una conversación; manejo del discurso según el contexto y uso de modelos en la interacción social.

Competencia sociolingüística: Habilidad que permite comprender y producir expresiones lingüísticas de acuerdo con sus normas de uso de la lengua en el discurso para interpretarlos en su contexto social (Canale y Swain, 1983).

Indicadores: Comunica sus conocimientos según el contexto; desarrolla las relaciones sociales con eficiencia y selecciona expresiones para su discurso de manera formal e informal.

\section{Fundamentación teórica de la estrategia metodológica}

Es necesario comenzar el análisis con la etimología del término estrategia. Al respecto Casado (2013), refiere que la estrategia es como un plan de acciones proyectadas a la obtención de conocimientos que mantienen una estrecha relación con el logro de los objetivos planteados presentados en el proceso de aprendizaje. 
Sobre la estrategia metodológica, Tobón (2010) hace una distinción entre un sector agricultor de Estados Unidos Americanos, que luego lo catalogó como una metodología activa de índole estructural, que identifica, interpreta y resuelve problemas, criterios y procedimientos. Configura así el rol docente como afirman Hernández (2017), Sánchez y Becerra (2005), Ramirez (2007), Diaz Barriga (2006) autores que servirán de base para la presente investigación científica educativa.

En lo relativo a la metodología, se define como un mecanismo especifico que se originan a partir de una postura teórica, el desempeño del docente y el estudiante durante el proceso de enseñanza - aprendizaje. De manera semejante Quintero (2011), expresa que la estrategia metodológica es una secuencia ordenada de actividades por el docente para conseguir el éxito del aprendizaje que ira en concordancia a la edad y nivel académico de los estudiantes (Arguello y Sequeira, 2016).

En este sentido, Brown (2000) considera la estrategia metodológica, como una maniobra sistematizada en la que se podrá reconocer la información procesada para lograr un fin particular que vaya acorde a la situación actual, eso conduce al aprendizaje de calidad y oportuna.

Sobre esta situación Nisbet (1991), afirmar que las estrategias de enseñanza cumplen un patrón de participación en el aula, determinado por el docente que incluye la regulación del comportamiento y el uso de recursos que influyen en la comprensión de las tareas, procedimientos o técnicas para alcanzar el aprendizaje de los discentes (Alcaraz et al,2004).

Para Barriga y Hernández (2010), la estrategia metodológica está formada por distintos procedimientos para dirigir la clase, con el fin de que los estudiantes apliquen distintos procedimientos, los concienticen y se conviertan para ellos en un aprendizaje consciente, de manera que puedan aplicar el autoaprendizaje y la autoevaluación de lo qué hacen, cómo lo hacen y qué pasos seguir para desarrollar una actividad de manera que incide en el desarrollo de las habilidades y la independencia cognoscitiva del educando.

Una posición similar expone Pimienta (2012), aunque no tan amplia como la anterior, al definir la estrategia metodológica como un instrumento pedagógico del que se vale el docente para contribuir al desarrollo de las competencias de los estudiantes durante el proceso de enseñanza- aprendizaje.

Por su parte, Hernández (2017) aporta una definición más completa, al afirmar que la estrategia metodológica es el conjunto de acciones y procedimientos mediante el empleo de métodos, técnicas, medios y recursos que la docente emplea con el propósito de lograr eficazmente el proceso educativo en una situación de enseñanza - aprendizaje especifica. 
Como se aprecia, el análisis realizado sobre la categoría estrategia metodológica, orienta que la misma se emplea en la enseñanza- aprendizaje y la integran un conjunto de métodos, técnicas y procedimientos a fin de alcanzar los objetivos previstos. Decisivo es el uso de los métodos por ser la forma de ordenar el planteamiento pedagógico para dinamizar, activar al educando, relacionar los saberes previos con los nuevos y potenciar las capacidades cognitivas, afectivas, volitivas y emocionales en los estudiantes para ser protagonista de su propio aprendizaje. Su importancia radica en la transformación cualitativa que se logre en el pensar, sentir y hacer de los estudiantes (Comes y Delors, 2004; Castellanos el al, 2007; Ortiz, 2012 y Addine ,2013).

Las técnicas son instrumentos que el método utiliza como recursos para el cumplimiento de los objetivos en el proceso para conseguir el producto de la actividad del aprendizaje; ellas ayudan al cumplimiento de los objetivos (Ortiz, 2012 y Addine ,2013 y Arguello y Sequeira, 2016).

Los procedimientos van orientadas al proceso y a la conquista del fin; para tal efecto Alcaraz, (2004), los define como un conjunto de actos consecutivos para dirigir el desarrollo de las habilidades que automatizadas se convierten en competencias (González, 2003, Castellanos et al, 2007, González, 2008 y Tobón, 2009).

En suma, la aplicación de un sistema métodos, procedimientos, técnicas, actividades de aprendizaje exigentes, coherentes y ordenados hacen posible una estrategia metodológica que tiene como centro del proceso de enseñanza- aprendizaje al educando y que estimula el interés por aprender, la motivación, el pensamiento y el desarrollo de la competencia comunicativa oral del idioma (Castelló et al, 2006, Castellanos et al, 2007 y Addine 2013).

Para lograr ese proceder profesional en la clase, es necesario que los docentes alcancen la capacitación pedagógica eficiente para orientar la enseñanza atendiendo a las necesidades del grupo, con situaciones comunicativas del contexto, promover el pensamiento, el lenguaje, la observación, el análisis, el diálogo, la colaboración y las capacidades comunicativas de los educandos para que sean conscientes de qué y cómo aprenden en la actividad conceptual, procedimental y actitudinal (Tobón, 2009; Domínguez, 2010 y Sequeira,2016 y Diaz et al.,2018).

En ese sentido es preciso que el docente aplique actividades de aprendizaje que estimulen las capacidades intelectuales, investigativas y creativas de los estudiantes, a través del empleo de esos métodos que inciden en la observación, análisis, reflexión, toma de decisiones y expresen sus ideas de forma oral a partir del trabajo realizado en equipos (Castellanos et al, 2007; Tobón, 2009 y Addine 2013). 
Se destaca en ello el proceso de mediación del docente con el objetivo de crear situaciones de aprendizaje para estimular las habilidades de expresión oral que orientará al estudiante a interiorizar, autoevaluarse para concientizar qué sabe y en qué falla para reorientarse en el aprendizaje. Las estrategias metodológicas tienen como fin de avivar el interés, la metacognición y la autorregulación en los educandos (Castellanos et al, 2007; Tobón, 2009 y De Corte, 2015).

Al concluir la sistematización teórica de la categoría apriorística, estrategia metodológica, ha permitido profundizar en la misma a partir de las distintas posiciones teóricas de los especialistas consultados. Ello permitió asumir como autor de base a Hernández (2017), por ser un constructo teórico integral que se ajusta a los objetivos del objetivo general de la investigación para su inserción en la enseñanza -aprendizaje de la asignatura Inglés. Desde una perspectiva metodológica, se analizaron una variedad de métodos, procedimientos y actividades con el propósito de dialogar, cuestionar, analizar, valorar los contenidos, aplicarlos y comunicar de forma oral lo aprendido influyendo de esa manera en la competencia comunicativa de los estudiantes.

A partir de ahí se identificaron las subcategorías apriorísticas: determinación de necesidades y objetivo general, base teórica de la metodología y etapas en la evaluación, sustentadas por (Brown, 2000; Quintero, 2011; Casado, 2013 y Briceño, 2017), y se reconocieron los indicadores (Anexo Nro. 2).

Subcategorías e indicadores:

. Determinación de necesidades y objetivos: es el fin prioritario orientado al proceso de aprendizaje del estudiante en relación al avance que se pretende lograr en un tiempo determinado y los recursos a su alcance (Vega, 2010).

Indicadores: Aplica el diagnóstico ante la realidad; formula objetivos en un plazo determinado y argumental el rol del docente y estudiante.

. Base teórica de la metodología: Conjunto de alcances teóricos interrelacionados para desarrollar y construir matices significativos del tema o problema de estudio planteado, induciendo al conocimiento actual a una determinada área (López,2011).

Indicadores: Sustenta el marco conceptual; fundamenta el sistema de actividades y los roles a implementar; aplica el sistema de métodos en el proceso de enseñanza aprendizaje. . Evaluación de la metodología: Proceso personalizado guiado con el fin de diagnosticar el cumplimiento de los objetivos previamente constituidos brindando una valoración que permita su contraste y actualización (Sánchez, 2018).

Indicadores: Determina las etapas de la metodología; propone acciones y procedimientos de cada etapa; elabora instrumentos y técnicas para evaluar la metodología. 
Es necesario añadir que la aplicación la aplicación de la estrategia metodológica es una tarea que requiere del rol profesional del docente, de la superación permanente desde su puesto de trabajo donde debe autorreflexionar sobre su propia práctica pedagógica como afirman Zegarra y Velázquez(2016) con el fin de contribuir al desarrollo de la competencia comunicativa oral del idioma Inglés de los estudiante La estrategia propuesta se basa en los referentes teóricos sociológico, psicológico, lingüístico, pedagógico y curricular que le dan rigor al modelo presentado. 


\section{Capítulo II}

\section{Diagnóstico o trabajo de campo}

\section{Diseño y validación de los instrumentos}

Con el propósito de constatar el estado actual del problema investigado en la práctica pedagógica, se realiza el diagnóstico de campo en una institución universitaria privada de Lima, seleccionada por conveniencia por reunir las condiciones para cumplir el objetivo planteado en el estudio.

Durante el proceso investigativo se diseñaron, validaron, aplicaron y procesaron diferentes técnicas e instrumentos empíricos para el recojo, procesamiento y triangulación de la información (Anexo 3 y 4).

La información obtenida de orden cualitativa y cuantitativa se procesó por medio de las tablas de reducción de datos y por las de frecuencia. Las tablas de reducción de datos posibilitaron la identificación de categorías emergentes, mientras que las de frecuencia permitieron determinar algunas tendencias y regularidades. En ambos casos se arribó a conclusiones parciales por cada instrumento que facilitaron una percepción holística del proceso e identificar las categorías emergentes sustantivas y las que inciden en el objeto investigado.

\section{Procesamiento de la información, análisis, interpretación y discusión de los resultados}

Análisis de los resultados de la entrevista aplicada a los docentes.

Se aplicó una entrevista semiestructurada a cuatro docentes de la especialidad de inglés II, cuyo proceso de codificación figura en el Anexo Nro. 5 y su interpretación es la siguiente.

Al indagar sobre la categoría competencia comunicativa oral, dos docentes dieron los argumentos, su funcionalidad, el rol que desempeñan al entablar una conversación y los elementos a tener en cuenta en su tratamiento en la clase; dos expresaron ideas básicas sin argumentar en lo teórico; y el último profesor refirió algunas ideas generales, pero en general demostró una insuficiente preparación sobre este contenido que enseña.

En cuanto a los teóricos de la competencia comunicativa oral, dos nombraron Chomsky y su posición teórica acerca de la gramatical universal y el aporte de Jeremy Hamer sobre los métodos comunicativos; uno se refirió a Dell Hymes sobre el desarrollo 
de la etnografía del habla; y los dos restantes reflejaron desactualización y falta de preparación teórica, siendo un aspecto esencial para la enseñanza de cualquier idioma.

Acerca de las subcompetencias de la competencia comunicativa oral, los cinco docentes concordaron en resaltar la fluidez, entonación, pronunciación; uno de ellos diferenció la competencia léxica y la pragmática como factores esenciales a nivel sociolingüístico y gramatical en la activación del pensamiento y la elaboración del mensaje oral o escrito por el hablante.

En relación al proceso de comprensión, los tres docentes resaltaron su valor en el dominio de la lengua, puesto que debe establecer la relación entre el plano sonoro y su representación léxico- semántico para que entienda lo escuchado y pueda producir sus ideas; indican que si fueran orientados bien, se motivarían, asimilarían y aprenderían sin mucho esfuerzo al enfatizarles en el qué hacer, cómo escuchar, analizar, comprender el sentido de las frases, las oraciones y en general los mensajes construido; los tres destacaron el peso que tiene la comprensión auditiva en la comprensión de las ideas poder expresarse sobre el tema tratado en el discurso.

Sobre los enfoques didácticos de la competencia oral, un docente fundamentó mencionando a Community language learning (CLL) como el marco de aprendizaje comunitario de idiomas a la inversa; en general se constató desconocimiento y desactualización en los docentes al no aportar ninguna idea.

Sobre el interés y motivación de los estudiantes, un docente expresó que es necesario identificar el punto de interés y generar las actividades comunicativas variadas y atractivas; dos puntualizaron desde un enfoque funcional el aprendizaje significativo empleando un sistema de preguntas; y dos agregaron el papel la sugestopedia a fin de estimular la comunicación libre y conocer el nivel de producción del estudiante.

Sobre la estimulación del docente para potenciar el nivel fónico, expresaron tener falta de tiempo para cumplir el sílabo y sobrecargarlo sería complicado para su ejecución; dos revelaron que son escazas las ocasiones en las que aprovechan las actividades en la clase y explicaron la necesidad de ofrecerle alguna ayuda y valor de analizar y repetir como técnica para mejorar la pronunciación de palabras del contexto a fin de que discriminen los sonidos propios de la lengua inglesa.

Respecto al tratamiento que dan a las habilidades comunicativas, un docente mencionó que las estrategias utilizadas se basan en el reforzamiento y la práctica, el empleo del método de Flipped Classroom (Aula invertida) es lo ideal en aquellos casos y el diálogo; mientras dos destacaron el aspecto emocional para lograr confianza para comunicarse con facilidad y evitar el silencio en su discurso. 
Al indagar sobre el rol del trabajo en grupo, los entrevistados resaltaron un gran valor para desarrollar habilidades orales, de responsabilidad, actitudinal siguiendo un tema y facilitando así la comunicación oral y para aprenden de sus compañeros; dos subrayaron la función social en la interacción continua que se alcanza en los trabajos grupales manteniéndose la aceptación, tolerancia y de valores.

Relacionado con las estrategias de aprendizaje que emplean en la clase, dos explicaron lo significativo que puede ser para el ponente cuando termina la presentación de la misma manera en que la empezó, da firmeza durante el discurso y ayuda al a entender la exposición con su desenvolvimiento a fin de influir en las ideas, proyección de voz adecuada, aunque los docentes restantes no contestaron de forma concreta.

Respecto a la aplicación de la metacognición y autocontrol, los entrevistados nombraron diversas técnicas para realizarlo, ayudan a reflexionar sobre su proceso de aprendizaje, hacen preguntarse para saber qué lograron y qué necesitan para reforzar lo aprendido, donde puedan interactuar en una situación comunicativa cotidiana y así conseguir una respuesta espontánea que ayuda al desarrollo de la oralidad.

En cuanto al proceso de evaluación del aprendizaje de las habilidades orales, los docentes mencionaron que evalúan con instrumentos probados y certificados por la universidad de Cambridge, lo cual revela la validez en el proceso porque usan las rúbricas con sus respectivos indicadores y seguidamente la explicación de estas 'por los alumnos, pero no precisaron nada de la evaluación integral.

El análisis realizado permite aseverar que los docentes presentan deficiencias en los sustentos teóricos y didácticos referidos a la competencia comunicativa oral, evidenciado en la falta de argumentos de los enfoques teóricos actuales, desconocimiento de la didáctica y de los métodos, estrategias y procedimientos dialógicos, colaborativos, lúdicos, creativos y problémicos que conducen al desarrollo de la competencia oral en los estudiantes.

\section{Análisis de los resultados de las observaciones a clases a los docentes.}

Se observaron cuatro clases a docentes en la disciplina de Inglés II. La interpretación permitió arribar a la siguiente reflexión:

La metodología empleada por los docentes al inicio de la clase es apropiada de manera general; utilizaron medios tecnológicos como videos, música e imágenes proyectadas que estimularon el interés por participar desde sus saberes previos y contextualizando las ideas que facilitó la comprensión, análisis e introspección del tema por los estudiantes. 
En el desarrollo de las sesiones se presentaron irregularidades en la aplicación de los métodos de enseñanza que no facilitaron establecer el diálogo para activar los procesos del pensamiento y el lenguaje y la posibilidad de poner en práctica lo aprendido por los estudiantes. Se apreció que tres docentes utilizaron actividades que incidieron en el pensamiento crítico y la toma de decisiones para expresarse y aprender activos, y justificar lo aprendido de forma alturada (Kayi, 2006), lográndose con ello una interacción comunicativa satisfactoria por los procedimientos aplicados.

Se evidenció la conexión del docente con el alumnado que facilitó un ambiente de aprendizaje dialógico de confianza que incidió en la tarea de estudio. El trabajo en grupo y la utilización de los distintos procedimientos de organización de la información influyó en la calidad de la sesión. En ese sentido, Prieto (2012) destaca la importancia de relacionar material novedoso con ideas ya existentes en la estructura cognitiva del estudiante. Por tal razón, el alumno al utilizar los organizadores respondió bien en su aprendizaje.

Un docente aplicó un procedimiento musical para comenzar con una actividad programada que fue bien aceptada por los estudiantes favoreciendo la concentración para su realización; atendió las diferencias individuales en el trabajo colaborativo y orientó la redacción de un párrafo sobre un tema en específico. De esa manera se evidenció un adecuado tratamiento que llevó a los educandos a producir un nuevo texto.

De igual importancia fue la música colocada desde el principio, cumplió con su rol de estimular el interés, confianza y motivación siendo estas categorías imprescindibles para el aprendizaje. Al respecto, Waisburd y Erdmenger (2007), resalta que la música ofrece es esencial, le da un enfoque creativo y nuevo a la enseñanza- aprendizaje. La música con fines pedagógico incide en el desarrollo de la inteligencia interpersonal y la intrapersonal lográndose un aprendizaje significativo.

En otra clase el docente relacionó sonora de superhéroes emblemáticos con el fin de que puedan identificarlos en espontaneo y a la misma vez mostrando los funkos de cada uno de estos captando el interés y atención; les pidió que elaboraran un dibujo creando un superhéroe para luego explicar lo realizado.

Seguido observaron un video y aplicó una lluvia de ideas acerca de la observación y se apreciaron dificultades en la fluidez, coherencia en las ideas y pronunciación que fueron atendidas. Se destaca el inicio como novedoso, les dio oportunidad a los estudiantes de participar por medio de las actividades dialógicas producidas desde la observación.

Otro rasgo importante es el clima muy bien generado e impulsado por el docente durante la clase en el proceso de enseñanza - aprendizaje; sobre todo para Printrich y Schunk (2006) quienes recalcaron el efecto del clima de aprendizaje en la motivación, 
siendo necesaria para el logro de los objetivos de clase. El clima de clase se establecerá principalmente a través de la interacción del docente y el alumno.

Al concluir el análisis se evidenciaron potencialidades en la motivación de la clase demostrándose una conexión natural entre los docentes y los estudiantes, acompañada de una enseñanza contextualizada conveniente para los estudiantes; y como deficiencias se destaca la falta de aplicación de metodologías efectivas para estimular el diálogo, la expresión activa y el tratamiento a los estilos de aprendizaje a fin de desarrollar la competencia oral en los estudiantes.

\section{Análisis de los resultados de la encuesta aplicada a los estudiantes.}

Para la aplicación de la encuesta se tomó una muestra de 15 estudiantes que cursan la asignatura de Inglés II, cuyo proceso de codificación figura en el Anexo Nro. 6, y la interpretación es la siguiente.

De los 15 estudiantes, 14 (93,3\%) destacan la importancia de esta materia para su futura profesión y uno $(6,7 \%)$ considera lo opuesto. Esos resultados muestran lo imprescindible del aprendizaje de este idioma dentro del mundo profesional y laboral en las esferas empresariales que es reconocida por los estudiantes.

En cuanto a la participación de los estudiantes mediante el uso de preguntas, diálogos, lectura y comentarios sobre el tema., 12 (80\%) refieren que el docente fomenta actividades colaborativas con vistas a la construcción oral, dos $(13,3 \%)$ expresan que a veces ejemplifica la construcción gramatical, y uno (6.7\%) señala que nunca lo hace, dejando en evidencia que el docente no llega de manera eficaz a todos los estudiantes.

En virtud del desarrollo de las actividades prácticas revelan que 10 (66,7\%), consideran que el docente orienta el aprendizaje mediante contextos ligadas a la realidad, $4(26,7 \%)$ consideran que nunca responde a sus dudas algunas veces durante el tratamiento del contenido y uno (I 6,7\%) opina que a veces, el docente apreciándose que el docente no efectúa una retroalimentación adecuada a los estudiantes durante la clase

Acerca de los recursos utilizados en clase, se demostró que $12(80 \%)$, señalan que la docente siempre emplea videos, películas y otros medios para identificar cómo escuchar, pronunciar y realización de diálogos orales; 2(13,3\%) menciona que los docentes nunca lo hacen y uno $(6,7 \%)$ refrenda que algunas veces indica reconocer la pronunciación y comprensión auditiva, de forma clara y precisa para todos los alumnos.

En lo relativo a la valoración de la comprensión, $10(66,7 \%)$ consideran que los profesores siempre emplean estrategias para el manejo del discurso; 4 (26,7\%), opinan que algunas veces se aplican y uno $(6,7 \%)$, responde que jamás experimentado el manejo de estas para entenderlas y comunicarse oralmente. 
Según la percepción del estudiante, $9(60 \%)$ de los estudiantes estiman que el docente siempre utiliza diversos tipos de evaluar; $5(33,3 \%)$ refieren que el docente no les orienta cuando empleará dichas evaluaciones, un (6,7\%) afirma que algunas veces aplica algún mecanismo o técnica de coevaluación.

En general se constata que los estudiantes no se sienten interesados y motivados por el aprendizaje del idioma, sin embargo, se aprecia una contradicción porque hay temáticas del curso que quisieran conocer.

Se refleja la necesidad de aplicar en la enseñanza- aprendizaje, métodos activos que estimule la comunicación, la investigación, la colaboración, el diálogo y organice las tareas de aprendizaje de los educandos a través de talleres y el trabajo en equipo donde asuman un rol protagónico en la comunicación oral para que sean conscientes de las estructuras lingüísticas esta segunda lengua, construyan frases, oraciones y se potencien la competencia comunicativa oral del idioma.

\section{Análisis de los resultados obtenidos en la prueba pedagógica a los} estudiantes.

Se aplicó una prueba pedagógica a 15 estudiantes, cuyo resultado fue parte del proceso de codificación que figura en el Anexo Nro. 7, e interpretación de estos se exponen a continuación.

El ejercicio primero, consistió en el uso de dos tarjetas una con una imagen y otra con partes de la información para que los estudiantes en pares realizaran preguntas y respuestas intercambiando roles con el objetivo de constatar el desarrollo de la competencia comunicativa oral; se comprobó que solo dos estudiantes (14,3\%), lo hicieron bien, establecieron una conversación fluida, amplitud de vocabulario, destrezas lingüísticas y cumplimiento del objetivo; mientras que 10 ( 71,4\%) presentaron un nivel limitado uso del vocabulario, inadecuada estructuras gramaticales, falta de dominio del tema, de fluidez, pronunciación, tono de voz, expresividad y claridad en las ideas que evidenció un bajo nivel de competencia comunicativa oral.

En el segundo ejercicio cada estudiante debía interactuar de forma oral con el docente sobre un asunto propuesto anteriormente con el fin de comprobar cuál es el nivel de desarrollo alcanzado al participar en un diálogo sobre distintas temáticas propias de su edades e intereses tratados en clases.

Se comprobó que dos $(14,3 \%)$, respondieron de manera aceptable al mantener fluidez, ajuste al tema, la expresividad en la comunicación interactiva y el manejo de la oralidad; 4 (28,6\% ), evidenciaron un desempeño gramaticalmente pobre y falta de fluidez que afectó el intercambio de las ideas; y 8 ( $57,1 \%)$ demostraron un insuficiente manejo 
del discurso, deficiente fluidez, pobreza de vocabulario, carencia sintáctica en las respuestas, ajuste al tema, y falta de confianza en sí mismos, inhibidos y rechazan la comunicación oral. Los resultados evidencian un bajo dominio del contenido en lo relativo al saber, hacer y el ser, pues de los 15 estudiantes tomados como muestra, 10 (67\%) obtuvieron una nota aprobatoria y $5(33 \%)$ desaprobaron, no pudieron desarrollar las actividades con el nivel requerido por la falta de conocimientos y habilidades idiomáticas.

Al concluir el análisis se constata que los estudiantes no han asimilado los aspectos cognoscitivos, procedimentales y actitudinales según lo indicado en el perfil profesional, evidenciado en el bajo nivel de los conocimientos y las habilidades orales que conducen a la competencia comunicativa oral como se precisa en los documentos normativos. Ello refleja las deficiencias docentes en la dirección de la enseñanza- aprendizaje de la competencia comunicativa oral por la falta de métodos y procedimientos que contribuyan a estimular el pensamiento y el lenguaje del idioma.

\section{Relaciones analíticas e interpretativas de las categorías emergentes sustantivas}

El proceso de triangulación efectuado posterior a la aplicación, procesamiento e interpretación de los datos obtenidos a través de los instrumentos, facilitaron el análisis de las similitudes y las discordancias al contrastarlos con los referentes teóricos. Durante el proceso investigativo se redujeron los datos, se codificaron y se arribó a la categorización integral, permitiendo identificar las categorías emergentes generales resultantes del proceso del diagnóstico o trabajo de campo.

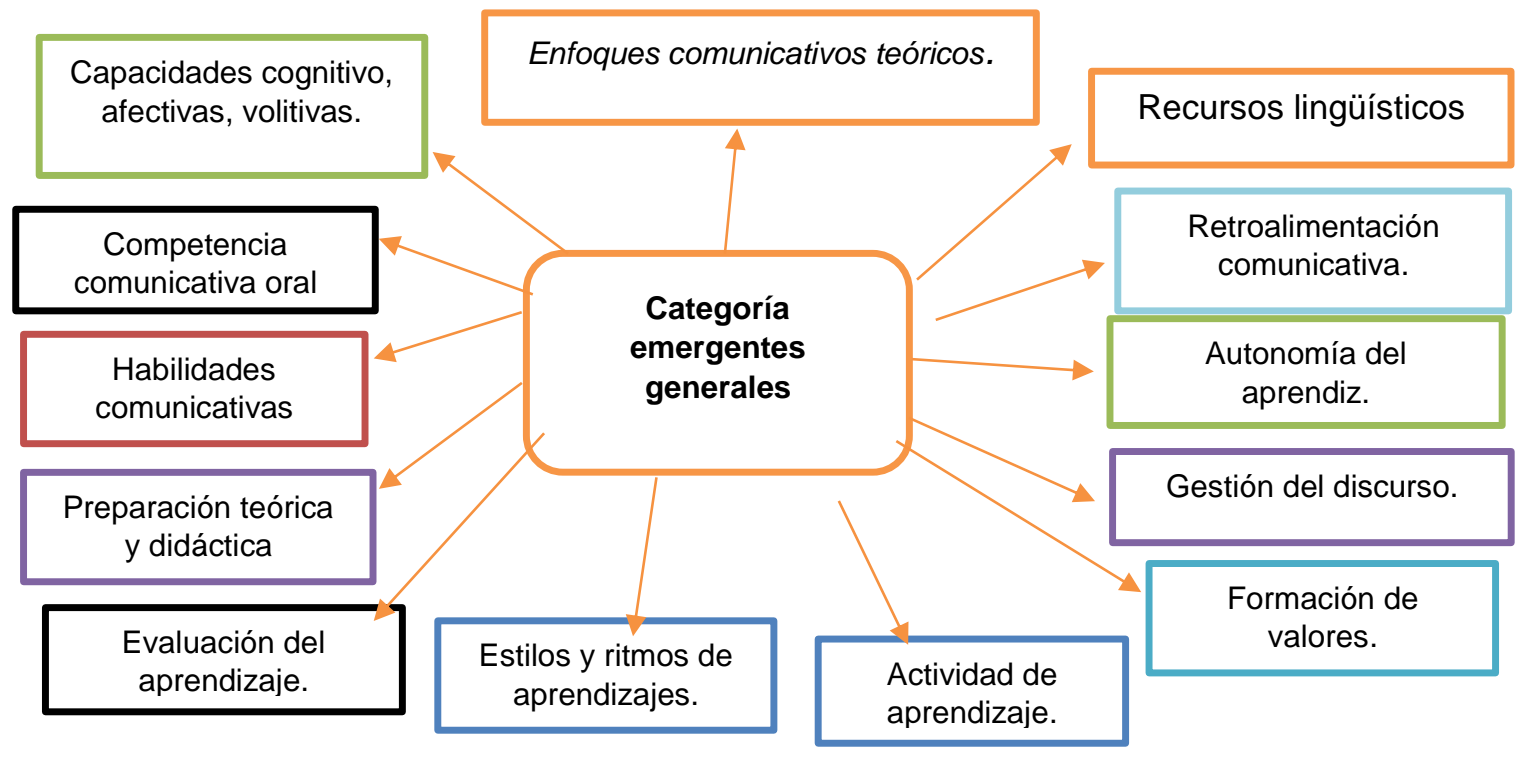

Figura 1 Categorías emergentes generales.

Fuente: Elaboración propia (2019). 
El análisis holístico efectuado sobre las categorías generales facilitó identificar las categorías emergentes que inciden en el problema investigado: bajo nivel de competencia oral en los estudiantes, deficiencias teóricas y didáctica en los docentes para guiar la enseñanza- aprendizaje y falta de fortalecimiento de la esfera afectiva, la confianza y la aceptación.

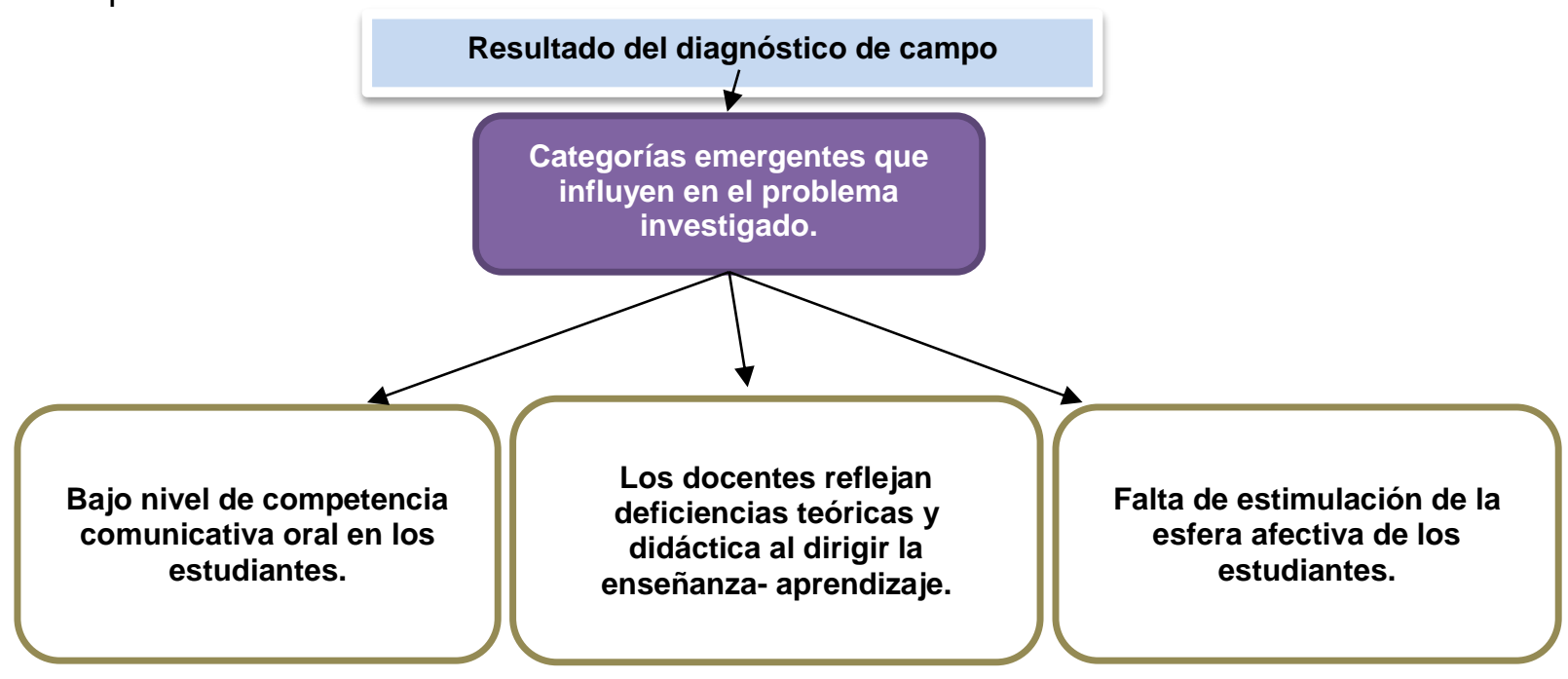

Figura 2 Categorías emergentes influyentes en el problema investigado.

Fuente. Elaboración propia (2019).

\section{Contrastación teórica de las categorías emergentes incidentes en el problema}

\section{Bajo nivel de la competencia oral en los estudiantes.}

Diferentes autores expresan la importancia de esta habilidad en el proceso de adquisición de una segunda lengua ya que mediante el constante contacto con ésta se obtendrá la capacidad de comprensión e intercambio de mensajes, así lo expresa Pérez et al. (2018) pues adjudica la ponderación del logro comunicativo e interactivo en el proceso de enseñanza - aprendizaje. El sistema de contenido de la asignatura de Inglés II, señala que el estudiante debe poseer la capacidad de utilizar sus habilidades y destrezas comunicativas necesarias que les permita expresarse en la lengua meta en situaciones cotidianas que están vinculadas con el quehacer profesional (Roméu, 2007; Domínguez, 2010; Maquerhua y Quiroz ,2017 y Granda, 2017).

Sobre esta categoría emergente, se reflejó en el resultado de la prueba pedagógica que muchos de los estudiantes tienen problemas para consolidar su oralidad en un contexto comunicativo fluido y con naturalidad puesto que existe una deficiencia de herramientas tanto lingüísticas, funcionales y sociales de las cuales valerse para alcanzar 
una comunicación eficaz. Sin lugar a duda, la habilidad oral está estrechamente asociada con su respectiva determinación frente a contextos sobre las que se intercambia en la clase y fuera de ella.

Deficiencias teóricas y didáctica en los docentes en la enseñanzaaprendizaje.

La práctica docente es uno de los elementos principales en el proceso de enseñanza aprendizaje del estudiante que demanda la participación de sus miembros, es a partir de la actuación del docente que empieza el procesamiento educativo pero que pasa si algunos de estos componentes no se desarrollan tal como se quisiera pues es ahí donde el activismo de la didáctica profesional entra a tallar.

En este sentido, en las entrevistas y las clases observadas se evidenció deficiencias en el manejo de las metodologías donde el educador utiliza estrategias innovadoras que carecen de objetividad en el momento de su aplicación lo cual disuade la interacción, análisis, reflexión y correlación con el contexto sin considerar los saberes previos del educando en la construcción del conocimiento. Madrid y Mc Laren (2004) enfatizo el saber aplicar las técnicas acompañado de recursos de índole práctico e infalible para conseguir su competencia de carácter comunicativo.

A este respecto, reconocer el déficit en el manejo de la metodología y didáctica en las entrevistas y clases observadas reafirma una notoria deficiencia no compensada en la formación profesional continua del docente reflejándose ineficiente accionar en el tratamiento de los momentos clave a desarrollar ya que produce inestabilidad sobre la edificación de las bases y en la efectividad de las actividades dialógicas causando una pasividad inconsciente en el educando. Es así que el empleo limitado de metodologías, recursos o materiales utilizados en clase descuidan el desarrollo progresivo de las destrezas comunicativas y orales (Hymes, 1966; Cassany, 2016 y Domínguez, 2010).

\section{Falta de estimulación de la esfera afectiva de los estudiantes.}

Lograr un clima psicológico de satisfacción, confianza, comprensión en las actividades de y las relaciones interpersonales positivas se debe direccionar en aras de potenciar la búsqueda de los conocimientos, su significación personal y explorar sus potencialidades del educando abre una nueva perspectiva en la realidad educativa que transforma lo obvio - invisible y da paso al reconocimiento de lo objetivo - subjetivo - visible en la proyección del estudiante (Conejeros, 2010).

Al respecto, las investigaciones de Abarca (2004), Conejeros et al. (2010) y López (2018) señalan lo complejo de generar confianza en el proceso pues depende de un equilibrio interactivo entre sus elementos (la escuela, familia y sociedad) para desarrollar funciones sociales tales como el respeto a la diversidad, tolerancia, solidaridad y alcanzar 
la equidad estructural expresado como un ingrediente necesario para la resolución de conflictos y la comunicación en el quehacer educativo.

Por otra parte, en las observaciones de clases y en la prueba pedagógica se constató una comunicación deficiente durante el aprendizaje evidenciándose en los resultados obtenidos; que basa el alcance de la confianza a través del autoritarismo docente impidiéndole percibir el miedo del estudiante al comunicarse que junto a su falta de madurez y la desvaloración personal afecta su procesamiento.

\section{Conclusiones aproximativas del análisis realizado}

De hecho, el análisis proporcionó una mirada distintiva hacia la problemática pues se pudo comprobar el nivel de los conocimientos, las habilidades y el desempeño actitudinal deficiente de los educandos frente a las exigencias de la asignatura. Estos elementos precisan carencias pedagógicas metodológicas, principios intervinientes en el aprendizaje y manejo adecuado de las estrategias que motiven el interés, la confianza, convivencia y las destrezas comunicativas en los estudiantes.

Ante los hechos evidenciados, se aprecia que los docentes requieren de capacitaciones auténticas que tomen un aspecto práctico, metodológico y continuo de manera tal que pueda garantizar su accionar ante las carencias comunicativas observadas en el aula en aras de desarrollar un activismo significativo que integre los conocimientos y destrezas del estudiante de forma armónica.

El proceso de sistematización teórica de las categorías apriorística, unido a la interpretación de los datos obtenidos mediante el diagnóstico de campo y la triangulación de la información a partir del análisis reflexivo de la problemática permitió identificar las categorías emergentes generales y las que influyen negativamente en el problema a partir de las cuales se modela la estrategia metodológica que tendrá como objetivo contribuir al desarrollo en los estudiantes la competencia comunicativa oral desde el proceso de enseñanza- aprendizaje de la asignatura de Inglés II. 


\section{Capitulo III}

\section{Modelación, validación y aplicación de la propuesta}

Como resultado del proceso investigativo se identificaron las categorías emergentes incidentes en el problema: bajo nivel de competencia oral en los estudiantes, deficiencias teóricas y didáctica en los docentes para guiar la enseñanza- aprendizaje y deficiente progreso al fortalecer la confianza y aceptación del estudiante. Al ser analizadas integralmente se procedió a modelar la estrategia metodológica que, como producto de la investigación, se orienta a contribuir al desarrollo de la competencia comunicativa oral de los estudiantes universitarios.

La propuesta metodológica diseñada se basa en un sistema de métodos, procedimientos y técnicas como: los comunicativos, investigativos, heurísticos, proyectos, trabajos colaborativos y metacognitivos que favorecen la dirección del proceso de enseñanza- aprendizaje a fin de potenciar la comunicación oral como expresión de un aprendizaje consciente, significativo, cooperativo y social donde el docente promueva las posiciones reflexivas, dialógicas y cuestionable encaminada a su producción de textos orales en los actos comunicativos.

\section{Propósito de la estrategia metodológica}

El propósito de la estrategia metodológica modelada es contribuir a desarrollar la competencia comunicativa oral en los estudiantes del idioma Inglés II de la carrera de Negocios Internacionales de una universidad privada de Lima. La propuesta responde al problema científico convirtiéndose el docente en un mediador eficiente del proceso de enseñanza- aprendizaje en la asignatura a partir de la capacitación teórica y metodológica que logra.

\section{Fundamentación de la estrategia metodológica propuesta}

La estrategia metodológica propuesta se basa en los referentes teóricos socioeducativo, psicológico, lingüístico, pedagógico y curricular que le dan rigor y coherencia al modelo teórico práctico presentado como resultado de la investigación.

\section{Fundamento socioeducativo.}

La estrategia metodológica propuesta se orienta al proceso de enseñanza- aprendizaje de la asignatura de inglés II, que reciben los estudiantes de la carrera profesional de Negocios Internacionales de una universidad privada de Lima, ubicada en el distrito de La Molina. En 
el aspecto académico, la institución es una empresa privada con prestigio de un modelo profesional exigente que cuenta con 38 carreras profesionales distribuidas en ocho facultades, siendo la facultad de Ciencias Empresariales de la cual es parte la carrera de estudio.

Para el semestre 2018-1, la población estudiantil que recibió la asignatura fue designado a un grupo de docentes que dispone de cuatro especialistas en la disciplina, y un coordinador general que combina esta labor con el desarrollo de la docencia que revelan necesidades de superación actualizada en el área.

Frente al contexto social, los estudiantes experimentan potencialidades y necesidades que se ven plasmados en planos psicológicos, de interés, expresivos y la falta de guía en su proceso los lleva a no desarrollarlos adecuadamente. La variedad de situaciones a partir de la propuesta metodológica planteada corresponde a la estrategia, motivación e interés por el aprendizaje desde la psicopedagogía como base. Ello precisa desde su dinámica (Ausubel 1983; Vygotsky, 1987; Gonzales, 2003; Castellanos et al. 2007; Ortiz, 2008; Froufe, 2011 y Mora, 2017), entre otros especialistas.

\section{Fundamento psicológico.}

La propuesta responde a las características psicológicas de los estudiantes, cuyas edades fluctúan entre los diecisiete años y veinticinco años. Se evidenció que los aspectos en su desarrollo como los psicológicos, físicos y biológicos de los estudiantes están en vías de maduración, razón por la cual estas deben ser atendidas y orientadas adecuadamente para mejorar las condiciones en su aprendizaje. Sin embargo, en el proceso investigativo salieron a relucir las carencias y potencialidades del grupo en el sentido afectivo emocional, siendo considerados en su formación integral (Piaget ,1981; Ausubel, 1983; Vygotsky, 1987 y Ortiz, 2015).

Los diferentes contextos impulsan la fundamentación de la propuesta metodológica que está diseñada para enriquecer el estudio en lo que refiere a las capacidades, intereses, necesidades, apropiación del aprendizaje, el papel de la gestión del discurso y sobre todo los factores psicológicos que contemplados en los planos volitivos, afectivos y físicos del proceso bio- psicosocial que experimentan en su formación integral. Sin duda estas especificidades son tomadas en cuenta en la propuesta y sustentada por Vygotsky (1987), Muñoz (2010), Brown (2014), Harmer (2015) y Cruz y Velázquez (2016).

Esta complejidad que forma al individuo es tomada en cuenta por diversos especialistas que resaltan con énfasis aspectos relativos a la construcción de confianza, la independencia estudiantil, formas de aprendizaje (ritmos y estilos) y elocuencia en la comunicación desde un enfoque metodológico - didáctico de la lengua extranjera como 
refieren Dolz et al. (2009), Navarro (2009), Richards y Rodgers (2014), Harmer (2015), Rueda y Wilburn (2014), Anaguano et al. (2017).

\section{Fundamento pedagógico.}

La propuesta se concreta en fundamentos de la pedagogía como ciencia social que tiene como objeto de estudio, la formación integral del ser humano. La estrategia es transformadora por su parte fundamenta su capacidad de orientar, planificar y dirigir el proceso de aprendizaje a partir de posiciones valorativas, dialógicas y desarrolladora. Al respecto Álvarez de Zayas (1999), Ortiz (2013) y Addine (2015), precisan que la pedagogía contribuye en a la formación de la personalidad para la vida, señalando como la responsable de la educación formal junto a la familia, las instituciones sociales y culturales, los individuos, los grupos, los medios de comunicación y la escuela; siendo esta última su máxima representante.

Desde este enfoque, Álvarez (1999), Castellanos et al. (2007), Ortiz (2013) y Addine et al. (2015), entre otros especialistas, definen el acto pedagógico como un proceso en el cual el docente cumple su papel de mediador para proyectar el estado actual al potencial de los estudiantes, mediante la práctica reflexiva, dialógica y problematizadora de manera que pueda cambiar el pensar, actuar y expresarse de forma oral a través de distintos textos del idioma inglés.

En tal sentido, la propuesta asume referentes teóricos - metodológicos orientados a conducir la enseñanza - aprendizaje en función del desarrollo de la oralidad del idioma inglés, propuesta hecha por Rodríguez (2010). Este propósito tiene un alcance significativo, pues impulsa la enseñanza interpersonal, el aprendizaje significativo y que se lleva a cabo en la clase de manera gradual, los diversos procesos socioeducativos que se realizan a fin de colaborar a la formación de los futuros profesionales.

\section{Fundamento lingüístico.}

La estrategia metodológica tiene una base lingüística que potencia el pensamiento y el lenguaje por la dualidad existente entre estos, punto esencial del cual se vale el estudiante para producir una idea y verbalizar acerca de lo que piensa de sí, de su entorno y de la información. $Y$ es a partir de la capacidad de escucha que el interlocutor comprende lo dicho por los demás, producto de la reciprocidad secuenciada hecha siendo capaz de mejorar la producción oral en los campos interactivos de acción. Estos elementos dialécticos de la comunicación oral le otorgan al hablante la capacidad de interpretar, explicar y expresarse de forma oral o escrita (Estrada, 2013).

En virtud de contribuir al desarrollo de la competencia oral del idioma inglés es necesario organizar las actividades a fin de que el educando se apropie de los contenidos y las habilidades orales. La metodología diseñada hará consciente al aprendiz de los 
procedimientos y acciones que conducen a la adquisición de las habilidades comunicativas con las destrezas funcionales atendiendo al contexto social en que se producen los actos lingüísticos (Hymes, 1966; Cassany, 2006- 2016; Romeú, 2007; Domínguez, 2010).

\section{Fundamento curricular.}

El diseño de la estrategia metodológica Propuesta se basa en los fundamentos científicos, exigencias, lineamientos y particularidades de la normativa universitaria peruana. Al respecto la Ley Universitaria N. 30220 (2014), precisa que las instituciones de Educación Superior deben incluir en el diseño académico, laboral e investigativo las demandas regionales, nacionales y globales que aporten al desarrollo cultural y social del país en función de formar egresados de calidad, estimular las competencias profesionales para facilitarle al egresado su incorporación al mundo laboral.

En congruencia a ello, en el perfil de la carrera profesional de Negocios Internacionales de una universidad privada de Lima se concreta el plan curricular que incluye las diversas disciplinas de primero al décimo ciclo. La asignatura de Inglés figura en el primer ciclo y tiene como objetivo que los futuros profesionales con la finalidad de que se apropien de los conocimientos y habilidades comunicativas como profesionales emprendedores bilingües.

El desarrollo de las habilidades: hablar, leer, comunicar y escribir en esta lengua es una vía para potenciar su cultura profesional y también para acceder a la información internacional y revertir los saberes en su desempeño profesional como especialistas poseedor de sólidos conocimientos a nivel teórico y en lo práctico acorde a las necesidades actuales. Debe poseer las habilidades profesionales para su desempeño eficiente y acorde a cada situación comunicativa frente al idioma de estudio.

El proceso de preparación de las clases y el contenido sea tratado adecuadamente en cada unidad de estudio, el docente debe realizar la dosificación y planificación de las horas clase, atendiendo a los distintos componentes que requiere cada unidad didácticas de la asignatura con el fin de que el profesor conozca de antemano qué contenido desarrollar, qué métodos emplear, cómo evaluar el proceso de enseñanza- aprendizaje. Ello le permite conocer que objetivos alcanzar a corto, mediano y largo plazo dentro del sistema de clase de cada unidad de estudio.

\section{Diseño de la unidad didáctica de aprendizaje}

A continuación, se presenta la dosificación de la Unidad Didáctica número I, que ejemplifica y garantiza la preparación del profesor sobre el contenido de las habilidades comunicativas orales y las estrategias a recurrir en la propuesta diseñada como se muestra a continuación 


\section{Tabla 2}

Dosificación del sistema de clases correspondiente a la unidad 1 de la asignatura Inglés II.

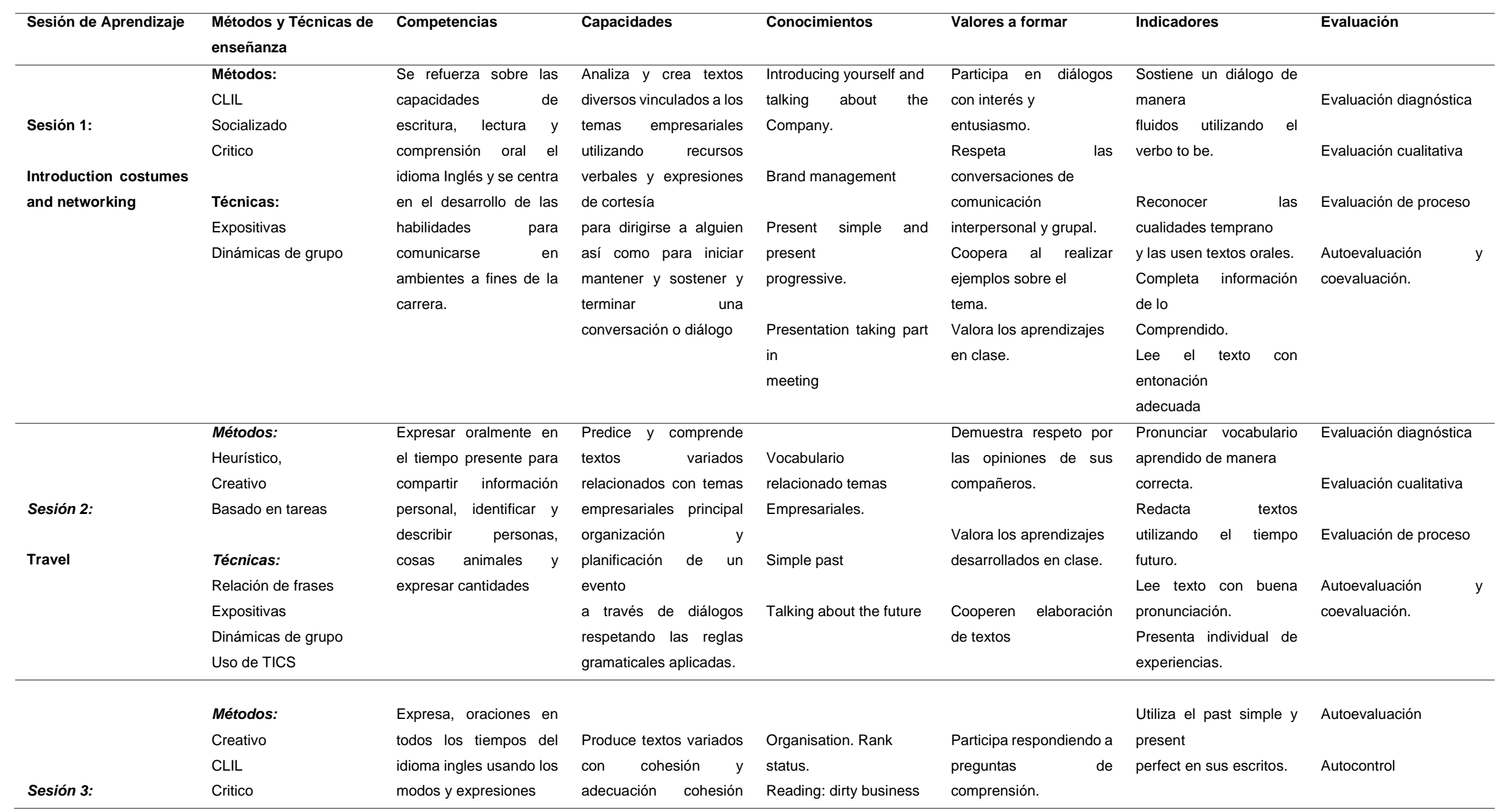




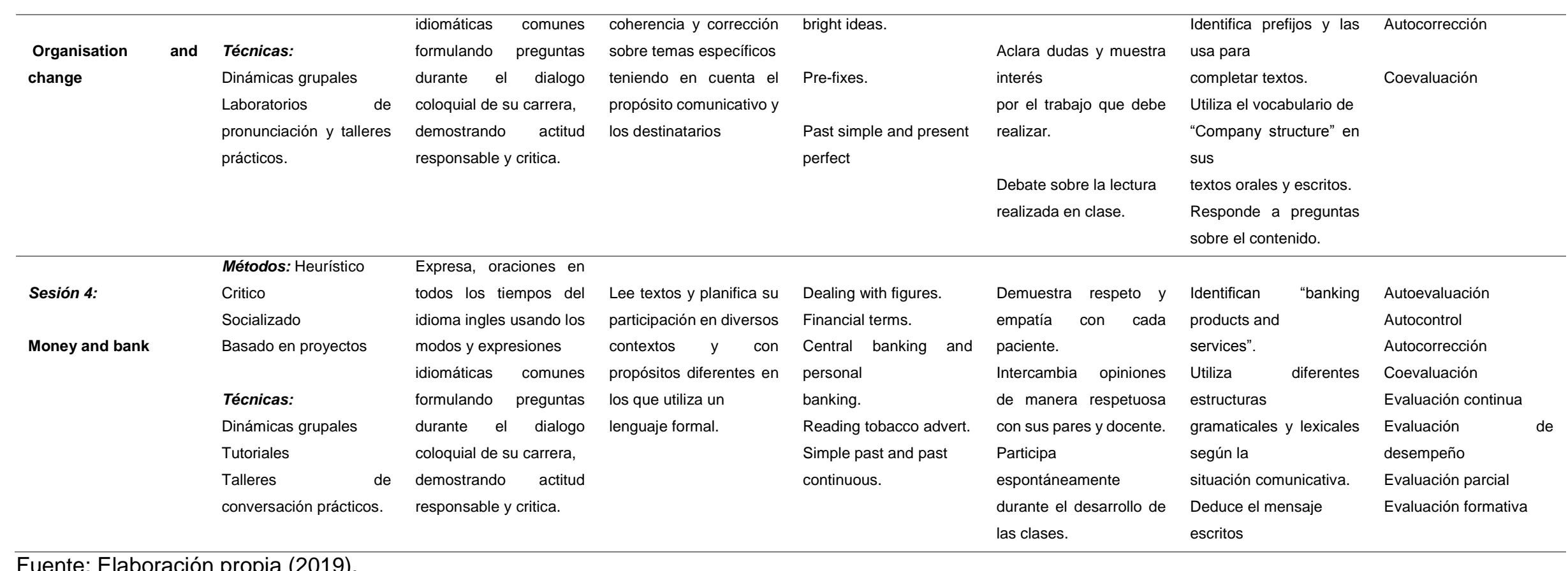




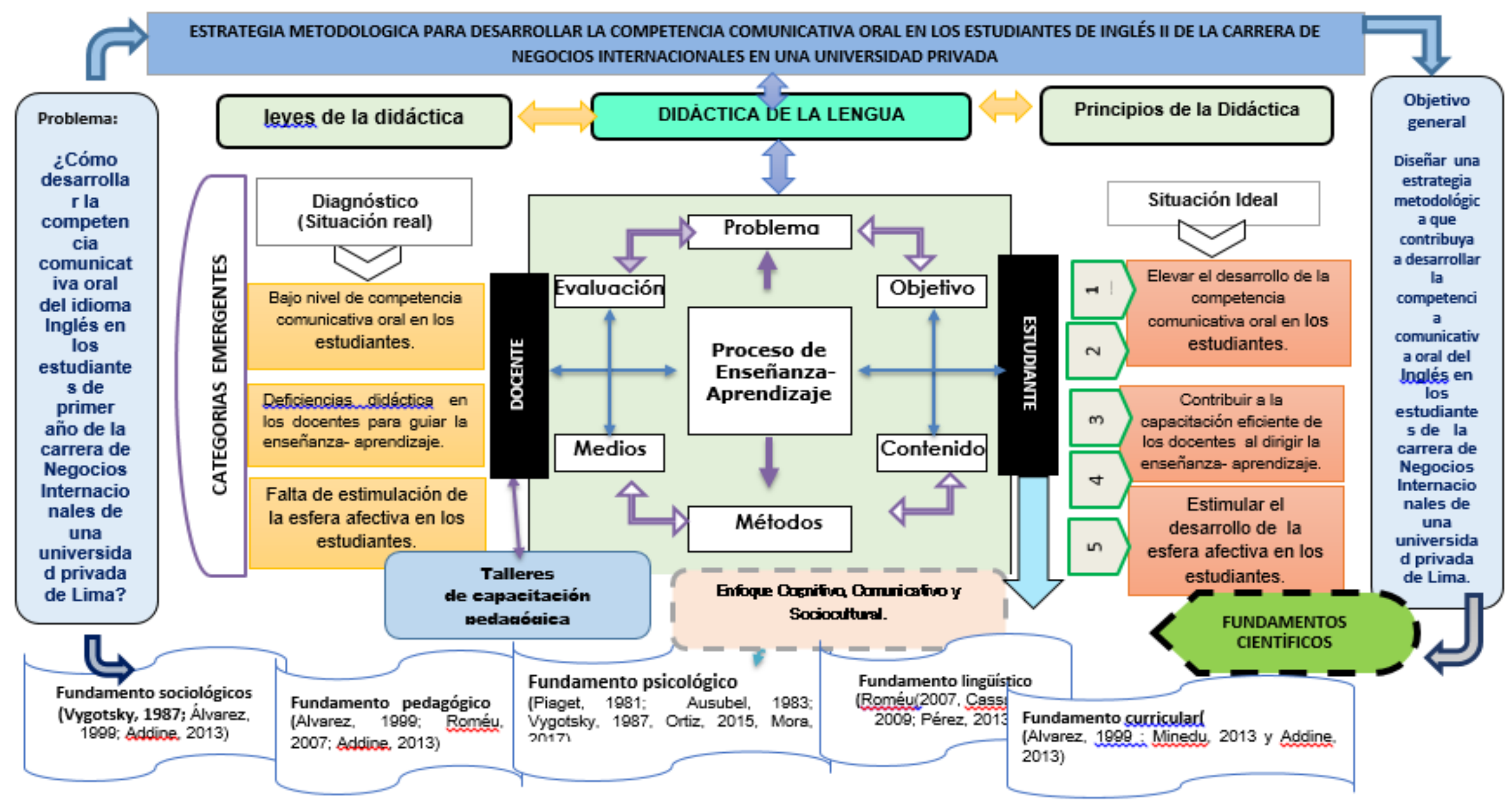

Figura 3 Esquema teórico - funcional de la estrategia metodológica

Fuente: elaboración propia (2019). 


\section{Explicación del esquema teórico - funcional de la propuesta.}

El esquema teórico - funcional muestra la dinámica interna, abierta y transversal del objetivo principal en el problema de estudio, siendo este orientado a su transformación por medio de la propuesta diseñada. En ella se identificó el desarrollo de las habilidades comunicativas en los estudiantes desde el procesamiento de enseñanza- aprendizaje de la asignatura Inglés II.

La estrategia modelada se establece a partir de los referentes expuestos en el marco teórico y la didáctica desarrolladora que integrados organiza, sistematiza, dinamiza y diagnostica las categorías, principios y disposiciones dados por la didáctica.

Se apoya en los principios didácticos considerados por Castellanos et al.(2007), Díaz y Hernández (2010), como postulados teóricos generales sobre los cuales se basa la estructuración del contenido, la organización, la evaluación, los medios didácticos y los métodos de enseñanza que se derivan de las leyes y de los objetivos de enseñanza que rigen el enseñar y el aprender en la clase a partir de la diversidad del grupo, sus estilos de aprendizajes, la comunicación, la socialización y la atención emocional desde el tratamiento al contenido de la enseñanza y en tal sentido se caracterizan por:

\section{Principios didácticos que rigen la enseñanza- aprendizaje de la propuesta \\ Principio de diagnóstico integral de la preparación.}

Es el inicio en la conducción del proceso de enseñanza - aprendizaje. Este puede ser de un amplio espectro en el cual el estudiante tenga la oportunidad de profundizar sus conocimientos ante las exigencias que demanda su desarrollo integral contemplando lo intelectual y valorativo.

Estos complejos requerimientos posibilitaran en gran medida al docente a conseguir una profunda y mejor concepción de los estudiantes a fin de consolidar su desenvolvimiento en la actividad docente y alcanzar los objetivos trazados. El instaurar las bases en el procesamiento resultante no solo nos brinda signos de eficiencia, sino que transforma la posición del aprendiz en el desarrollo de su aprendizaje.

En la propuesta diseñada se sugieren aplicar múltiples técnicas e instrumentos que responde a la evaluación diagnostica al inicio de la unidad como: encuestas sobre los intereses comunicativos, cuestionario para constatar los saberes previos de índole cognoscitivo, afectivo y valorativo del estudiante. Ello le permitirá al docente desde el principio conocer el nivel de partida real de sus estudiantes a fin de intervenir con unas estrategias adecuadas que responda a la diversidad de la realidad del grupo. 


\section{Configuración del proceso de enseñanza - aprendizaje hacia la búsqueda}

activa del conocimiento por el alumno.

La búsqueda del conocimiento por el estudiante, debe atender no solo las exigencias básicas requeridas en los distintos momentos de la actividad sino en la interrelación que alcanzan en el proceso de enseñanza - aprendizaje en la asignatura de Inglés II desde la dirección, ejecución y control del docente. Esta postura que asume el educador aporta con el protagonismo real de sus estudiantes como ser parte de su aprendizaje de un modo consciente y reflexivo del contenido que obtiene a fin de que este pueda organizar una búsqueda que le permita saber qué necesita y carece.

En el proceso de búsqueda, el estudiante debe reconocer las particularidades del objeto de estudio desde un aspecto valorativo esencial, social y de significancia el cual es el producto de un análisis comparativo previo guiado por un nivel de síntesis favoreciendo de esa manera desarrollar el intelecto del aprendiz y facilitar su autoaprendizaje.

Para el logro de tales propósitos, es fundamental impulsar la utilización de procesos mentales de alta complejidad como es el planteamiento de problemas y la incorporación estructurada de las habilidades orales mediante la búsqueda de soluciones a través del uso de métodos heurísticos, problémicos, decisorios y de oralidad.

\section{Actividades para la exploración y búsqueda por el alumno.}

Principio vinculado con la conducción de la exploración analítica y reflexiva del conocimiento que involucre al estudiante de un modo dependiente hacia el contenido con el objeto de interiorizar lo aprendido. Lo dicho hasta aquí supone una determinación de una conveniente orientación para la ejecución y posterior inspección del docente durante los diversos momentos de la actividad.

En este sentido el estudiante desarrolla una interacción trascendental a fin de crear oportunidades complejas de acción que facilite el aprendizaje significativo del contenido de la asignatura en mención, estos elementos abren paso al papel que cumplen las tareas en el proceso pues contienen ordenes que en buena parte estimula el desarrollo cognoscitivo llevándolo a establecer relaciones interesantes y productivas.

Dentro de la propuesta, la planificación de las actividades contempla un aprendizaje del tipo creativo, práctico y eficaz sobre los contenidos de la asignatura, y concebirlas a través de un sistema que logre relacionar las acciones y tareas que fomentan el desarrollo de las habilidades comunicativas en los estudiantes.

\section{Orientación de la motivación y el objetivo de la actividad de estudio.}

El éxito del aprendizaje está vinculado a la constante motivación presente en el aula debiéndose alcanzar en el proceso, para tal efecto el estudiante debe mostrar una disposición autentica y eficaz hacia el objetivo de la actividad de estudio contribuyendo al 
éxito del proceso de enseñanza- aprendizaje. Sin duda, alcanzar el éxito o el fracaso en el cumplimiento de una tarea está asociado directamente con la permanencia de la motivación durante la actividad.

Dentro de este marco, la propuesta pretende motivar a los estudiantes a una práctica continua de sus habilidades comunicativas utilizando recursos de oralidad pertinentes a cada contexto presentado. Para lograr un enlace entre la teoría, los saberes previos con la práctica es necesario estimular el protagonismo del aprendiz mediante la utilización de materiales didácticos y complementarios, en su necesidad de aprender y entrenarse en cómo hacerlo.

En virtud de propagar el interés por el aprendizaje, se aplicaran métodos didácticos, trabajo colaborativo y personalizado, estrategias metacognitivas y de autorregulación.

Formación de conceptos y desarrollo de los procesos lógicos del pensamiento hasta obtener el nivel teórico.

Este principio está muy relacionado con el éxito del aprendizaje desde una perspectiva pragmática donde el estudiante debe alcanzar una profundización del conocimiento, reconocer lo esencial e instaurar las relaciones necesarias entre las partes en una actitud recreativa y proyectiva respecto a este. De estas evidencias, la propuesta comprende la programación de las actividades y tareas que impulsa la autosuficiencia cognoscitiva que una vez integrada el dominio de sus habilidades comunicativas le permitirá al estudiante desenvolverse y mejorar la práctica oral en los diversos contextos idiomáticos.

\section{Aplicación de actividades y de comunicación colectiva que beneficie el desarrollo intelectual}

Las actividades individuales y colectivas encuentran una correlación significativa que estimula el desarrollo intelectual y dialéctico que van de lo sencillo a lo complejo, de lo conocido a lo desconocido, de lo fácil a lo difícil. Para ello, se parten de actividades comunes, lúdicas y novedosas que potencien la cooperación entre los integrantes del grupo otorgándoles un valor agregado en el proceso.

Dentro de este marco, la propuesta concibe el rol activo del docente en donde este pueda crear escenarios comunicativos grupales, en parejas o individuales que se pueda extender tanto dentro como fuera del aula, lo cual debe formar parte de las formas de estructuración del proceso educativo de la asignatura en mención.

Reconocimiento de las diferencias individuales en el proceso de enseñanza De este principio se precisa identificar sus potencialidades y el nivel que alcanza el estudiante; para ello es fundamental realizar un diagnóstico previo que analiza todos los avances significativos vividos en el procesamiento lo cual ayuda al docente a establecer estrategias diferenciadas e influenciar en la formación de sus estudiantes. Para tal efecto, 
el docente hace un exhaustivo seguimiento durante el proceso a objeto de conducir homogeneidad en el aprendizaje, siendo de suma importancia el momento en que aplica su estrategia e impulsar su papel de mediador frente a la interiorización del conocimiento en el plano educativo con miras a alcanzar los objetivos planteados.

Al respecto, hablar de independencia por parte del estudiante es lograr resultados de aprendizaje mediante su esfuerzo contando con el mínimo apoyo del docente y finalmente alcanzar el éxito procesal.

\section{Relacionar el aprendizaje con la práctica social y valoración del proceso educativo.}

Es precisamente en la comunicación donde se procura atribuir una valoración social que contemple la consolidación de las cualidades, sentimientos y valores que cuenten con el desarrollo intelectual apropiado del alumno, fomentando de esa manera el interés por el objeto de estudio a tratar. Para tal efecto la estrategia diseñada fortalece en gran medida el rol docente permitiéndole dar una perspectiva social actualizada a los contenidos presentados; brindando la posibilidad a los estudiantes de establecer especificidad y coherencia en sus argumentos de opinión y comportamiento en el plano educativo en el cual se desenvuelve.

La aplicación del sistema de principios didácticos propicia una articulación rigurosa a la clase a fin de lograr un aprendizaje significativo como respuesta a las demandas actuales relacionadas con el protagonismo estudiantil con el fin de enfatizar en la formación integral de los estudiantes. El accionar didáctico desde estos principios se orienta a perfeccionar las habilidades comunicativas a través de la aplicación de métodos, procedimientos, estrategias y el uso de recursos audiovisuales que fomentan la motivación por el aprendizaje. De manera semejante, la Didáctica de la lengua y el enfoque cognitivo, comunicativo y sociocultural es una alternativa que estimula la problematización, el análisis y la realización de las actividades de aprendizaje desde los ritmos, estilos de aprendizaje y aptitudes de los estudiantes a fin de potenciar su desarrollo.

\section{Características de la estrategia modelada \\ Carácter integrador.}

La estrategia diseñada estima sus fundamentos desde la composición de los factores que una vez integrados contribuyen a su organización y la apropiada personalización de las actividades de aprendizaje a aplicar. Esta situación contempla potenciar el sistema formado de modo de desarrollar adecuadamente las habilidades comunicativas que lleven a interiorizar el contenido en los aspectos tanto cognitivo, afectivo, emocional y actitudinal. 


\section{Carácter sistémico.}

La propuesta está organizada e interconectada desde una compleja composición que incluyen su estructura académica, laboral, investigativa y personal propiciando un abordaje participativo en el plano educativo (Fingermann, 2012). Para lograr un proceso coherente e integrador es necesario cumplir con las etapas estipuladas que garanticen la sistematización requerida y estas son: el diagnostico, el diseño, la implementación y la evaluación cualitativa de los estudiantes.

\section{Carácter creativo.}

La estrategia diseñada promueve una gama de destrezas distintas que ejercita los conocimientos de una forma un tanto experimental llevando al aprendiz a explorar nuevas direcciones y ser capaces de cambiar la realidad de manera singular. El objetivo es estimular en los estudiantes una autoexpresión de tal forma que demuestre una individualidad potencial en vías de concientizar su aprendizaje en un entorno contextualizado a la profesión de su elección. A este respecto, el docente debe tener presente que la creatividad es una actividad compleja el cual se puede cultivar y que a medida que orienta al alumno va formando, simplificando y configurando una realidad desarrolladora que le proporciona ampliar y superar su nivel de percepción como futuro profesional.

\section{Carácter comunicativo.}

La propuesta recoge como punto de partida la naturaleza comunicativa real de la actualidad social y lingüística de quienes estudian, enseñan y aprenden propiciando diversos contextos eficientes para la enseñanza- aprendizaje de la lengua inglesa. Dentro de ese marco, Roméu (2007), Domínguez (2010) y Cassany (2013), consideran a la tarea comunicativa como un medio que integra el realismo y autenticidad a la clase provocando una necesidad de comunicación y creación de significados. Con esa finalidad el docente debe facilitar situaciones de aprendizaje contextualizadas a su especialidad y estructuradas que remarque un objetivo claro y específico para los que realizan la tarea.

\section{Estructura de la estrategia metodológica modelada}

\section{Misión de la estrategia.}

La estrategia presentada tiene en cuenta las categorías emergentes que inciden el problema objeto de la investigación en el desarrollo de la competencia oral de los estudiantes y el nivel de preparación teórica y didáctica de los docentes con el fin de transformarlo a partir de lograr la eficiencia en el proceso de enseñanza- aprendizaje de la disciplina Inglés. 


\section{Visión de la estrategia.}

La estrategia presentada tiene como misión transformar el proceso de enseñanzaaprendizaje de la disciplina Inglés, a fin de lograr el desarrollo de la competencia oral de los estudiantes y el nivel de preparación teórica y didáctica de los docentes con el fin de transformar su desempeño y que asuman un rol eficiente en la enseñanza, que enfaticen en el paradigma social, lingüístico, psicológico y cultural del educando para incidir en el interés por la investigación, el autoaprendizaje, la autoevaluación y autoaprendizaje que redunde en el desarrollo de la competencia comunicativa oral.

\section{Objetivo de la estrategia.}

El objetivo de la estrategia es contribuir a la transformación del proceso de enseñanzaaprendizaje de la disciplina Inglés, a fin de lograr el desarrollo de la competencia oral en los estudiantes y el nivel de preparación teórica y didáctica de los docentes, con el fin de transformar su desempeño y que asuman un rol eficiente en la enseñanza, que enfaticen en el paradigma social, lingüístico, psicológico y cultural para incidir en el interés por la investigación, el autoaprendizaje, la autoevaluación y autoaprendizaje que redunde en el desarrollo de la competencia comunicativa oral del educando.

A partir del objetivo se establecieron las alternativas para potenciar el desarrollo de las capacidades, los conocimientos, las habilidades y la competencia comunicativa oral, y se concretan en las siguientes líneas de acción estratégicas que se orientan a los participantes principales y los lineamientos metodológicos específicos de la propuesta:

Primer lineamiento, se orienta su argumentación desde la conducción y aplicación de actividades que propicien internalización del contenido a partir de problemáticas, situaciones dialógicas, cognoscitivas y reflexivas que desencadenen en el estudiante la necesidad de comunicación y dominio de sus habilidades permitiéndole su actuar personal o colectivo, académica y profesional.

. La primera línea: tiene como premisa partir de la planificación, orientación y realización de diversas actividades de orden teórico -práctico sobre la competencia comunicativa oral, el aprendizaje y la problematización de las actividades desde la realidad. Ello exige el estudio de los enfoques científicos, teóricos, didácticos y práctico contemporáneos de esa categoría conceptual y estimular los procesos cognitivo, afectivo, motivacional y emocional del estudiante en el proceso de aprendizaje para que pueda responder a la exigencia de la actividad de aprendizaje en la que debe ser consciente de sus acciones y autorregular su comportamiento en cada paso hasta concluir la tarea.

La segunda línea: se proyecta a la capacitación teórica, didáctica y metodológica de los docentes de la disciplina de Inglés con el objetivo de incidir en su desempeño profesional para dirigir el proceso de enseñanza- aprendizaje a partir de la aplicación de 
situaciones comunicativas problematizadoras, colaborativas y creativas desde un enfoque integral a fin de ejercitar las habilidades de reflexionar por sí mismo, analizar, analizar el contenido, comunicar sus puntos de vistas, sentimientos y relacionarse asertivamente con sus iguales al realizar las tareas donde debe primar la construcción de textos orales para potenciar el desarrollo de la competencia comunicativa oral y la formación integral de los educandos.

Congruente con la segunda línea de acción orientada a la capacitación metodológica de los docentes de la institución diagnosticada, se diseñaron un conjunto de talleres teórico- práctico para contribuir a su preparación profesional para dirigir el proceso de enseñanza - aprendizaje y lograr el desarrollo de la inteligencia emocional.

\section{Concepción de la Didáctica de la lengua en la dirección del proceso de enseñanza-} aprendizaje

Los fundamentos teóricos y científicos de la Didáctica de la lengua se integran dialécticamente al enfoque cognitivo, comunicativo y sociocultural (Roméu, 2007 y Cassany, 2009). Desde esta posición teórica, las categorías didácticas se proyectan con el objeto de desarrollar la competencia comunicativa oral en los estudiantes a través del proceso de enseñanza - aprendizaje de la disciplina de Inglés II.

La categoría didáctica problema. Es el resultado de la contracción originada en el estudiante frente a los conocimientos nuevos con los ya establecidos, produciéndose de ese modo que el aprendiz vaya en busca de otras fuentes de información próxima "otros participantes" a fin de encontrar soporte y orientación en el proceso de dar una solución a la problemática propuesta, generándose un andamiaje de tipo cognitivo. Asimismo, este proceso impulsa la utilización del autocontrol y la autorregulación de los procedimientos lógicos mentales, facilitando el aprendizaje significativo y contribuyendo a la formación integral del estudiante.

Dentro de este marco, el papel del docente se ve reflejado en esta categoría ya que su rol orientador se evidencia durante el desarrollo de las actividades ya sea en la interiorización de los conocimientos, habilidades o destrezas como en la apropiación actitudinal y valorativa. En virtud de la propuesta, la problemática radica en el bajo nivel de desarrollo de las habilidades orales en los estudiantes.

Categoría objetivo. Se orienta al reconocimiento del problema en el acto pedagógico, igualmente el objetivo se procesa tomando en cuenta las acciones para modelar el resultado anhelado.

Se concreta en la contradicción que se da entre los saberes adquiridos ya por el estudiante y el nuevo aprendizaje que va a desarrollar en el proceso de enseñanza aprendizaje. Por ello se requiere del docente un sistema de preguntas para explorar lo 
conocido, sobre sus vivencias y experiencias del contexto y formulará otras interrogantes, cuyas respuestas no conocen para genera el conflicto cognitivo. Atendiendo a estas consideraciones, el alcanzar un nivel adecuado en la motivación e interés de los educandos se formula y orienta el logro de aprendizaje esperado en la clase.

Categoría contenido. Según Álvarez de Zayas (1996), Castellanos (2004) y Addine (2013), el contenido cumple una funcionalidad integral. Desde su función instructiva, educativa y desarrollador se integran en la actividad de aprendizaje de tal forma que el estudiante aplique sus conocimientos, refleje su manera de pensar, actuar, sentir y el hacer dándole el valor personal y social a lo aprendido para la vida con un carácter pedagógico. El contenido de la asignatura comprende temas de los distintos niveles de la lengua que se tratan en la clase con un enfoque profesional propios de la especialidad o carrera con la intención de que reafirmen el interés por la asignatura a partir de la base gnoseológica, procedimental y actitudinal. La estrategia propuesta tiene por contenido de la enseñanza- aprendizaje el aprendizaje de los conocimientos y las habilidades de oralidad que le permitirá a los estudiantes desde su estudio, fomentar los valores éticos profesionales y comunicarse de forma eficiente.

Categoría métodos de enseñanza. Los métodos permiten establecen un sistema estructurado de actividades y procedimientos que indica el camino, la vía o la forma que regula la actividad del profesor y la de los estudiantes por alcanzar los objetivos trazados. El método orienta la dinámica del proceso de enseñanza - aprendizaje en su relación con el objetivo y el contenido a tratar. Su selección, organización y aplicación deviene en interacciones vitales entre el estudiante, el docente y el grupo para garantizar la asimilación consciente del contenido objeto de estudioque van acorde con los contenidos específicos propios de la especialidad (Álvarez, 1996; Zilberstein, y Silvestre, 2002, Castellanos et al ,2007; Barriga y Hernández, 2010; Pimienta, 2012 y Addine, 2013).

La estrategia diseñada potencia el aprendizaje de la comunicación oral a través de la aplicación de los métodos comunicativos, productivos, dialógicos, heurísticos, colaborativos y actividades que exigen del esfuerzo mental, la interacción cognoscitiva y la creatividad, a fin de desarrollar los conocimientos lingüísticos y la competencia comunicativa oral en el idioma. La elaboración de las tareas cognoscitivas llevará al aprendiz aplicar sus conocimientos a través de procedimientos problémicos, heurísticos, colaborativos y participativos que favorezca la estimulación del pensamiento, el lenguaje y la comunicación oral de los estudiantes en la clase .

Categoría medios de enseñanza. Este componente permite la objetivación del contenido de la enseñanza, provoca en los educandos la observación, el activismo y facilitan la comunicación bidireccional efectiva entre los protagonistas permitiéndoles 
alcanzar los objetivos planteados sin llegar a suplir la función educativa en el proceso. En este sentido, los docentes deben tener pleno conocimiento de cómo usar los medios audiovisuales elegidos con el objetivo de facilitar la comprensión del contenido, avivar el interés y objetivar la enseñanza- aprendizaje. Los medios de enseñanza propuestos deben incidir en la memoria visual, auditiva y gnoseológico de las clases de palabras, frases, oraciones y el diálogo que son esenciales desde la Didáctica de la lengua integrado dialécticamente al enfoque cognitivo, comunicativo y sociocultural (Roméu, 2007 y Cassany, 2009) que fundamenta la asimilación, las funciones intelectuales para la adquisición del conocimiento, el desarrollo de la competencia comunicativa en los educandos.

Categoría evaluación. Desde el punto de vista de Álvarez de Zayas (1996), Castellanos (2004) y Addine (2013), afirman que la evaluación es una categoría didáctica esencial para incidir en el desarrollo, evolución y efectos satisfactorios en $r$ el estudiante en el ámbito educativo, ya sea por su naturaleza totalizadora al obtener una funcionalidad compleja de índole instructiva - educativa al lograr la calidad en el hecho de evaluar o de ser evaluado. Basa el progreso integral de los estudiantes a la recolección de información pertinente y análisis prospectivo de acuerdo con los resultados evidenciados por el docente que llevara a la mejora sistemática y la redirección de la futura planificación.

La estrategia modelada, sugiere la aplicación de la evaluación diagnóstica, formativa, procesual, criterial y sumativa como parte del proceso de aprendizaje que influye en que el educando sea consciente de lo que aprende y cómo aprende. Es una concepción evaluativa del aprendizaje que potencia el desarrollo de la crítica, la reflexión y la formación del sujeto en los aspectos cognitivos, procedimentales y actitudinales. Es un tipo de evaluación que requiere del docente una orientación constante del qué y cómo aprende, a partir de los métodos participativos que fomenta el interés, la motivación y eleva los niveles de calidad del aprendizaje y fomenta la independencia cognoscitiva y el proceder éticomoral del estudiante.

Se recomienda hacer uso de las técnicas e instrumento de la evaluación formativa como: las rúbricas, el cuestionario, la ficha de observación, lista de cotejo, ficha de autoevaluación, coevaluación y heteroevaluaciòn que propicia el desarrollo de las habilidades metacognitivos, interpersonales, el autoconocimiento de sí y el ejercicio de la crítica y la autocrítica. Estos instrumentos orientan al estudiante a reflexionar respecto a su desempeño en la tarea realizada en cuanto a qué hizo, cómo y orientarse mejor en las acciones a realizar para mejorar tanto en lo académico como en lo actitudinal.

Otro aspecto para tener en cuenta es la forma de organización de la clase. Sobre las formas de organizar la clase, Addine (2004), Ortiz (2012) y Rico et al (2013), 
afirman que, de la interrelación entre los protagonistas de la clase, deviene en un accionar integral continuo donde los componentes didácticos y los personales cumplen una labor esencial en el proceso enseñanza -aprendizaje al garantizar el cumplimiento de los objetivos propuestos. Es necesario planificar el proceso de la clase de forma interactiva entre el profesor - alumno, potenciarlos con actividades que promuevan el pensamiento y las habilidades en el trabajo colaborativo.

Los métodos dialógicos y colaborativos se sugieren con el propósito de estimular la asimilación consciente de los estudiantes desde sus experiencias y saberse previos, fortalecer la expresión de ideas y fluidez comunicativa de manera permanente en el aula mediante actividades grupales y en parejas para incidir en el desarrollo de las habilidades interpersonales y reflexivas de los estudiantes a partir de la tarea de aprendizaje. En ello desempeña una función o rol excepcional el docente.

El rol del docente. En la opinión de Castellanos et al. (2002), Díaz Hernández (2010) y Anfibia (2016), el rol docente es de mediador, guía y orientador social entre la cultura y el estudiante. La interiorización de los contenidos seleccionados ayuda a la formación de la personalidad del educando frente a la sociedad, siendo necesaria la instauración de un espacio pedagógico oportuno que exhorte a todos a aprender y a construir su aprendizaje de forma progresiva hacia niveles superiores.

El docente cumple una función orientadora y metodológica articulando el trabajo pedagógico con las competencias transversales durante el proceso de asimilación y producción del conocimiento; su rol docente va más allá de instruir y responder a las dudas que se presentan, sino que se contempla el tratamiento personológico, la inclusión de actividades creatividad, la innovación y la autonomía en el ejercicio profesional con miras de lograr un aprendizaje desarrollador.

En este sentido la estrategia diseñada acoge la perspectiva de Cassany (2010) y Díaz Barriga (2013), sobre la función del docente en aula catalogándolo de organizador de metodologías y facilitador de saberes en un proceso de consolidación de conocimientos en donde el educando autoevalúa su propia práctica estimulando a buscar, seleccionar y procesar de forma significativa su aprendizaje. En consecuencia, el educador debe proporcionar y aplicar una variedad de tareas de aprendizaje que vayan de lo fácil a lo difícil; emplear diversos recursos didácticos para estimular la motivación y métodos problémicos, heurísticos y comunicativos que den respuesta a las expectativas, intereses y capacidades de los estudiantes donde asuman un rol protagónico.

El rol del estudiante. A juicio de Castellanos et al. (2007), Ortiz (2008), Tobón (2009) y Addine (2013), el estudiantes debe ser protagonista, responsable y activo en el proceso de asimilación y procesamiento de la información hasta construir el 
conocimiento. Debe ser un participante activo en la construcción de su propio aprendizaje, ello lo conducirá a pensar y reflexionar en la actividad de manera metacognitivos, autorregulada y autoevaluando la pertinencia de sus acciones en interacción con sus iguales de forma solidaria y respetuosa.

La tarea de aprendizaje debe exigirle al estudiante, deberá esforzar su pensamiento al realizar acciones intelectuales de indagación, predicción y crear tareas productivas en todas las etapas de la actividad. Al realizar un ejercicio el educando debe concientizar las acciones, y los procedimientos a realizar para la búsqueda del qué aprender, qué utilidad tiene lo aprendido, para qué le sirve mediante la problematización al trabajar en grupo donde socializan sus ideas, opiniones, consensuan y proponen la solución al problema planteado lo que potencia la comunicación oral y el aprendizaje significativo.

En ese sentido, Fullan y Langworthy (2014), precisa que el docente y el estudiante se tornan colaboradores donde todos aprenden y enseñan en los diferentes momentos del proceso educativo, pues este último explora y construye su conocimiento a través de la orientación y el diálogo con otros compañeros donde socializan ideas, identifican sus necesidades, investigan y resuelven conflictos donde ponen a prueba sus saberes en todos los sentidos. Asimismo, el educando se convierte en un agente reflexivo, eficaz y consciente de su propia formación profesional que le permita tener una experiencia de un aprendizaje enriquecedor y real que fortalezca su confianza a medida que no dependa de límites que dificulten su proceso.

El rol del grupo. Para que el estudiante alcance autonomía eficaz en niveles sobresalientes es necesario que interactúe con los demás en contextos que fomenten su accionar autónomo y verdadero; visto desde un enfoque histórico- cultural. Al respecto Castellanos $(2002,2007)$, estima que el aprendizaje en forma grupal es un proceso de interrelación e influencia mutua que permite el descubrimiento gradual de las propias potencialidades y limitaciones del estudiante. Precisamente en la comunicación generada entre los participantes que lo conforman cumplimiento de las normas y funciones orientando la interiorización de los contenidos.

Los estudios significan que la actividad grupal da la oportunidad a los educandos socializar las ideas, relacionarse con sus compañeros y debatir sobre el contenido propiciando una apropiación eficiente, producir conocimientos y reconstruir las experiencias en un diálogo y ayuda mutua que modifica y mejora las destrezas sociales en el plano individual y grupal. El docente incentiva la realización de las actividades en colectivo, asignándoles roles a los estudiantes que favorezcan el desenvolvimiento de la personalidad y en el autocontrol para lograr el desarrollo satisfactorio de la actividad. 


\section{Concepción de la tarea de estudio en el proceso de enseñanza- aprendizaje}

La tarea de aprendizaje se formula a partir de un objetivo meta que en función de una situación de aprendizaje debe orientar al estudiante en el qué, cómo y para qué potenciándose la esfera cognitiva, afectivo - motivacional y emocional de manera que pueda asimilar, procesar la información y convertirla en un conocimiento útil, autónomo y significativo (Álvarez de Zayas, 1999; Zilberstein y Silvestre, 2002, Benítez et al. 2010, Rico et. al 2013).

La actividad de aprendizaje_es un proceso mediante el cual el estudiante interactúa con el objeto, el medio que le rodea y otros sujetos incidiendo en él, transformando y al mismo tiempo recibiendo influencias que en mayor o menor medida también transforman al propio sujeto Al respecto Márquez (1999) y González (2003).

Para su realización es necesario la participación eficaz del educando en aras de promover su autonomía cognoscitiva, regulación y sistematización de sí mismo al tener conciencia de los errores que comete en esta etapa ejecutoria, llevándolo a reflexionar sobre su praxis interactiva concebida en el proceso lógico de apropiación del idioma meta que guiado por las exigencias didácticas generales y metodológicas particulares del docente impulsa la asimilación de la oralidad desarrolladora y continua en el aula como respuesta al desarrollo reproductivo alcanzado en un entorno sociocultural (Zilbertein y Silvestre ,2002; Arenas La Torre, 2019).

Durante la planificación de la tarea comunicativa, el docente debe considerar los niveles de desempeño de manera que responda a los objetivos rectores de la enseñanzaaprendizaje a fin de desarrollar las destrezas orales de la lengua.

En este contexto la tarea comunicativa fundamenta su accionar desde un enfoque didáctico de la lengua sopesándose como un medio real que fortalezca y desarrolle plenitud la competencia oral del educando(Godoy, 2009).A este respecto Benítez, et al.(2010) reconoce a la tarea comunicativa como una herramienta pragmática que antepone la descontextualización del lenguaje oral en los distintos momentos de la actividad propiciando la formación integral particular al cual el estudiante aspira llegar, por lo que se pueden tomar como referentes para acondicionar los contenidos a la asignatura de Inglés II en la carrera de Negocios Internacionales.

En resumen, las tareas deben permitirle al estudiante tomar conciencia de su aprendizaje y poder comunicarse libremente en un clima de cooperación, respecto y ayuda mutua para potenciar el desarrollo de las capacidades, habilidades y competencias progresivamente. Ello exige que los estudiantes se expresen y comuniquen sus ideas en la lengua inglesa, a través de situaciones cotidianas a fin de potenciar las habilidades comunicativas. 
Desarrollar las habilidades comunicativas en la clase requiere orientar al estudiante en los distintos momentos de la actividad de aprendizaje para que el educando tenga éxito en el qué, cómo hacerla y cómo aplicar lo aprendido en la solución de problemas idiomáticos. A continuación, se presentan algunos ejemplos de la tarea de aprendizaje.

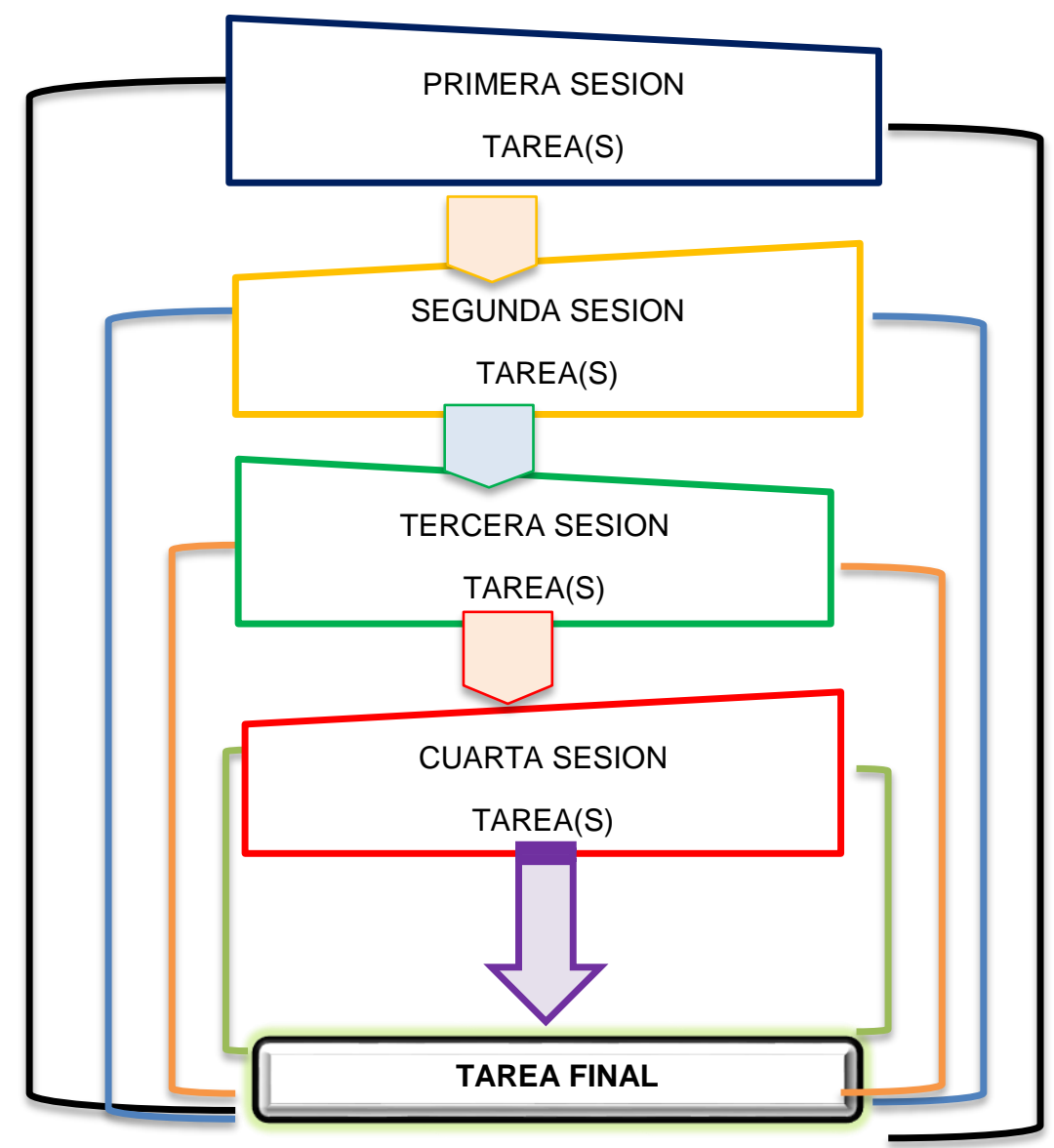

Figura 4. Estructura de una unidad didáctica a través del enfoque por tareas (Estaire, 1990).

Fuente. Estaire (1990).

\section{Ejemplo de tareas de aprendizaje}

Tarea I: Escribir un relato corto (doce líneas como máximo) sobre las impresiones percibidas de cuan patriotas son los ciudadanos del Reino Unido y si creen que Rule Britannia representa lealtad hacia el país.

Fuente. Elaboración propia (2019).

Se empieza por insertar el tema de trabajo, la temática del proyecto a realizar, sus objetivos y cuál será la tarea final. Luego se procederá al desarrollo de la sesión invitando a los educandos a escuchar un clásico musical británico Rule Britannia, canción símbolo 
del Reino Unido para establecer diálogo agrupándolos en parejas y tríos y brainstorming de lo experimentado al expresar las ideas en un organizador visual de su elección.

Seguido se le facilita un texto impreso que aporta nuevas informaciones y se formula un sistema de preguntas para destacar su significado social y cultural. Se promueve un diálogo que refleja la asimilación del contenido por los estudiantes.

Con esta actividad se incentivan los procesos lógicos mentales como la observación, la escucha, la comprensión, producir las ideas, frases u oraciones a los estudiantes y desarrollar la lengua meta en la que el educando pone en práctica sus conocimientos de forma grupal e individual y se favorece la comunicación oral.

Tarea 2: En grupos, crear un discurso compromiso de lealtad frente a la familia, amigos, equipo deportivo, grupo de música...

Fuente. Elaboración propia (2019).

Se inicia la actividad con un repaso del contenido tratado en el ejercicio anterior a través de un cuestionario donde activan los saberes adquiridos. Luego se continúa con Rule Britannia, enfatizando en el tratamiento que le otorgan los residentes del territorio británico en la actualidad y por qué actúan así.

A continuación, se proyecta un vídeo referente donde se escuchan cómo entonan este clásico a viva voz, que tiene por objetivo complementar las ideas argumentadas con anterioridad. Se les pregunta: qué impresión ha ocasionado en ustedes el video; se escuchan sus ideas y opiniones a fin de llegar a una resolución precisa de que esta consigna tiene para ellos un gran valor y por ello se repite cada día en las instituciones académicas como muestra de respeto.

Este tipo de ejercicio estimula la escucha, la comprensión e impulsa el interés y la motivación en los estudiantes por conocer, indagar, investigar, aprender y valorar y la cultura anglosajona. De esa manera se ha creado una situación comunicativa que tiene como objetivo rector el desarrollo de la comunicación oral en los estudiantes, pues se prepara en grupo y posteriormente exponen ante el plenario de la clase su producto y una vez concluida deberán responder a las preguntas y opiniones de sus compañeros y autoevaluarse a partir de los indicadores establecidos.

Tarea 3: En grupos deben elaborar una descripción de algunos atractivos emblemáticos del Reino Unido proporcionándoles la información.

Fuente. Elaboración propia (2019).

En la introducción de esta actividad se plantea a los estudiantes nombrar atracciones famosas de su país o de alguna ciudad de su interés (La Torre de Londres, Hylands House 
and Estate, La Catedral de San Pablo, La Abadía de Westminster, Zoológico y parque de atracciones Flamingo Land, Los cruceros de Windermere entre otros).

Al finalizar la dinámica, se le facilita una ficha con monumentos emblemáticos inglés conjuntamente de un párrafo descriptivo de cada uno de ellos. Los estudiantes deben leer y relacionarlos y exponerlo en el salón.

Tarea 4: Role play, hacer un pedido en un restaurante

Fuente. Elaboración propia (2019).

El docente puede comenzar explicando sobre la diversificación de temas de culinaria que existen en la cultura alimenticia y realiza la siguiente pregunta: ¿Qué platos típicos hacen en casa en días festivos?; ¿Cuáles son los tipos de dietas saludables que existen o conocen ustedes?; ¿Qué importancia tiene asumir hábitos alimenticios sanos?, entre otras preguntas que pueden surgir en la interacción comunicativa. Luego se reúnen por equipos y leerán una materia informativa a fin de que debatan entre todos. El docente desempeña su rol como guía, conductor y regulador de la actividad para cumplir la tarea. Con el objeto de utilizar WH questions como what is your favorite food? Where do you go to eat? When do you eat? haciendo énfasis en la construcción de preguntas y respuestas al emplear el "Do/ Does" de conjunto con el verbo to be al finalizar la actividad.

En la segunda parte de la sesión se realiza la tarea final, consistente en establecer un diálogo sobre una situación cotidiana, como ir a un restaurante donde deben emplear los pronombres interrogativos: dónde, qué, cómo o cuánto vale comer fuera, entre otras. Al presenciar la situación comunicativa, el docente escucha y reformula otras interrogantes vinculadas con el fin de estimular la comunicación oral. Para la realización de la actividad es necesario que el docente proponga un sistema de preguntas relacionadas con el tema objeto de estudio de tal manera que los estudiantes de orienten por ellas y compruebe cómo por su nivel de preparación cómo excluyen o rechazan aquellas que no forman parte del tema a tratar.

Tarea 5: Realizar una receta de alimento

Fuente. Elaboración propia (2019).

Se continúan de forma coherente con una actividad que responde al objetivo iniciado en la actividad anterior, la alimentación sana. Como tarea deberán realizar analizar y realiza en cada equipo, la elaboración de una receta de cocina de un país europeo pero la condición es, comunicarse en inglés. En este sentido el educador entregará a cada grupo una receta 
de una comida representativa de cada país europeo, leerán el material y comentan entre toda la información, los verbos a utilizar, los pasos a seguir en cada procedimiento, lo que expresan las imágenes y otros detalles. Con ello se estimula la inquietud por hacerlo bien, la curiosidad por el proceso de aprendizaje aplicando sus destrezas para lograr tal propósito comunicativo.

Seguido se realizará una pequeña dinámica grupal en la que los estudiantes reciben distintos elementos gastronómicos requeridos para una actividad culinaria en desorden total. Los estudiantes se reúnen por equipos, no cuentan con las ilustraciones referenciales ni otra ayuda, pues el objetivo es dificultar el ejercicio con un sentido lógico, pues la finalidad es que comenten y expresen en el grupo cómo resolver la tarea y exponerla ante la sala. Finalmente exponen a nivel de plenaria cómo procedieron en cada momento en la elaboración de los distintos platos típicos británico para alcanzar el objetivo propuesto.

Tareas 6 : Elaboración de un programa turístico

Fuente. Elaboración propia (2019).

Una vez alcanzado los objetivos trazados en las tareas anteriores, los estudiantes podrán ser capaces de utilizar sus destrezas de forma integradora y más complejas acorde a los conocimientos adquiridos en el procesamiento.

La tarea final consiste en la elaboración de un programa turístico publicitario donde informen aspectos vistos en el aula (lugares emblemáticos, tradiciones, sociedad y alimentación) en el cual cada miembro del grupo asuma una posición respecto a su rol participativo como director, presentador, actores, mensajes y escenarios, el propósito de esta actividad es que los educandos actúen en un contexto socio - cultural y lingüístico anglosajón de manera efectiva, eficiente e innovadora.

Ello requiere de diseñar dos sesiones para construir el estilo del programa, el guion, la funcionalidad que desenvolverán los miembros de cada grupo y presentar la tarea final propuesta. Sin duda el papel docente es de esencial importancia en la realización de la tarea para encauzar las ideas que se suscitan durante el proceso e inspeccionar el trabajo antes de exponerlo ante la clase.

Estos ejemplos de actividades de aprendizaje de cómo el educador puede combinar el conocimiento teórico con lo reflexivo, creativo y lúdico al dirigir y aplicar convenientemente las actividades de aprendizaje en la enseñanza- aprendizaje donde orienta y conduce a los estudiantes a una posición de reflexión creativa que estimula el interés y la motivación por expresar sus ideas desde una situación comunicativa equis en un contexto determinado con lo cual favorece el pensamiento y el desarrollo de la 
independencia cognitiva, las habilidades comunicativas orales en un ambiente de colaboración y producción textual oral .

\section{Orientaciones para la aplicación del método problémico en la estrategia}

El aprendizaje consciente el estudiante lo demuestra cuando utiliza, valora y le da importancia a lo aprendido. Lograrlo significa que el docente debe orientarlos suficientemente a través de un conjunto de preguntas problémica. Al respecto Álvarez de Zayas (1996) señala que problematizar el contenido de la clase empodera al estudiante de la relación de la escuela con la vida. Es a partir de los conflictos y su libración que el estudiante tiene la oportunidad de desarrollar sus capacidades y actitudes comunicativas en la clase (Hernández, 2014; Pérez, 2014; Addine, Velázquez y Figarella, 2014).

La estrategia propuesta canaliza la enseñanza problémica y heurística de manera integral en el estudio de los niveles de la lengua como un todo integral y no como una selección de las partes u objetivos para que mejore la comunicación interactiva con sus compañeros en el aula; es decir, que a través del oído fonemático y el hablar perciben y asimilan el contenido, potenciando el conocimiento y el desarrollado de la competencia comunicativa oral. Para ello es necesario destacar la relevancia de la participación activa, coherente y la fluidez en las ideas y disposición de corrección (Rey, 2014).

En la siguiente Figura (Fig. 5) se muestra cómo ha de programarse una unidad didáctica a través de una secuenciación docente de seis pasos ya sea en solitario o en conjunción con los alumnos.

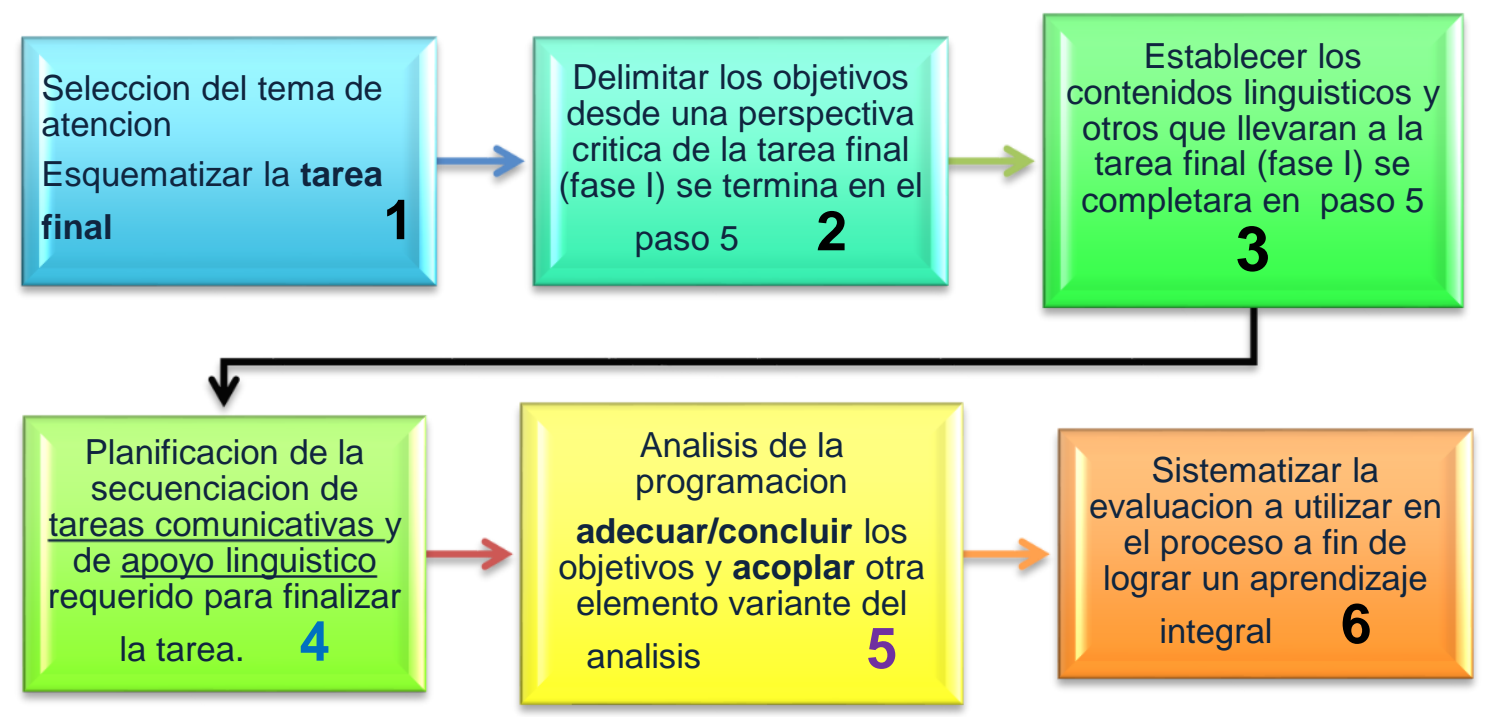

Figura 5. Secuenciación de una unidad didáctica desde este enfoque.

Nota: Adaptado para la programación por tareas (Estaire, 1990). 
La perspectiva de la clase comprende un conjunto de actividades que parten del método comunicativo y colaborativo en la realización de la tarea y lograr del aprendizaje esperado en los estudiantes. Estas se pueden organizar de la siguiente manera:

Selección del tema y tarea final. Orientada a las necesidades, inquietudes, intereses y destrezas de los alumnos impulsando su desarrollo en el proceso de aprendizaje.

Delimitación de objetivos. Es necesario establecer objetivos consecuentes al estado actual en que se encuentra el estudiante abordado desde la concreción de actividades para alcanzar el cumplimiento de la tarea final.

Determinar los contenidos, habilidades y valores. Acciones que fomentan el interés y necesidades del estudiante hacia la generación de conocimientos, destrezas y valores que se desarrollara a lo largo del contenido en la asignatura.

Presentación de las tareas. Guía al educando a través del desarrollo de actividades comunicativas a alcanzar la tarea final teniendo en cuenta los momentos, los recursos a utilizar y la interconectividad entre ellas.

Fortalecer la estructura cognitiva, instrumental y emocional. El docente brinda la oportunidad experiencial de desarrollar los conocimientos, habilidades y valores

Accionar de los estudiantes. Desempeño actitudinal, procedimental y cognitivo del educando en las actividades y tareas que lo llevara a analizar- modelar- crear soluciones al cuestionamiento planteado.

Concluir y amoldar los pasos previos. El estudiante diseña y revisa la solución haciendo las modificaciones necesarias paso por paso para que finalmente sea socializado y debatido sobre ello.

Incorporar la evaluación como parte del proceso. Aplicación de herramientas evaluadoras que verifiquen distintos aspectos de lo aprendido remarcando la autoevaluación consciente de los fallos realizados en la programación por parte de cada estudiante.

Estos elementos evidencian lo complejo que puede ser llevar a cabo los procedimientos metodológicos con efectividad; pues el proceso lógico seguido permite el desarrollo de las capacidades comunicativas.

Presentación de dos sesiones de aprendizaje de la disciplina Inglés.

A partir de la sistematización realizada se proponen dos clases o sesiones de aprendizaje que emergen de la unidad didáctica de la asignatura de inglés dosificada y que se muestran a continuación (Anexo N8).

\section{Propuesta de talleres pedagógicos a los docentes.}


El diagnóstico de campo evidencia las deficiencias en el personal docente en su preparación teórica - metodológica en el manejo del proceso educativo en aras de desarrollar las habilidades comunicativas en los estudiantes de primer año de la carrera de Negocios Internacionales de la asignatura de Inglés II.

Tras encontrar el déficit en los docentes en la preparación didáctica se plantea la realización de talleres pedagógicos con un objetivo claro de consolidar las capacidades del docente con contenidos teóricos y metodológicos en el tratamiento de las habilidades comunicativas en los estudiantes en la asignatura.

El taller es una forma de organización del proceso de enseñanza- aprendizaje donde se aplica el principio pedagógico de la relación entre la teoría y la práctica, se conjuga el pensar con el saber hacer. Estos talleres se conciben como un espacio de reflexión teórica y de experiencias profesionales respetando la diversidad de criterios, la expresión individual en un ambiente de diálogo, comunicación, empatía y respeto al criterio ajeno en la problematización del tema donde confluye la experiencia cognitivo la convergencia o la divergencia para potenciar un saber colectivo en lo gnoseológico, la experiencia profesional y la autocrítica del desempeño profesional.

Desde esa perspectiva, el taller ofrece un marco de análisis teórico y experiencial como medio para ampliar, enriquecer los conocimientos teóricos y didácticos que conduce a consensos entre los docentes y en cómo aplicarlos en el aula, a fin de contribuir al desarrollo de la competencia comunicativa oral de los estudiantes en el proceso de enseñanzaaprendizaje. Esa forma de capacitación profesional desde el puesto de trabajo estimula el crecimiento, fortalece la autoestima, la autorreflexión, la socialización, la superación permanente e incide en la calidad del desempeño del docente, y el compromiso por la excelencia en la institución (Zegarra y Velázquez, 2016).

\section{Tabla 3}

Diseño de los talleres de capacitación docente

\begin{tabular}{|c|c|c|c|c|}
\hline Tema de taller & Problema & Objetivo & Campo temático & Actividades \\
\hline $\begin{array}{l}\text { Fundamentos } \\
\text { de la didáctica } \\
\text { de la lengua } \\
\text { inglesa en el } \\
\text { proceso de } \\
\text { enseñanza- } \\
\text { aprendizaje }\end{array}$ & $\begin{array}{l}\text { Deficiencias } \\
\text { teóricas y } \\
\text { didácticas de la } \\
\text { lengua inglesa al } \\
\text { dirigir el } \\
\text { procesamiento. }\end{array}$ & $\begin{array}{l}\text { Reflexionar } \\
\text { sobre los } \\
\text { fundamentos de } \\
\text { la didáctica de } \\
\text { las lenguas como } \\
\text { ciencia y sus } \\
\text { repercusiones en } \\
\text { el proceso } \\
\text { educativo. }\end{array}$ & $\begin{array}{l}\text { Principios, exigencias y } \\
\text { categorías } \\
\text { metodológicas de la } \\
\text { Didáctica y enseñanza } \\
\text { desarrolladora. } \\
\text { Orientaciones de la } \\
\text { didáctica } \\
\text { desarrolladora para el }\end{array}$ & $\begin{array}{l}\text { Organizadores } \\
\text { visuales } \\
\text { Diseño de } \\
\text { cuadros } \\
\text { explicativos } \\
\text { Diseño de } \\
\text { sesiones de } \\
\text { clase de la } \\
\text { asignatura }\end{array}$ \\
\hline
\end{tabular}




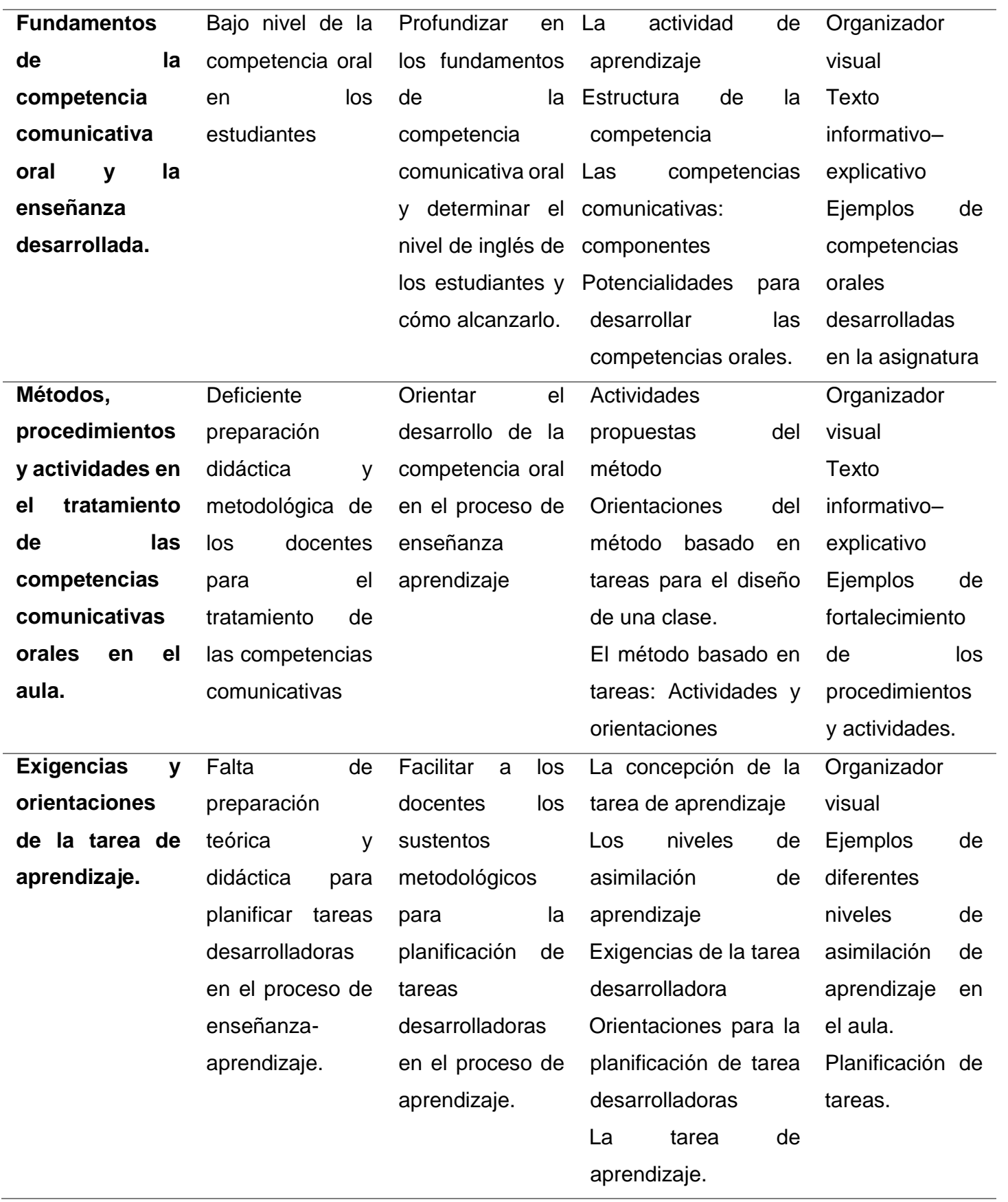

Fuente: Elaboración propia (2019).

Se sugiere que la evaluación de cada taller se realice atendiendo a los indicadores: Estudio previo del tema del taller, enfoques teóricos, exposición de experiencias, trabajar en equipo, propuestas de soluciones, aplicación en el proceso de enseñanza- aprendizaje 
lo aprendido y la autoevaluación por cada participante. El propósito es contribuir a mejorar el desempeño docente a partir de la discusión y reflexión personal de las carencias existentes tantos teóricos como didácticas. En cada sesión se presenta un tema se exploran los saberes previos, luego trabajan en equipo y por último exponen los resultados de la tarea para lograr la interacción activa y consciente de todos los participantes y llegar a consensos.

Cada taller pedagógico está diseñado sistemáticamente en forma grupal e individual hacia el cumplimiento de indicadores establecidos.

\section{Etapas para la aplicación de la estrategia metodológica en la práctica educativa}

\section{Primera etapa.}

Se propone analizar con los directivos de la carrera de Negocios Internacionales estructura de la estrategia metodológica modelada en cuanto a: misión, definición y alcance del objetivo, los lineamientos metodológicos establecidos sobre las acciones centrales de la propuesta: una orientada a profundizar en los fundamentos teóricos, las habilidades y la competencia a desarrollar en los estudiantes y la otra, dirigida a la capacitación teórico- práctico de los docentes.

\section{Segunda etapa.}

Participar en una reunión con el personal docente de la carrera de Negocios Internacionales para darle a conocer la problemática resultante del diagnóstico de campo de la investigación realizada. Se enfatizará en las fortalezas y limitaciones encontradas que obstaculizan el desarrollo de la competencia comunicativa oral en el área de Inglés en los estudiantes y en los docentes en la enseñanza- aprendizaje de esta materia curricular. Se debe promover el debate del informe expuesto, intercambiar opiniones, ideas y hacer reflexiones sobre sus vivencias pedagógicas personales. Se sugiere estimular a los participantes para comprender la necesidad del cambio de manera gradual tanto en la preparación del docente en los fundamentos teórico como al orientar la enseñanza- aprendizaje para lograr el desarrollo de la competencia comunicativa oral en los estudiantes.

Acercamiento a los docentes de la especialidad de Inglés de la carrera de Negocios Internacionales. Este acercamiento tiene como propósito concientizar a los docentes participantes sobre los fundamentos teóricos, didácticos, metodológicos que se utilizó para la construcción de la propuesta e implementarla en el proceso de enseñanzaaprendizaje dela asignatura Inglés II en los estudiantes de primer año.

Se plantea la necesidad de conocer y estudiar los documentos normativos de la carrera. Se explica a los docentes a cargo de la disciplina curricular Inglés, que para 
planifica y dirigir el proceso de enseñanza - aprendizaje con eficiencia se deben conocer los documentos que guían la docencia universitaria como: la Ley Universitaria N. 30220 (2014), el diseño curricular de la carrera, el plan de estudio, el perfil del egresado, el programa de la disciplina y dosificar cada unidad de estudio para estar mejor preparados al diseñar el sistema de clases.

Se sugiere analizar el programa de la disciplina idiomática desde el punto de vista de las competencias a lograr, el contenido, los métodos, los medios audiovisuales, las unidades de estudio, las actividades de aprendizaje, la estructura metodológica, la concepción de la evaluación e instrumentos a utilizar, organización de las sesiones y el rol del estudiante en la clase a partir de los métodos empleados.

\section{Tercera etapa.}

El análisis realizado con los participantes tiene como objetivo sensibilizarlos en el compromiso a seguir para provocar un cambio cualitativo superior para lograr un desempeño sobresaliente y eficiente del docente en la clases que estimule el rol protagónico del estudiantado y el desarrollo de la competencia comunicativa oral en el entorno académico, social y familiar. Para tal efecto se identificaron aspectos teóricos, los momentos estratégicos de la actividad, la reflexión sobre la situación problematizadora, el diseño de métodos, recursos materiales, el cotejo del análisis previo a fin de llegar a las conclusiones.

\section{Para lograr esta tarea se explican los fundamentos teóricos y didácticos.}

Se presentan los enfoques teóricos, didácticos y las distintas fuentes referenticas para que puedan acceder a esos sustentos teóricos. Se enfatizó en las fuentes de la didáctica de la lengua y el enfoque cognitivo, comunicativo y sociocultural, con el objetivo de explicarles y que perciban que estos modelos, aplican un sistema de métodos, procedimientos y estrategias lingüísticas y dialógicas que estimulan la escucha, la comprensión, la libre expresión de ideas e incluye las tareas y las actividades de aprendizajes que respondan a esa línea y a la diversidad de los hablantes orientados por la mediación y guía del docente responsable con miras a contribuir al desarrollo de las destrezas comunicativas.

\section{Cuarta etapa.}

Se enfatiza la necesidad de establecer la coherencia lógica entre los elementos o estructura de la unidad de estudio analizada con sus respectivas horas clases. En cada clase debe lograrse la correlación entre el contenido, los métodos, las habilidades, los recursos audiovisuales, la forma de evaluación a aplicar, los valores que el contenido de la clase permite reforzar, la concepción de la actividad atendiendo a los niveles de asimilación del aprendizaje y el rol del estudiante dirigidos y estimulados por el accionar 
docente en el tratamiento de cada unidad de estudio programada con el objeto de aplicar sus destrezas orales en el proceso y secundar la formación integral de los estudiantes de la asignatura de Inglés II.

\section{Quinta etapa.}

La aplicación de la estrategia metodológica modelada se aplicará en el primer ciclo de la carrera para el que se diseñó. Ello precisa de realizar cortes evaluativo-parciales para constatar el progreso y las dificultades y hacer los reajustes adecuados y al final se realiza la evaluación conclusiva para medir el impacto en el proceso de enseñanza - aprendizaje y en el desarrollo de la competencia comunicativa oral en los estudiantes de la asignatura de Inglés II de la carrera de Negocios Internacionales.

\section{Validación de las potencialidades de la estrategia por consulta a especialistas}

La validación cualitativa de la estrategia diseñada está orientada a solucionar la problemática objeto de la investigación, aplicándose el método de juicio de expertos a fin de apreciar tanto los aspectos externos e internos de la propuesta modelada mediante el diseño fichas de valoración. Para ello se seleccionó a tres especialistas que validaran la estrategia modelada, por ese motivo se tuvo en consideración los siguientes criterios de selección: contar con el grado académico de maestro o doctor en Educación, el título académico de licenciado en educación y tener más de 15 años de experiencia docente 0 ejercer la dirección pedagógica en una institución educativa universitaria.

Los especialistas seleccionados que avalan la propuesta modelada cuentan con la experiencia profesional y la autoridad para la valoración. En el siguiente cuadro se identifica a los especialistas y los criterios que se tomó en el proceso.

Tabla 4

Relación de expertos que validaron la propuesta

\begin{tabular}{|c|c|c|c|c|c|}
\hline $\begin{array}{l}\text { Nombres y } \\
\text { apellidos }\end{array}$ & Grado académico & $\begin{array}{l}\text { Especialidad } \\
\text { profesional }\end{array}$ & & Ocupación & $\begin{array}{l}\text { Años de } \\
\text { experiencia }\end{array}$ \\
\hline $\begin{array}{l}\text { Fernando } \\
\text { Goñi Cruz }\end{array}$ & $\begin{array}{l}\text { Doctor } \\
\text { Educación }\end{array}$ & $\begin{array}{l}\text { Licenciado } \\
\text { Física } \\
\text { Matemática }\end{array}$ & en & $\begin{array}{l}\text { Docente de la Escuela de } \\
\text { Postgrado de la Universidad } \\
\text { San Ignacio de Loyola }\end{array}$ & 28 años \\
\hline $\begin{array}{l}\text { Hernán } \\
\text { Gerardo } \\
\text { Flores }\end{array}$ & $\begin{array}{lr}\text { Magister en } \\
\text { Administración } \quad y \\
\text { Gerencia social }\end{array}$ & Sociólogo & & $\begin{array}{l}\text { Docente de la Escuela de } \\
\text { Postgrado de la Universidad } \\
\text { San Ignacio de Loyola. }\end{array}$ & 40 años \\
\hline
\end{tabular}




\begin{tabular}{|c|c|c|c|c|c|}
\hline Marilyn & Magister & en & Licenciada & en & Coordinadora del Centro de 25 años \\
\hline Soto & Gestión & la & Educación & & Idiomas de la Universidad San \\
\hline Galarza & Educación & & & & Martin de Porres. \\
\hline
\end{tabular}

Fuente: Elaboración propia (2019).

\section{Validación interna y externa por criterio de expertos de la estrategia metodológica}

Para la comprensión de la validación de la propuesta, se diseñó dos fichas de evaluación, una para la validación interna referida al contenido y la otra para la validación externa referida a la forma que presenta la propuesta, con diez criterios de orden cualitativo y cuantitativo.

Desde un aspecto cuantitativo los validadores señalaron su apreciación en cada uno de los criterios: deficiente (puntaje 1), bajo (puntaje 2), regular (puntaje 3), buena (puntaje 4) y muy bien (puntaje 5).

Tabla 5

Tabla de Valoración

\begin{tabular}{ll}
\hline Valoración & \\
\hline Deficiente & $\mathbf{0 - 2 5}$ \\
Baja & $25-50$ \\
Regular & $51-70$ \\
Buena & $71-85$ \\
Muy Buena & $86-100$
\end{tabular}

Fuente: Documentos de elaboración de tesis USIL (2018).

De manera general en cada ficha se obtuvo un puntaje máximo de cincuenta puntos que sumados hacen un total de cien puntos. Por su parte, el aspecto cualitativo de la propuesta se solicitó una apreciación crítica del objeto examinado teniendo en cuenta las siguientes dimensiones: positivos, negativos y sugerencias.

En la ficha de validación interna, el experto evalúa el contenido de la propuesta atendiendo a los indicadores : (a) factibilidad de la aplicación del resultado presentado; (b) claridad de la propuesta para ser aplicado por otros; (c) posibilidad de la propuesta de extensión a otros contextos semejantes; (d) correspondencia con las necesidades sociales e individuales; (e) congruencia entre el resultado propuesto y el objetivo fijado; (f) innovación en el uso de conceptos y procedimientos de la propuesta; ( $\mathrm{g}$ ) la modelación contiene propósitos basados en los fundamentos educativos, curriculares y pedagógicos, 
detallado, preciso y efectivo; (h) la propuesta está contextualizada a la realidad en estudio; (i) presenta objetivos claros, coherentes y posibles de alcanza y (j) contiene un plan de acción de lo general a lo particular.

Para apreciar la validez externa se utilizó una ficha en la que se presentan los indicadores, el puntaje según la escala de valoración correspondiente y los aspectos positivos, negativos y sugerencias pertinentes (ver anexo 9) como: (a) claridad, (b) objetividad, (c) actualidad, (d) organización, (e) suficiencia, (f) intencionalidad, (g) consistencia, (h) coherencia, (i) metodología y (j) pertinencia. Para valorar los criterios de validación externa se presenta los criterios, el puntaje a escala correspondiente y los aspectos positivos, negativos y sugerencias que amerite (ver anexo 11).

Los resultados independientes de las fichas de validación interna y externa se encuentran en el (Anexo 9) y las fichas de validación de cada uno de los especialistas representan el resumen de la valoración respecto a la sumatorias de cada uno de los especialistas como se detalla a continuación:

Tabla 6

Sumatoria de la valoración interna y externa de los expertos

\begin{tabular}{|c|c|c|c|c|c|}
\hline № & Especialista & Grado académico & $\begin{array}{l}\text { Ficha de } \\
\text { validación } \\
\text { interna }\end{array}$ & $\begin{array}{l}\text { Ficha de } \\
\text { validación } \\
\text { externa }\end{array}$ & $\begin{array}{l}\text { Sumatoria } \\
\text { de } \\
\text { valoración }\end{array}$ \\
\hline 01 & Soto Galarza Marilyn & $\begin{array}{l}\text { Magister Ciencias de la } \\
\text { Educación }\end{array}$ & 39 & 42 & 81 \\
\hline 02 & $\begin{array}{l}\text { Flores Valdiviezo } \\
\text { Hernán Gerardo }\end{array}$ & $\begin{array}{l}\text { Magister Gerencia Social y } \\
\text { Administración }\end{array}$ & 50 & 50 & 100 \\
\hline \multirow[t]{2}{*}{03} & Goñi Cruz Fernando & $\begin{array}{l}\text { Doctor Ciencias de la } \\
\text { Educación }\end{array}$ & 45 & 43 & 88 \\
\hline & & & & Total & 269 \\
\hline
\end{tabular}

Fuente: Fichas de validación y externa USIL (2019).

Resultado de la valoración de los especialistas y conclusiones.

Los resultados consolidados de la valoración de especialistas son los siguientes:

Tabla 7

Resultado de la valoración interna y externa de la estrategia por los expertos

\begin{tabular}{lll}
\hline Sumatoria de valoración total & Promedio de valoración & Valoración \\
\hline 269 & 90 & Muy bien \\
\hline
\end{tabular}


Fuente: Fichas de validación interna y externa USIL (2019).

Ante los resultados y las sugerencias recibidas se realizó un análisis integral de la validación hecha por los expertos, se concluye que la estrategia metodológica propuesta es válida y aplicable en la institución universitaria para la que se diseñó y otras afines. Se fundamenta por los expertos que el producto científico-pedagógico aportado por la investigación es una contribución a la práctica docente al guiar el proceso de enseñanzaaprendizaje de la competencia comunicativa oral de la asignatura Inglés en la que los estudiantes son protagonistas en la producción de los conocimientos y las habilidades comunicativas. 


\section{Conclusiones}

Al finalizar el proceso investigativo es necesario tomar en cuenta la sistematización de los referentes científicos, el análisis resultante del diagnóstico de campo y la modelación de la estrategia metodológica, se llegó a las siguientes conclusiones.

\section{Primera}

Habiéndose cumplido con el objetivo general de la investigación de desarrollar la competencia comunicativa oral de los estudiantes de inglés en la carrera de Negocios Internacionales de una universidad privada de Lima donde el aprendiz se hace cargo de su rol protagónico desde una perspectiva metodológica problémica, heurística, creativa, dialógica e independiente que inciden en la forma de pensar, sentir y hacer de los estudiantes.

\section{Segunda}

La organización de las categorías y subcategorías apriorísticas como del aprendizaje, la competencia comunicativa oral y la estrategia metodológica abordados desde un aspecto holístico - reflexivo y didáctico capaz de contribuir a un aprendizaje consciente y autorregulado que contribuye a la consolidación de sus conocimientos de los profesionales en formación.

\section{Tercera}

La estrecha relación ente la tarea de aprendizaje con el diagnostico de campo se dio a partir del diseño de las unidades de análisis y la posterior aplicación de las técnicas e instrumentos de recolección de datos. La valoración del resultado permitió tomar una muestra real en el desarrollo de la competencia comunicativa oral de los estudiantes, que al contrastarse con las categorías apriorísticas se pudo establecer la influencia de las categorías emergentes que enmarcan la modelación hacia una transformación pedagógica desde el proceso educativo.

\section{Cuarta}

En la modelación de la estrategia se tuvo en cuenta diversos criterios teóricos, prácticos y metodológicos planteados en la investigación; así como los criterios de expertos en la validación final. La propuesta diseñada es el resultado del desempeño pertinente de las tareas de aprendizaje orientado desde un enfoque didáctico en el tratamiento de la competencia oral donde el educador cumple su rol de mediador y guía en el proceso de 
aprendizaje que se verán reflejados ya sea en su forma de pensar, sentir e interactuar del estudiante.

\section{Quinta}

Los especialistas evaluaron de manera positiva la estrategia metodológica modelada como resultado de la investigación el cual resalta sus fundamentos teóricos y prácticos en el proceso educativo, siempre y cuando el docente pueda asumir un nivel superior de competencia profesional e impulsar el autoaprendizaje y desarrollar la competencia oral en los educandos, a partir de una postura problémica, heurísticas, creativa y dialógicas desde el contenido de la asignatura de Inglés. 


\section{Recomendaciones}

\section{Primera}

Al analizar la estrategia metodológica diseñada como producto de la investigación con los directivos de la facultad en aras de considerar su potencial ejecución en la práctica pedagógica universitaria y verse como una alternativa educativa innovadora que oriente al docente en la conducción del proceso de aprendizaje a partir de una dinámica reflexiva que inciden en la apropiación consciente del aprendizaje y el desarrollo de la competencia comunicativa oral en los estudiantes.

\section{Segunda}

Recomendar realización de talleres de capacitación orientado a los docentes donde se fundamenten los sustentos teórico - didáctico sobre cómo orientar y dirigir el proceso de enseñanza- aprendizaje de la competencia comunicativa oral de una segunda lengua con el objetivo de contribuir a la transformación de la práctica pedagógica.

\section{Tercera}

Presentar la investigación realizada en los distintos eventos científicos y reuniones metodológicas con el propósito de socializar los resultados alcanzados en el desarrollo de la competencia comunicativa oral en el idioma Inglés en los estudiantes y continuar el estudio de otras aristas de la problemática de la enseñanza de las segundas lenguas a fin de contribuir a la solución de los problemas en la práctica pedagógica. 


\section{Referencias}

Addine, F., Álvarez, L., Martínez, M., Parra, I., Sierra, R., Gutiérrez, M., Calzado, D. (2016). Didáctica de la pedagogía y la Psicología. Pueblo y Educación. La Habana .

Addine, F. (2004). La didáctica: Teoría y Práctica. La Habana: Pueblo y Educación.

Álvarez de Zayas, R. M. (1996). Hacia un currículum integral y contextualizado. Academia. file:///C:/Users/crowned/Downloads/Rita\%20Marina\%20Alvarez.

Arenas La Torre, J. E. (2019). Estrategias de enseñanza basadas en los medios de comunicación y el logro de competencias comunicativas orales-lectoras en inglés, en un colegio de secundaria de Surco.

Atiro, Q., y Edzon, W. (2017). Competencia oral del idioma inglés en estudiantes del tercer grado de secundaria de la institución educativa El Mártir José Olaya de Ventanilla, 2016. (Tesis de pregrado). Universidad Cesar Vallejo. Trujillo, Peru.

Ballesteros, $L$ (Marzo de 2012). La importancia de la lectura en el aprendizaje de lenguas extranjeras en la ESO. Sociedad de la Información. Recuperado de http://www.sociedadelainformacion.com/34/lectura.pdf

Barbarán Gari, V. (2017). Efectos del aprendizaje basado en el pensamiento (TBL) en la enseñanza de las ciencias naturales. Implicaciones para la formación del profesorado.

Barrios, J. (2019). La expresion oral herramienta indispensable dentro del proceso comunicativo. Cienciamatria, 1(1), 90-100.

Benítez Gener, A., Pérez Martínez, D., Labrador Labrador, E., Pino Ledesma, L., \& Pagani Lobo, B. (2010). Tareas comunicativas para el desarrollo de la expresión oral en inglés en 4to año de Medicina. Revista de Ciencias Médicas de Pinar del Río, 14(3), 32-37.

Blanch, G. G., Ripoll, A. R., García, M. T., \& Martínez, A. V. (2007). Fundamentos de neurociencia (Vol. 69). Editorial UOC.

Briceño . E. (2017). Estrategias comunicativas del idioma inglés y nivel de expresión oral con los criterios del test estándar internacional Ket Cambridge a los estudiantes del tercer ciclo de educación-especialidad de inglés de la Universidad Nacional de Cajamarca.

British Council. Educational Intelligence. (2015). Inglés en el Perú. Un análisis de las políticas, las percepciones y los factores de influencia. 2015.

Brown, H. (2014). Principles of language learning and teaching. A course in second language acquisition. Pearson Education. United States of America.

Calderón L. (2019). Content and Language Integrated Learning (CLIL) en la producción oral del idioma Inglés (Bachelor's thesis, Quito: UCE). 
Canale, M. (1983). From communicative competence to communicative language pedagogy. En J. Richards \& R. Schmidt (Eds.), Language and Communication (pp.127). New York, USA.

Caravedo C. Román, D., y Marizel, G. (2018). Implementación de la metodología Aprendizaje Basado en Proyectos en el curso de inglés de 4to de Secundaria de un colegio inclusivo bilingüe.

Cassany, D., Luna, M. y Sanz, G. (2003). Enseñar lengua. Serie Didáctica de la lengua y la literatura. España: Editorial Graó.

Cassany, D. (2013). Tras las líneas. Sobre la lectura contemporánea. Barcelona: Anagrama.

Cassany, D. (2016). La escritura extensiva. La enseñanza de la expresión. Enunciación (21), 91-116. http://dx.doi.org/10.14483/udistrital.jour.enunc.2016.1.a06.

Castañeda, C (2017). Actividades basadas en inteligencias múltiples para el mejoramiento de la habilidad de producción oral en el idioma inglés en los alumnos de una universidad de la ciudad de Trujillo.(Tesis de maestría). Universidad Privada Antenor Orrego, Trujillo, Perú.

Castellanos, D., Castellanos, B., Llivina, M., Gómez, M., Cápiro, C. y Sánchez, C. (2002). Aprender y Enseñar en la Escuela: Una concepción desarrolladora. Pueblo y Educación. La Habana.

Castellanos, D., Reinoso, C. y García, C. (2007). Para promover un aprendizaje desarrollador. La Habana: Colección de proyectos.

Castelló et al. (2006)

Chávez , L. (2016). Competencia comunicativa en el desarrollo de la expresión oral del idioma inglés en los estudiantes de un instituto superior. (Tesis de maestría). Universidad Cesar Vallejo. Trujillo, Perú.

Chomsky , C. (1972).Stages in language development and reading exposure. Harvard Educational Review, 1972, vol. 42, no 1, p. 1-33. Linguarum.vol.(12), pp 155 - 177. Recuperado de http://ugranada.com

Cisterna, C., F. (2005). Categorización y triangulación como procesos de validación del conocimiento en investigación cualitativa. Theoria, 14(1), 61-71. Recuperado de http://www.ubiobio.cl/theoria/v/v14/a6.pdf

Conejeros et al. (2010) Estrategias para mejorar la calidad y equidad educacional. En García- Cepero (Ed.) Talentos en el Bicentenario; Educación para el desarrollo de estudiantes sobresalientes. Antofagasta: Centro de Investigación y Desarrollo de Talento DeLTAUCN, Universidad Católica del Norte, 47-53. 
Consejo de Europa. (2002). Marco Común Europeo para las Lenguas: Aprendizaje, Enseñanza y Evaluación. (MCER). Madrid, España: Instituto Cervantes para la traducción en español.

Cordeiro, D. M. (2018). Las inteligencias múltiples como herramienta para mejorar las destrezas orales en el aula de español como lengua extranjera: una investigación acción (Doctoral dissertation, Universitat de València).

Criado, R. (2013). A critical review of the presentation-practice-production model (PPP) in foreign language teaching. Homenaje a Francisco Gutiérrez Díez, 97-115.

Cruz, O. y Velázquez, M. (2016) Metodología innovadora para la práctica de ejercicios físicos. Revista de Educación, Argentina, 7(9), 317-335. http://fh.mdp.edu.ar/revistas/index.php/r educ/article/view/1915

De Corte, E. (2015). Aprendizaje constructivo, autorregulado, situado y colaborativo: un acercamiento a la adquisición de la competencia adaptativa (matemática). Páginas de Educación, 8(2), 1-35.

Delgado, C., y Pepe, S. (2018). Estrategias de expresión oral para elevar el análisis crítico en los alumnos y alumnas del quinto y sexto grado de educación primaria de la Institución Educativa №16913 del Caserío Túpac Amaru del Distrito de Huarango San Ignacio, 2016.

Díaz Barriga, F. R. I. D. A. (2006). La evaluación auténtica centrada en el desempeño: una alternativa para evaluar el aprendizaje y la enseñanza. Enseñanza situada: vínculo entre la escuela y la vida, 125-163.

Díaz Barriga, y Barriga, A. (1995). Docente y programa: Lo institucional y lo didáctico.

Díaz, P, Linares, Y. y Mora, M. (2018). Lineamientos metodológicos para el trabajo con las estrategias de aprendizaje de lenguas extranjeras/methological guidelines to work with foreign language learning strategies. Pedagogía Universitaria, 23(3).

Dolz, J., Gagnon, R., \& Mosquera, S. (2009). La didáctica de las lenguas: una disciplina en proceso de construcción. Didáctica. Lengua y literatura, 21, 117-141.

Domínguez, I. (2010). Comunicación y texto. Cuba: Editorial Pueblo y Educación.

Estaire, S. (1990). "La programación de unidades didácticas a través de tareas". En CABLE. Revista de didáctica del español como L25, pp. 19-27. la programación de unidades didácticas a través de tareas

Estrada, S. (2013). Fundamentos Lingüísticas de la Composición Oral y Escrita.

Fàbregas, M. C. B., Fuentes, M., y Royo, M. P. (2015). La competencia comunicativa oral en la formación inicial de maestros y maestras. Opción: Revista de Ciencias Humanas y Sociales, (5), 130-146. 
Fernández, C. y Aguado, M. (2017). Aprendizaje basado en problemas como complemento de la enseñanza tradicional en Fisicoquímica. Investigación Educativa. 1(27), 154162.

Fingermann, H. (2012). Enfoque Sistémico del proceso Enseñanza-Aprendizaje. Retrieved Noviembre, 28, 2016.

Fuertes ,N. (2015). Sinergia de los principales métodos activos en el nivel de la competencia comunicativa del idioma inglés. Caso: estudiantes del Centro de Idiomas de la Facultad de Ciencias de la Salud de la Universidad Nacional de Chimborazo. (Tesis doctoral). Riobamba, Ecuador.

Fullan, M., \& Langworthy, M. (2014). New pedagogies for deep learning. Michael Fullan. Retrieved April, 22, 2016.

García, M. (5 de julio de 2010). http://es.slideshare.net. Recuperado el 28 de enero de 2018, de http://es.slideshare.net/analuciacavalheiro/enseanza-comunicativa

Godoy, M. (2009). La tarea comunicativa: información de entrada y posibles tareas subsidiarias para una clase de 120 minutos. In El profesor de español LE-L2: Actas del XIX Congreso Internacional de la Asociación para la Enseñanza del Español como Lengua Extranjera (Asele) (pp. 1013-1026). Servicio de Publicaciones.

González, F. (2003). Sujeto y subjetividad: una aproximación histórica cultural. Ediciones Paraninfo. México.

Gonzales. (2007). Investigación cualitativa y subjetiva: los procesos de construcción de la información. Ciudad Federal, México. McGraw- Hill Interamericana Editores.

González-Such, J., Jornet, J. y Bakieva, M. (2013). Consideraciones metodológicas sobre la evaluación de la competencia oral en L2. Revista Electrónica de Investigación Educativa, 15(3), 1-20. Recuperado de http://redie.uabc.mx/vol15no3/contenidoglez-jornet.html

Guamán E. (2019). El aprendizaje basado en tareas (task based learning) en la producción escrita de los estudiantes del Instituto PRALI año 2018-2019 (Bachelor's thesis, Quito: UCE).

Guevara, A. (2016). Método Total Physical Response (T.P.R.) y su influencia en el proceso de enseñanza-aprendizaje del vocabulario (vocabulary) del idioma Inglés en los estudiantes de la Unidad Educativa "Oswaldo Villamil Auz" del Cantón Quevedo. Quevedo: Universidad Técnica de Babahoyo. http://dspace.utb.edu.ec/bitstream/49000/1937/1/P-UTB-FCJSE-IDM-000035.pdf

Harmer, J. (2015). The practice of English Language Teaching. England: Pearson Education. 
Hernández, C., y Guárate, A. (2017). Modelos didácticos: Para situaciones y contextos de aprendizaje (Vol. 146). Narcea Ediciones.

Hernández F.. y Baptista, M.(2014). Metodología de la Investigación. Ciudad de México, México: Interamericana editores.

Hymes, D. (1996). Acerca de la competencia comunicativa. (J. Gómez, trad.). En Pride and Holmes (Eds.). Sociolinguistics. (Obra original publicada en 1972).

Llatas, A.(2017). Influencia del método "oral situacional" para mejorar competencias comunicativas orales de inglés en IOs estudiantes de la especialidad de primaria $v$ ciclo del ISPP Octavio Matta Contreras (Tesis de maestría). Universidad Cesar Vallejo. Cutervo - Perú.

Lopez, A. ( 2018). Métodos y técnicas de enseñanza [Mensaje en un blog]. Recuperado de https://andrealopez909.wordpress.com/2016/11/23/4-metodo-sugestopedia/

López de Bozik,E. (2011). Metodología de la investigación Guía instruccional. Caracas, Venezuela. UNA.

López, E. , Amaguaya, P, Paulina P., Eugenia, R. , y Georgina, R. (2019). Incidencia Del Uso Del Podcast Como Estrategia De Aprendizaje Para La Comprensión auditiva del Inglés. European Scientific Journal, ESJ, 15(2), 27.

Luján-García, C. (2012). The impact of English on Spanish daily life and some pedagogical implications. Nordic Journal of English Studies, 11(1), 1-21.

Manrique Ramírez, A. (2014). Diseño de un proyecto educativo para enseñar inglés a niños y jóvenes en edad escolar pertenecientes a la comuna 20 de Santiago de Cali [recurso electrónico] (Doctoral dissertation).

Maquerhua M. y Quiroz G. (2017). Fortaleciendo la comunicación bilingüe: estrategias metodológicas interactivas para mejorar la expresión oral y desarrollar habilidades comunicativas en el idioma inglés en los estudiantes del cuarto grado " $A$ " y " $B$ " del nivel secundario de la Institución Educativa Ángel de la Guarda. Camaná-Arequipa 2016.

Martínez Iglesias, M: (2009) "Estrategia didáctica para desarrollar la competencia sociolingüística en los alumnos de los cursos preparatorios de español como lengua extranjera", Edición electrónica gratuita. Texto completo en www.eumed.net/tesis/2009/mimi/

Maza Granda, S. I. (2017). Estrategias didácticas, para mejorar el aprendizaje en función del análisis de la propuesta curricular 2016.

Medina, A. y Mata, F. (2009). Didáctica General. España: Pearson Educación. 
Ministerio de Educación, Cultura y Deporte (2002). Marco Común Europeo de Referencia para las lenguas: aprendizaje, enseñanza, evaluación. (2001). Recuperado de http://cvc.cervantes.es/obref/marco.

Ministerio de Educación del Perú. Decreto Supremo No.012-20015-Minedu. Decreto Supremo que aprueba la Política Nacional de Enseñanza, Aprendizaje y Uso del Idioma Inglés "Inglés, puertas al mundo".

Navarro,P.(12 de Junio de 2014). Todo lo que debe saber sobre el lenguaje corporal. [Blog]. Recuperado de https://habilidadsocial.com/el-lenguaje-corporal/

Ortiz, P. (2008). Educación y formación de la personalidad. Universidad de Ciencias y Humanidades, Lima.

Ortiz, A. (2012). Didáctica problematizadora y aprendizaje basado en problemas. Cali, Colombia: Litoral.

Ortiz, A. (2015). Neuroeducación, ¿Cómo aprende el cerebro humano y cómo deberían enseñar los docentes? Bogotá: Ediciones de la U.

Pérez, A. , Arquímedes D, Quiñones y Batista, M (2018). Fundamentos teóricos para una concepción del desarrollo de la comunicación oral. Revista Atlante: Cuadernos de Educación y Desarrollo (agosto 2018). En línea: https://www.eumed.net/rev/atlante/2018/08/desarrollo-comunicacion-oral.html

Pintrich, P. Schunk, D. y Luque, M. (2006). Motivación en contextos educativos: teoría, investigación y aplicaciones. Madrid: Pearson Prentice Hall.

Piaget, J. (1981). La teoría de Piaget. Infancia y Aprendizaje. Ediciones Morata. 4(2), $12-$ 54.

Pompilla, F., Ramos, M., Nicolasa, L., Portaro, T., Giuliana, C. , y Zapata C. (2019). Aplicación de estrategias de enseñanza cognitiva para favorecer la habilidad de comprensión oral del idioma inglés de los estudiantes del Inglés $V$, sección $A$, del Centro de Idiomas del IPNM.

Prieto, J. (2012). Estrategias de enseñanza-aprendizaje. Pearson educación.

Quintero, L. C., \& Segura, J. A. (2011). El desarrollo profesional de los docentes en entornos personales de aprendizaje (PLE). In La práctica educativa en la Sociedad de la Información: Innovación a través de la investigación (pp. 83-95). Editorial Marfil.

Quispe, W. (2017). Competencia oral del idioma Inglés en estudiantes del Tercer Grado de Secundaria de la Institución Educativa El Mártir José Olaya de Ventanilla, 2016.

Quiroz, M. T. (2003). Educar en la comunicación/comunicar en la educación. Revista Diálogos, Lima, n³7, FELAFACS, julio/1993. Aprendizaje y comunicación en el siglo XXI, Buenos Aires, Grupo Editorial Norma. 
Ramírez, J. L. (2007). Las investigaciones sobre la enseñanza y el aprendizaje de lenguas extranjeras en México. México: Plaza y Valdez.

Richards, J. y Rodgers, T. (2001). Approaches and methods in language teaching (Cambridge language teaching library). Cambridge University, Cambridge.

Rico. Ramirez. Montiel (2016). Desarrollo de la competencia oral de Inglés mediante recursos educativos abiertos. Apertura, Revista de Innovación Educativa. Vol.8, 114.

Rico, P., Santos, E. y Viaña, V. (2013). Enseñanza- aprendizaje desarrollador escuela primaria. Teoría y práctica. La Habana: Pueblo y Educación.

Roca, J. S., Abarca, M., \& Marzo, L. (2002). La educación emocional y la interacción profesor/a-alumno/a. Revista electrónica interuniversitaria de formación del profesorado, 5(3), 1.

Rodríguez. (2010). Consideraciones teóricas sobre la expresión oral profesional pedagógica en inglés. Cuba: Ciencias Holguín.

Rodríguez. (2015). Actividades enfocadas para el desarrollo de la destreza oral del idioma inglés. Ecuador: Universidad Técnica de Ambato.

Romeú, A. (2007). El enfoque cognitivo, comunicativo y sociocultural en la enseñanza de la Lengua y Literatura. Pueblo y Educación. La Habana.

Rueda Cataño, M. C., \& Wilburn Dieste, M. (2014). Enfoques teóricos para la adquisición de una segunda lengua desde el horizonte de la práctica educativa. Perfiles educativos, 36(143), 21-28.

Salgado R. (2019). El enfoque metodológico del Ministerio de Educación del Ecuador para la enseñanza del inglés basado en AICLE, en el desarrollo de las habilidades comunicativas de los estudiantes de décimo año de Educación General Básica del Colegio Nacional "Dr. Emilio Uzcátegui”, año lectivo 2018-2019 (Bachelor's thesis, Quito: UCE).

Sánchez. B. (2015) Desarrollo de competencias comunicativas mediante la lectura crítica, escritura creativa y expresión oral. Revista Encuentros, Universidad Autónoma del Caribe, 13 (1), pp. 117-141. DOI: http://dx.doi.org/10.15665/re.v13i2.502

Sanz (2010). Aspectos Regresivos en la retención de la competencia comunicativa oral en Inglés en la Educación Obligatoria. (Tesis doctoral). Universidad Santiago de Compostela. Santiago de Compostela, España.

Silva, B., y Elena, N. (2019). El aprendizaje basado en tareas como método para desarrollar la expresión oral en estudiantes de inglés de un Instituto Superior Tecnológico de Lima. 
Silvestre, M y Zilbertein, K.(2002). Hacia una didactica desarrolladora. La Habana: Pueblo y Educación.

Superintendencia Nacional de Educación Superior Universitaria (Sunedu, 2014). Ley Universitaria: Ley Nro. 30220. https://www.sunedu.gob.pe/nueva-ley-universitaria30220-2014/

Tobón, S. (2009). Proyectos formativos: didáctica y evaluación de competencias. Las competencias en educación básica: un cambio hacia la reforma. México: Secretaría de Educación Pública.

Organización de las Naciones Unidas para la Educación, la Ciencia y la Cultura, (Unesco, 2015). Banco Mundial. Declaração Mundial sobre educação para todos.

Erdmenger, E., y Waisburd, G. (2007). El poder de la música en el aprendizaje. Como lograr una aprendizaje acelerado y creativo. España: Trillas Edufor.

Vega, I. C. (2002). Análisis de necesidades y establecimiento de objetivos. In Didáctica del español como lengua extranjera (pp. 23-36). Fundación Actilibre.

Velázquez, L, Figarella ,F. (2014). ¿Cómo facilitar la problematización en el aprendizaje para desarrollar cultura científica y promover participación ciudadana?. Congreso Iberoamericano de Ciencia, Tecnología, Innovación y Educación

Vygotsky, L. (1987). Historia del desarrollo de las funciones psíquicas superiores. La Habana. Editorial Scientific - Técnica.

Zebadúa, M. d., \& García, E. (2011). Cómo enseñar a hablar y escuchar en el salón de clases. México DF.: Medios Gráficos.

Zegarra, R. y Velázquez, M. (2016). El coaching: una forma para fortalecer el profesionalismo del docente en el aula. Páginas de educación. Uruguay: Universidad Católica del Uruguay. doi: https://doi.org/10.22235/pe.v9i2.1294. 
Anexos 
Anexo 1

\section{Matriz metodológica}

Estrategia metodológica para el desarrollo de la competencia comunicativa oral en los estudiantes de inglés de negocios internacionales de una universidad privada de Lima.

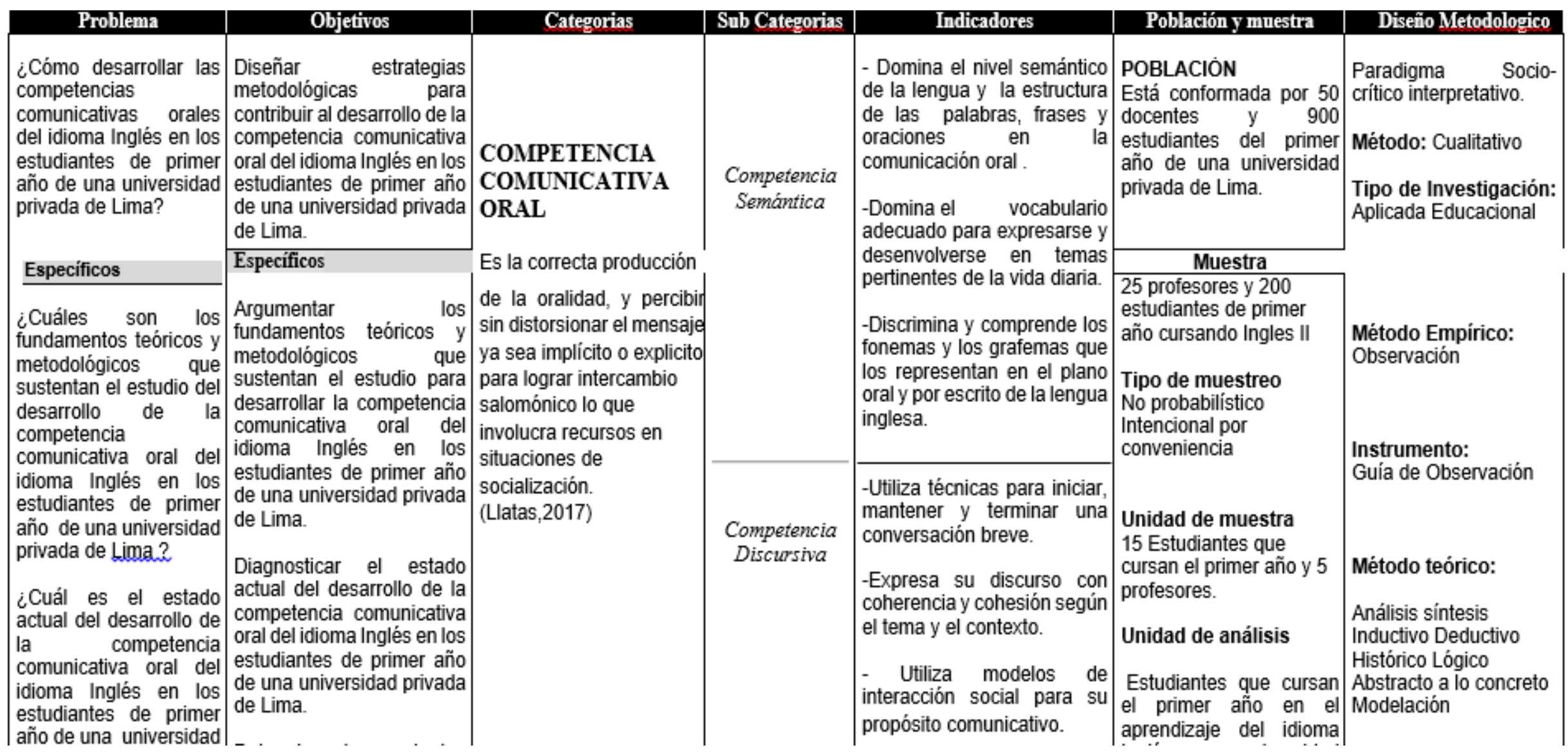




\begin{tabular}{|c|c|}
\hline $\begin{array}{l}\text { año de una universidad } \\
\text { privada de Lima? } \\
\text { ¿Qué sustentos }\end{array}$ & $\begin{array}{l}\text { Determinar los sustentos } \\
\text { teóricos y metodológicos } \\
\text { sirven de base de la } \\
\text { modelación de la estrategia }\end{array}$ \\
\hline $\begin{array}{l}\text { teóricos y } \\
\text { metodológicos sirven } \\
\text { de base a la modelación } \\
\text { de la estrategia } \\
\text { metodológica para } \\
\text { contribuir al desarrollo } \\
\text { de la competencia } \\
\text { comunicativa oral del } \\
\text { idioma Inglés en los } \\
\text { estudiantes de primer } \\
\text { año de una universidad } \\
\text { privada de Lima? }\end{array}$ & $\begin{array}{l}\text { metodológica para } \\
\text { contribuir al desarrollo de } \\
\text { la } \\
\text { comunicativa del idioma } \\
\text { Inglés en los estudiantes } \\
\text { de primer año de una } \\
\text { universidad privada de } \\
\text { Lima. }\end{array}$ \\
\hline $\begin{array}{l}\text { ¿Cómo validar por } \\
\text { criterios de expertos la } \\
\text { efectividad de la } \\
\text { estrategia metodológica }\end{array}$ & \\
\hline
\end{tabular}

modelada para

contribuir al desarrollo

de la competencia

comunicativa oral del

idioma Inglés en los

estudiantes de primer

año de una universidad

privada de Lima?

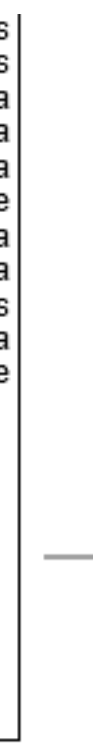

ESTRATEGIA
METODOLOGICA

Es el conjunto de

procedimientos,

mediante el empleo de

métodos, técnicas,

medios y recursos que el

docente emplea con el Base teórica de

propósito de lograr la metodología

eficazmente el proceso

educativo en una

situación de enseñanza -

aprendizaje especifica

(Hernández, C. 2017)

\begin{tabular}{|c|c|c|}
\hline \multirow[b]{2}{*}{$\begin{array}{c}\text { Competencia } \\
\text { Sociolingüistico }\end{array}$} & propósito comunicativo. & \multirow{2}{*}{$\begin{array}{l}\text { Inglés en una universidad } \\
\text { privada de Lima. }\end{array}$} \\
\hline & $\begin{array}{l}\text {-Comunica } \\
\text { conocimientos y usa el } \\
\text { lenguaje según las } \\
\text { circunstancias. } \\
\text {-Desarrolla las relaciones } \\
\text { sociales con sencillez y } \\
\text { eficacia. } \\
\text {-Selecciona palabras, frases } \\
\text { y expresiones del contexto } \\
\text { cultural para producir el } \\
\text { discurso oral de manera } \\
\text { formal e informal. }\end{array}$ & \\
\hline & $\begin{array}{l}\text { Aplica el diagnóstico y } \\
\text { caracteriza la realidad. }\end{array}$ & \\
\hline
\end{tabular}

\begin{tabular}{|c|l|}
$\begin{array}{c}\text { Determinación } \\
\text { de necesidades } \\
\begin{array}{c}\text { yel objetivo } \\
\text { general }\end{array}\end{array}$ & $\begin{array}{l}\text { Formula objetivos a corto, } \\
\text { mediano y largo plazo. } \\
\text { Argumenta el rol del } \\
\text { docente y estudiante. }\end{array}$ \\
\hline $\begin{array}{l}\text { Base teórica de } \\
\text { la metodología }\end{array}$ & $\begin{array}{l}\text { Sustenta los conceptos, } \\
\text { principios y enfoques } \\
\text { teóricos que sirve de base a } \\
\text { la propuesta. } \\
\text { Fundamenta el sistema de } \\
\text { actividades, rol } \\
\text { implementar. }\end{array}$ \\
& $\begin{array}{l}\text { Aplica el sistema de métodos } \\
\text { en la dirección del PEA. } \\
\text { and }\end{array}$
\end{tabular}




$\mid$\begin{tabular}{|l|l|l|} 
Etapas y & $\begin{array}{l}\text { Determina las etapas de la } \\
\text { metodología propuesta. } \\
\text { evaluación de } \\
\text { la metodología. }\end{array}$ & $\begin{array}{l}\text { Propone las acciones y los } \\
\text { procedimientos de cada } \\
\text { etapa. } \\
\text { Elabora los instrumentos y } \\
\text { técnicas para evaluar la } \\
\text { metodología. }\end{array}$ \\
\hline
\end{tabular}

ecnicas para evaluar la 
Anexo 2

Matriz de categorías, subcategorías e indicadores

\begin{tabular}{|c|c|c|c|c|}
\hline $\begin{array}{l}\text { Problema de } \\
\text { investiqación }\end{array}$ & $\begin{array}{l}\text { Objetivo } \\
\text { qeneral }\end{array}$ & Categorías & Subcategorías & Indicadores de subcategorías \\
\hline $\begin{array}{l}\text { ¿Cómo } \\
\text { desarrollar la } \\
\text { competencia } \\
\text { comunicativa } \\
\text { oral del idioma } \\
\text { Inglés en los } \\
\text { estudiantes de } \\
\text { Negocios } \\
\text { Internacionales } \\
\text { de una } \\
\text { universidad } \\
\text { privada de } \\
\text { Lima? }\end{array}$ & $\begin{array}{l}\text { Diseñar una } \\
\text { estrategia } \\
\text { metodológica } \\
\text { para contribuir } \\
\text { al desarrollo } \\
\text { de la } \\
\text { competencia } \\
\text { comunicativa } \\
\text { oral del idioma } \\
\text { Inglés en los } \\
\text { estudiantes de } \\
\text { Negocios } \\
\text { Internacionales } \\
\text { de una } \\
\text { universidad } \\
\text { privada de } \\
\text { Lima }\end{array}$ & $\begin{array}{l}\text { Estrategia } \\
\text { metodológica } \\
\text { Es el conjunto } \\
\text { de acciones y } \\
\text { procedimientos, } \\
\text { mediante el } \\
\text { empleo de } \\
\text { métodos, } \\
\text { técnicas, } \\
\text { medios y } \\
\text { recursos que el } \\
\text { docente } \\
\text { emplea con el } \\
\text { propósito de } \\
\text { lograr } \\
\text { eficazmente el } \\
\text { proceso } \\
\text { educativo en } \\
\text { una situación } \\
\text { de enseñanza } \\
\text { - aprendizaje } \\
\text { especifica } \\
\text { (Hernández } \\
\text { 2017). }\end{array}$ & $\begin{array}{l}\text { Determinación } \\
\text { de } \\
\text { necesidades y } \\
\text { el objetivo } \\
\text { general } \\
\text { Base teórica de } \\
\text { la metodología }\end{array}$ & $\begin{array}{l}\text {-Domina el nivel semántico de la } \\
\text { lengua y la estructura de las } \\
\text { palabras, frases y oraciones en la } \\
\text { comunicación oral. } \\
\text {-Domina el vocabulario adecuado } \\
\text { para expresarse y desenvolverse en } \\
\text { temas pertinentes de la vida diaria. } \\
\text {-Discrimina y comprende los fonemas } \\
\text { y los grafemas que los representan } \\
\text { en el plano oral y por escrito de la } \\
\text { lengua inglesa. } \\
\text {-Utiliza técnicas para iniciar, } \\
\text { mantener y terminar una } \\
\text { conversación breve. } \\
\text {-Expresa su discurso con coherencia } \\
\text { y cohesión según el tema y el } \\
\text { contexto. } \\
\text { - Utiliza modelos de interacción social } \\
\text { para su propósito comunicativo. } \\
\text {-Comunica sus conocimientos y usa } \\
\text { el lenguaje según las circunstancias. } \\
\text {-Desarrolla las relaciones sociales } \\
\text { con sencillez y eficacia. } \\
\text {-Selecciona palabras, frases y } \\
\text { expresiones del contexto cultural para } \\
\text { producir el discurso oral de manera } \\
\text { formal e informal. } \\
\text { Aplica el diagnóstico y caracteriza la } \\
\text { realidad. } \\
\text { Formula objetivos a corto, mediano y } \\
\text { largo plazo. } \\
\text { Argumenta el rol del docente y } \\
\text { estudiante. } \\
\text { Sustenta los conceptos, principios y } \\
\text { enfoques teóricos que sirve de base } \\
\text { a la propuesta. } \\
\text { Fundamenta el sistema de } \\
\text { actividades, rol a implementar. } \\
\text { Aplica el sistema de métodos en la } \\
\text { dirección del PEA. } \\
\text { Determina las etapas de la } \\
\text { metodología propuesta. } \\
\text { Propone las acciones y los } \\
\text { procedimientos de cada etapa. } \\
\text { Elabora los instrumentos y técnicas } \\
\text { para evaluar la metodología. }\end{array}$ \\
\hline
\end{tabular}




\section{Anexo 3}

\section{Instrumentos de recolección de datos}

\section{ENTREVISTA A DOCENTES}

Objetivo: Constatar los conocimientos teóricos y didácticos que poseen los docentes acerca de la competencia oral y su tratamiento en los estudiantes de primer año de Inglés en una universidad privada de Lima.

Docente del área:

Fecha

1. Distintos psicólogos se han referido sobre la competencia comunicativa oral y su importancia para el desarrollo del proceso de enseñanza- aprendizaje. ¿Al respecto podría comentar qué es para usted la competencia comunicativa oral?

2. ¿Cuáles son los autores que abordan los fundamentos teóricos de la competencia comunicativa oral?

3. ¿Qué subcompetencias abarca la competencia comunicativa oral?

4. ¿Qué autores abordan de forma más integral la competencia comunicativa oral?

5. ¿Qué importancia tiene para usted atender la comprensión como parte de la competencia oral?

6. ¿Qué enfoques teóricos y didácticas conoce que estimulan el desarrollo de la competencia comunicativa oral en la enseñanza- aprendizaje del Inglés como segunda lengua?

7 ¿Cómo usted logra interesar y motivar a los estudiantes en las clases para que se comuniquen, den opiniones, puntos de vista, reflexionen, critiquen y valoren en el aula?

8. ¿Cuáles son los métodos de enseñanza que promueven el protagonismo y la motivación de los estudiantes por las actividades de aprendizaje de idioma?

$9 i$ Cree usted que en la enseñanza de idiomas se deben utilizar variados medios audiovisuales? Fundamente por qué.

10. ¿Cómo estimula en sus estudiantes el nivel semántico del idioma inglés? Argumente sus ideas

11. ¿Qué tratamiento le brinda usted a los estudiantes que presentan distintos niveles de desarrollo de las habilidades comunicativas?

12. ¿Qué importancia tiene el método de trabajo en grupo para los estudiantes de Inglés y por qué?

13¿Qué características debe tener la actividad de aprendizaje para lograr interés en los estudiantes por aprender el contenido y desarrollar las habilidades orales en la clase? 14. ¿Qué estrategias de aprendizaje emplean sus estudiantes para iniciar y concluir la exposición de un tema en la clase?

15 ¿Cómo valora el desarrollo del vocabulario de sus estudiantes y qué actividades realiza para su desarrollo?

16. ¿Cómo estimula la metacognición y el autocontrol en los estudiantes?

17. ¿Cómo lleva a cabo el proceso de evaluación de los conocimientos, las habilidades orales de los estudiantes en la clase?

\section{PAUTA DE OBSERVACIÓN DE CLASES AL DOCENTE}

\section{Objetivo}

Construir el nivel de conocimiento teórico que posee el docente al guiar el proceso de enseñanza aprendizaje de las estrategias para el desarrollo de la competencia comunicativa oral 


\section{Datos generales}

Carrera:

Ciclo:

Fecha:

Aula:

Hora:

\section{GUIA DE OBSERVACIÓN}

\begin{tabular}{|c|c|c|c|}
\hline \\
\hline Indicadores & SI & NO & Observaciones \\
\hline $\begin{array}{l}\text { 1. Establece con claridad los objetivos de } \\
\text { la clase }\end{array}$ & & & \\
\hline $\begin{array}{l}\text { 2. Desarrolla la clase de acuerdo a los } \\
\text { Objetivos planteados. }\end{array}$ & & & \\
\hline $\begin{array}{l}\text { 3. Vincula el desarrollo de la clase con } \\
\text { Elementos de la vida diaria. }\end{array}$ & & & \\
\hline $\begin{array}{l}\text { 4. Utiliza los conocimientos previos de sus alumnos en } \\
\text { el desarrollo de sus } \\
\text { Contenidos. }\end{array}$ & & & \\
\hline $\begin{array}{l}\text { 5. Estimula en el alumno el desarrollo de } \\
\text { Habilidades capacidades y competencias. }\end{array}$ & & & \\
\hline $\begin{array}{l}\text { 6. Realiza mediación especialmente con aquellos } \\
\text { que presentan mayores } \\
\text { dificultades }\end{array}$ & & & \\
\hline $\begin{array}{l}\text { 7. Genera y mantiene un ambiente de } \\
\text { trabajo y colaboración. }\end{array}$ & & & \\
\hline $\begin{array}{l}\text { 8. Corrige a los alumnos oportunamente y } \\
\text { con afecto. }\end{array}$ & & & \\
\hline $\begin{array}{l}\text { 9. Hace el cierre de la clase de manera } \\
\text { conjunta ordenando con los alumnos los contenidos } \\
\text { tratados }\end{array}$ & & & \\
\hline 10.Responde las preguntas de los alumnos & & & \\
\hline $\begin{array}{l}\text { 11.Las actividades planteadas permiten el logro del } \\
\text { objetivo en el tiempo establecido }\end{array}$ & & & \\
\hline $\begin{array}{l}\text { 12. Exige que los alumnos reelaboren las } \\
\text { ideas, expresándolas en su propio } \\
\text { vocabulario }\end{array}$ & & & \\
\hline 13. Promueve la expresión oral entre sus alumnos & & & \\
\hline $\begin{array}{l}\text { 14. Promueve la comprensión del significado } \\
\text { a la simple memorización. }\end{array}$ & & & \\
\hline $\begin{array}{l}\text { 15. Promueve la respuesta reflexiva en sus } \\
\text { Alumnos. }\end{array}$ & & & \\
\hline 16. Fomenta el desarrollo de la autoestima & & & \\
\hline $\begin{array}{l}17 \text { Crea condiciones ambientales } \\
\text { adecuadas para el desarrollo de la clase }\end{array}$ & & & \\
\hline 18. Centra al alumno en la tarea & & & \\
\hline $\begin{array}{l}\text { 19. Promueve el uso de diversas técnicas de } \\
\text { organización de la información(resúmenes, esquemas, } \\
\text { mapas } \\
\text { conceptuales) }\end{array}$ & & & \\
\hline 20. Estimula la planificación del trabajo. & & & \\
\hline $\begin{array}{l}\text { 21. Utiliza distintas estrategias para enseñar( clase } \\
\text { expositiva, exposiciones de alumnos, trabajos de } \\
\text { alumnos, trabajo } \\
\text { individual) }\end{array}$ & & & \\
\hline
\end{tabular}

\section{OBSERVACIÓN:}




\section{CUESTIONARIO A ESTUDIANTES}

Objetivo: Conocer el nivel de satisfacción que sienten los estudiantes por la estrategia aprendizaje de la asignatura de Ingles II

\section{Datos generales:}

Carrera:

Ciclo:

Fecha:

Hora:

\begin{tabular}{lllll}
\hline NUNCA & CASI NUNCA & A VECES & $\begin{array}{l}\text { CASI } \\
\text { SIEMPRE }\end{array}$ & SIEMPRE \\
\hline $\mathbf{1}$ & 2 & 3 & 4 & 5
\end{tabular}

\section{Instrucciones:}

Como parte de una investigación que se realiza para la mejora de la enseñanza aprendizaje, necesitamos que colabores con tus criterios los que serán muy útiles para el trabajo que llevamos a cabo. Lee el siguiente cuestionario, y responde con sinceridad cada una de las preguntas, marcando $(X)$ entre las siguientes alternativas:

\begin{tabular}{|c|c|c|c|c|c|c|}
\hline & INDICADORES & 1 & 2 & 3 & 4 & 5 \\
\hline 1 & ¿Consideras importante el contenido de la asignatura de Inglés para ti? & & & & & \\
\hline 2 & $\begin{array}{l}\text { ¿Consideras que los contenidos aprendidos en las clases son importantes } \\
\text { para tu futura profesión? }\end{array}$ & & & & & \\
\hline 3 & ¿El docente demuestra dominio en los temas que desarrolla en las clases? & & & & & \\
\hline 4 & $\begin{array}{l}\text { ¿En la clase se fomenta la participación a través de preguntas, diálogos, } \\
\text { lecturas y comentarios sobre el contenido? }\end{array}$ & & & & & \\
\hline 5 & $\begin{array}{l}\text { ¿En la clase se ponen ejemplos de cómo construir frases, oraciones, } \\
\text { diálogos breves y se enseña la construcción gramatical en inglés? }\end{array}$ & & & & & \\
\hline 6 & $\begin{array}{l}\text { ¿En el desarrollo del contenido se impulsa hacer preguntas, expresar ideas u } \\
\text { otra actividad con vista a estimular la participación de los estudiantes? }\end{array}$ & & & & & \\
\hline 7 & $\begin{array}{l}\text { ¿Al realizar las actividades prácticas; el profesor orienta en el qué hacer, } \\
\text { cómo, para qué y cómo seré evaluado? }\end{array}$ & & & & & \\
\hline 8 & $\begin{array}{l}\text { ¿Al realizar la tarea de aprendizaje reconoce mis logros y me explica cómo } \\
\text { realizar las actividades cuando tengo dificultades? }\end{array}$ & & & & & \\
\hline 9 & ¿El profesor brinda actividades adicionales para mejorar mi fluidez oral? & & & & & \\
\hline 10 & $\begin{array}{l}\text { ¿Durante el desarrollo de la clase pone ejemplos de expresiones en contexto } \\
\text { a la realidad y cómo emplearlas en inglés para comunicarme oralmente? }\end{array}$ & & & & & \\
\hline 11 & $\begin{array}{l}\text { ¿Considero que aprendo mejor cuando realizo actividades en colaboración } \\
\text { con mis compañeros en grupos? }\end{array}$ & & & & & \\
\hline 12 & $\begin{array}{l}\text { ¿El profesor emplea en la clase videos, películas y otros medios para } \\
\text { demostrar cómo escuchar, pronunciar y realizar diálogos orales? }\end{array}$ & & & & & \\
\hline 13 & $\begin{array}{l}\text { ¿Cuándo realizas la actividad de aprendizaje sabes cuando trabajas bien y } \\
\text { cuándo tienes dificultades? }\end{array}$ & & & & & \\
\hline 14 & $\begin{array}{l}\text { ¿Empleas técnicas para iniciar, mantener y terminar un diálogo o una } \\
\text { conversación breve? }\end{array}$ & & & & & \\
\hline 15 & $\begin{array}{l}\text { ¿El docente te orienta aplicar instrumentos y técnicas para evaluar tu } \\
\text { resultado? }\end{array}$ & & & & & \\
\hline 16 & ¿En la clase exponen de forma oral los temas estudiados? & & & & & \\
\hline 17 & ¿El docente aplica diferentes tipos de evaluación? & & & & & \\
\hline 18 & $\begin{array}{l}\text { ¿Después de recibir la evaluación el profesor, realiza actividades por } \\
\text { estudiante para mejorar? }\end{array}$ & & & & & \\
\hline
\end{tabular}




\section{PRUEBA PEDAGÓGICA PARA ESTUDIANTES}

OBJETIVO: Comprobar el nivel de conocimientos teóricos y la competencia comunicativa oral desarrolladas del Inglés en los estudiantes de primer año de una universidad privada de Lima.

\section{DATOS GENERALES:}

Carrera:

Ciclo:

Part $1 \quad 3-4$ minutes (Prompt card activity)

Read the instructions and gives a question card to one candidate and an answer card to the other. After the candidates have asked and answered the questions, they change roles, as in the example below.

Candidate $\mathbf{A}$, there is some information about a skateboarding competition.

Candidate B, you don't know anything about the skateboarding competition, so ask A some questions about it. Now $B$, ask $A$ your questions about the skateboarding competition and $A$, you answer them.

\section{Candidate A - your answers $\quad$ Candidate B - your questions}
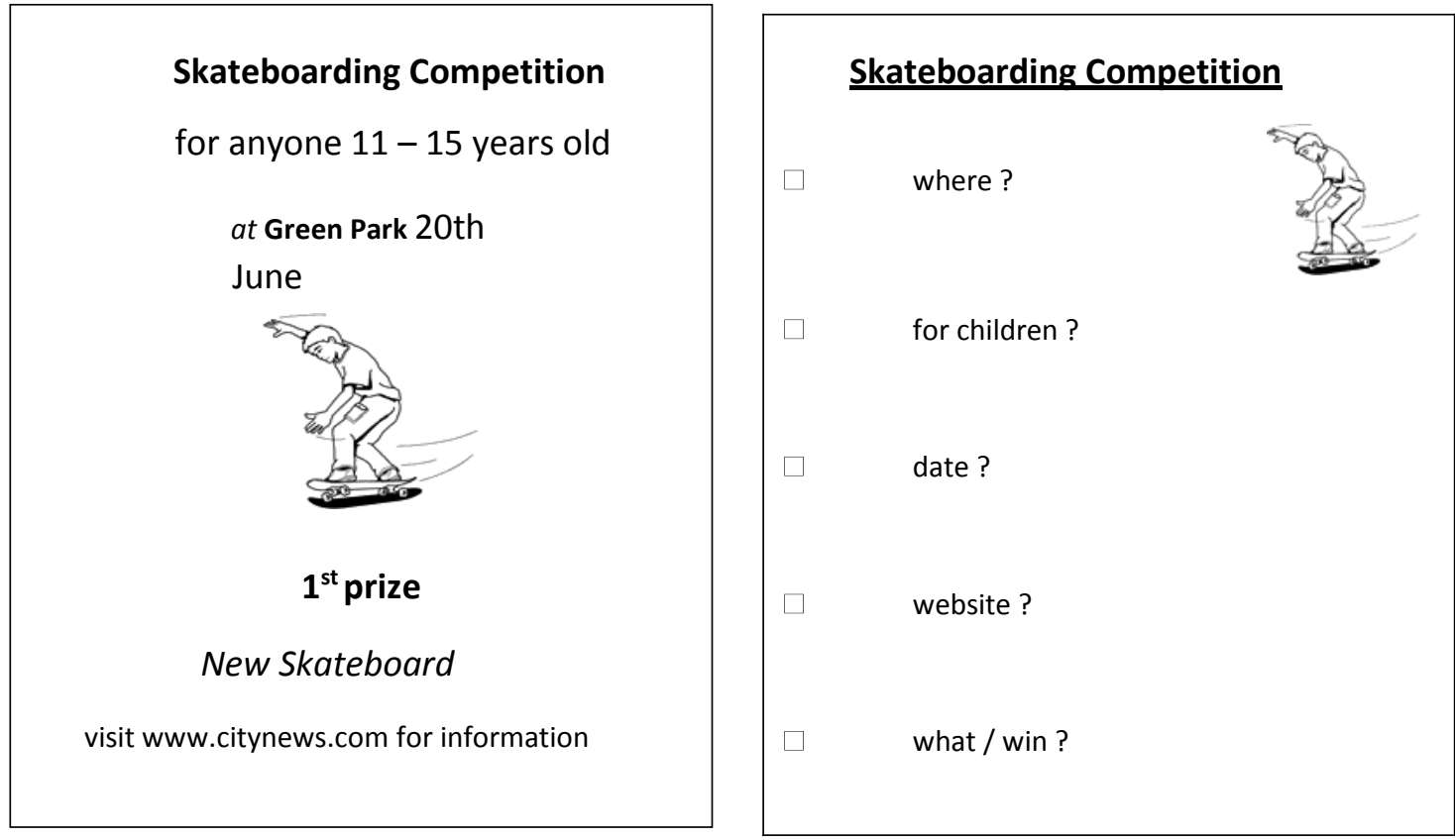

A different set of prompt cards is then given out, so that Candidate $A$ has the opportunity to ask questions and Candidate $B$ to answer them. In this example, the questions are about a theatre school.

Candidate $\mathbf{B}$, here is some information about a theatre school.

Candidate A, you do not know anything about the theatre school, so ask B some questions about it. Now A, ask B your questions about the theatre school and B, you answer them. 


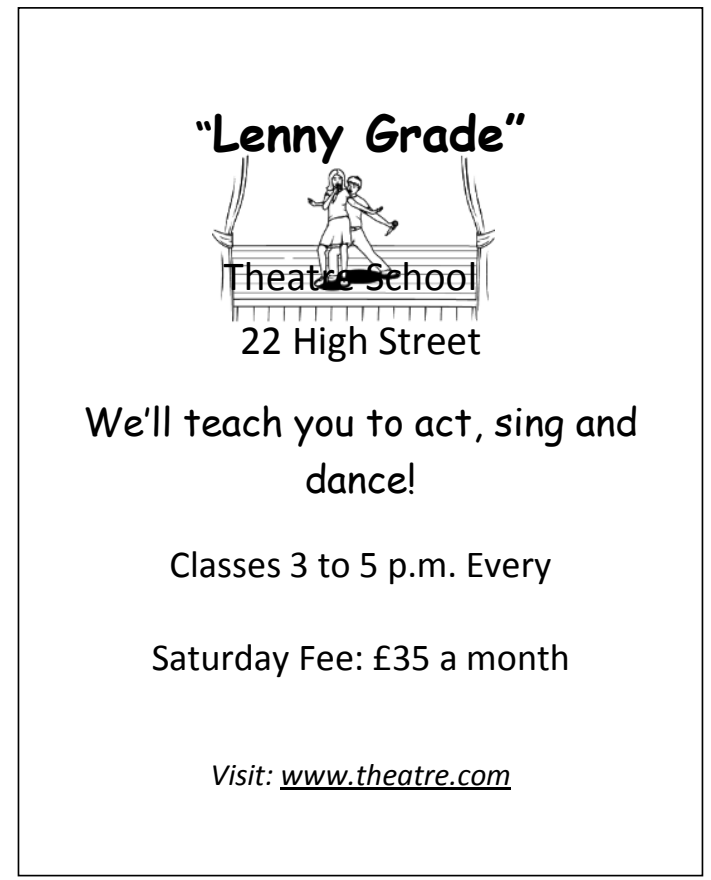

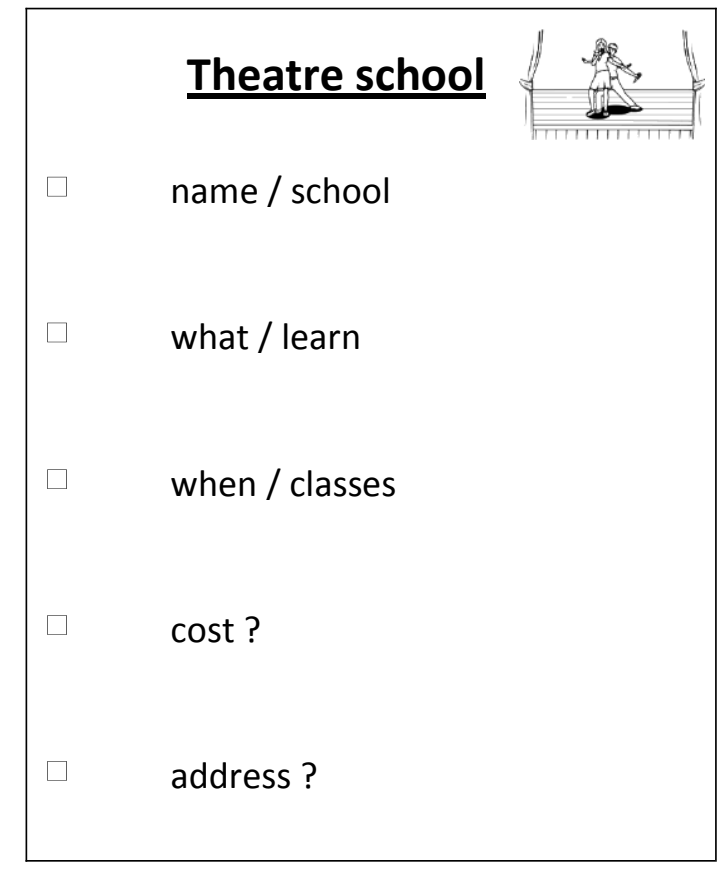

Anexo 4

Fichas de validación de los instrumentos

Observaciones generales del especialista

Aspectos a observar:

1. Pertinencia de las preguntas con los objetivos:

Suficiente: ___ Medianamente Suficiente: ____ Insuficiente:

Para casos en los cuales hay más de un instrumento de recolección de datos, favor usar cuadro, dejando solo en enunciado:

Observaciones:

2. Pertinencia de las preguntas con la(a) categoría(s):

Suficiente: ___ Medianamente Suficiente: ___ Insuficiente:

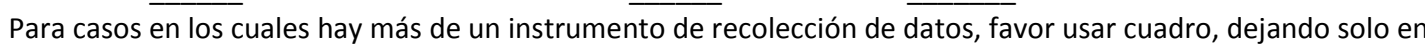
enunciado:

\begin{tabular}{lll}
\hline Instrumentos & Suficiente & $\begin{array}{l}\text { Medianamente } \\
\text { suficiente }\end{array}$
\end{tabular}

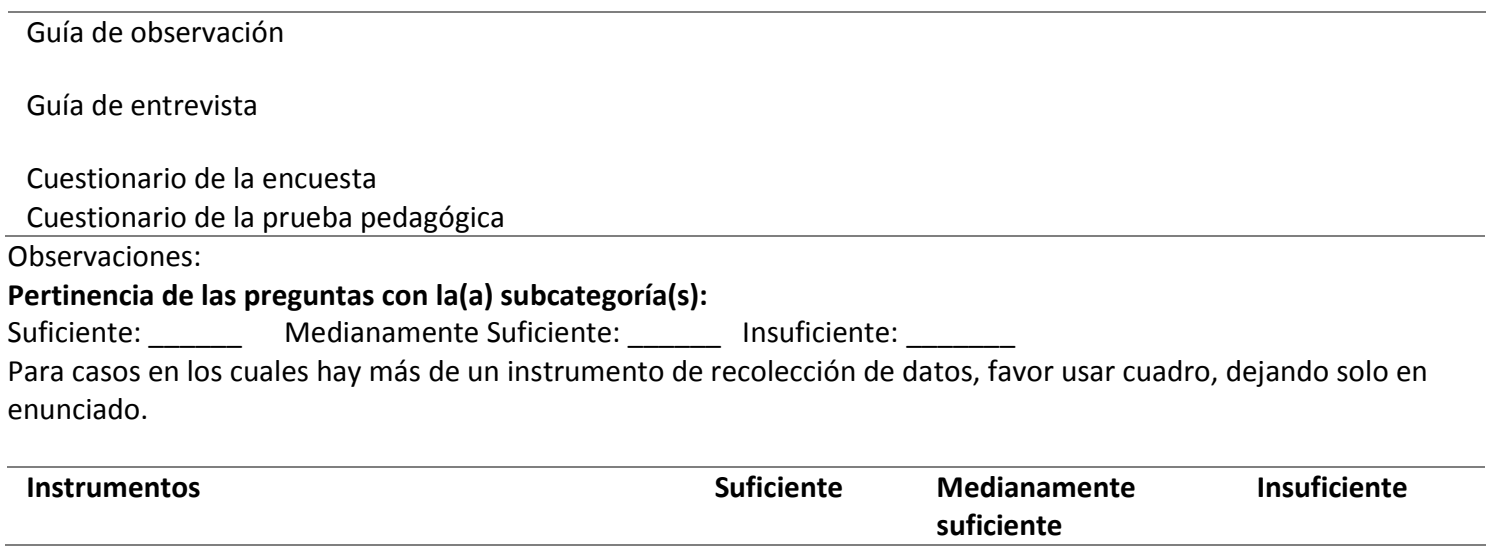


Guía de observación

Guía de entrevista

Cuestionario de la encuesta

Cuestionario de la prueba pedagógica

Observaciones:

Pertinencia de las preguntas con los indicadores:

Suficiente: ___ Medianamente Suficiente:

Insuficiente:

Para casos en los cuales hay más de un instrumento de recolección de datos, favor usar cuadro, dejando solo en enunciado.

\begin{tabular}{|c|c|c|c|}
\hline Instrumentos & Suficiente & $\begin{array}{l}\text { Medianamente } \\
\text { suficiente }\end{array}$ & Insuficiente \\
\hline
\end{tabular}

Guía de observación

Guía de entrevista

Cuestionario de la encuesta

Cuestionario de la prueba pedagógica.

Observaciones:

Redacción de las preguntas:

Adecuada: Inadecuada:

Para casos en los cuales hay más de un instrumento de recolección de datos, favor usar cuadro, dejando solo en enunciado.

Instrumentos

Adecuada

Inadecuada

Guía de observación

Guía de entrevista

Cuestionario de la encuesta

Cuestionario de la prueba pedagógica

Requisitos que reúnen los expertos seleccionados.

\begin{tabular}{|c|c|c|c|c|c|}
\hline $\mathbf{N}^{\circ}$ & Especialista & $\begin{array}{l}\text { Grado } \\
\text { académico }\end{array}$ & Especialidad & $\begin{array}{l}\text { Ocupación } \\
\text { profesional }\end{array}$ & $\begin{array}{l}\text { Años de } \\
\text { experiencia }\end{array}$ \\
\hline E1 & $\begin{array}{l}\text { Hernán Gerardo } \\
\text { Flores Valdiviezo }\end{array}$ & Magister & $\begin{array}{l}\text { Sociólogo } \\
\text { comunicador }\end{array}$ & $\begin{array}{l}\text { Docente } \\
\text { investiaador }\end{array}$ & 40 \\
\hline E2 & $\begin{array}{l}\text { Hugo Montes de } \\
\text { Oca }\end{array}$ & Doctor & $\begin{array}{l}\text { Psicólogo } \\
\text { educativo }\end{array}$ & $\begin{array}{l}\text { Docente } \\
\text { investigador }\end{array}$ & 20 \\
\hline E3 & $\begin{array}{l}\text { José Manuel Muñoz } \\
\text { Salazar }\end{array}$ & Doctor & $\begin{array}{l}\text { Ciencias de la } \\
\text { educación }\end{array}$ & $\begin{array}{l}\text { Docente } \\
\text { investigador }\end{array}$ & 30 \\
\hline
\end{tabular}

Resultados de la validación de los instrumentos.

Pertinencia de las preguntas con los objetivos:

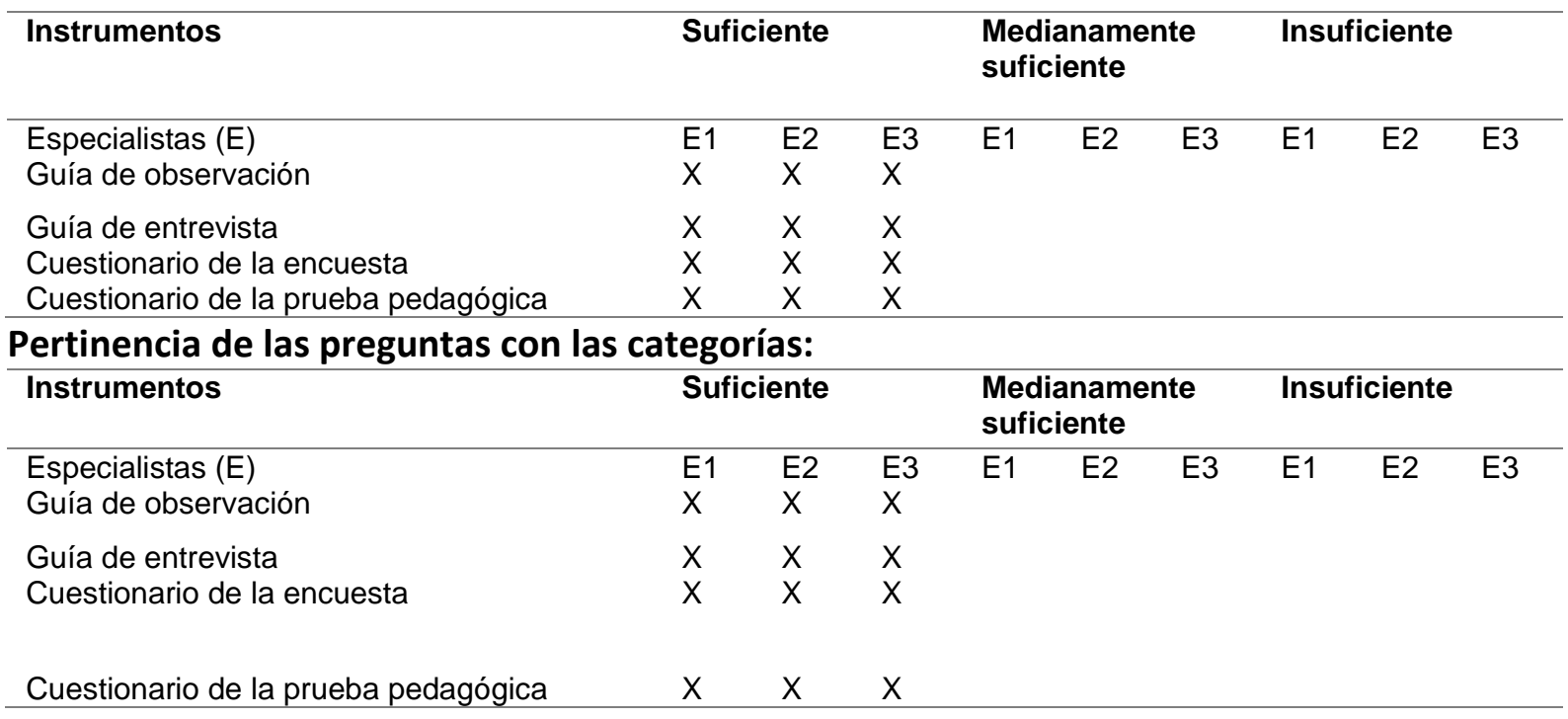


Pertinencia de las preguntas con las subcategorías:

Instrumentos Suficiente

\begin{tabular}{|c|c|c|c|c|c|c|c|c|c|}
\hline \multirow{2}{*}{$\begin{array}{l}\text { Instrumentos } \\
\text { Especialistas (E) } \\
\text { Guía de observación }\end{array}$} & \multicolumn{3}{|c|}{ Suficiente } & \multicolumn{3}{|c|}{$\begin{array}{l}\text { Medianamente } \\
\text { suficiente }\end{array}$} & \multicolumn{3}{|c|}{ Insuficiente } \\
\hline & $\begin{array}{l}E 1 \\
X\end{array}$ & $\begin{array}{l}\text { E2 } \\
X\end{array}$ & $\begin{array}{l}\text { E3 } \\
X\end{array}$ & E1 & E2 & E3 & E1 & E2 & E3 \\
\hline Guía de entrevista & $\mathrm{x}$ & $\mathrm{x}$ & $\mathrm{x}$ & & & & & & \\
\hline Cuestionario de la encuesta & $\mathrm{x}$ & $\mathrm{x}$ & $\mathrm{x}$ & & & & & & \\
\hline Cuestionario de la prueba pedagógica & $\mathrm{x}$ & $\mathrm{x}$ & $\mathrm{x}$ & & & & & & \\
\hline
\end{tabular}

Pertinencia de las preguntas con los indicadores:

\begin{tabular}{llllllllll}
\hline Instrumentos & \multicolumn{3}{c}{ Suficiente } & \multicolumn{4}{c}{$\begin{array}{l}\text { Medianamente } \\
\text { suficiente }\end{array}$} & \multicolumn{3}{c}{ Insuficiente } \\
\hline Especialistas (E) & E1 & E2 & E3 & E1 & E2 & E3 & E1 & E2 & E3 \\
Guía de observación & X & X & X & & & & & & \\
Guía de entrevista & X & X & X & & & & & & \\
Cuestionario de la encuesta & X & X & X & & & & & & \\
Cuestionario de la prueba pedagógica & $\mathrm{X}$ & $\mathrm{X}$ & $\mathrm{X}$ & & & & & & \\
\hline
\end{tabular}

Redacción de las preguntas:

\begin{tabular}{llllllll}
\hline Instrumentos & \multicolumn{2}{c}{ Adecuada } & & \multicolumn{3}{c}{ Inadecuada } & Observaciones \\
\hline Especialistas (E) & E1 & E2 & E3 & E1 & E2 & E3 & \\
Guía de observación & X & X & X & & & & \\
Guía de entrevista & X & X & X & & & & \\
Cuestionario de la encuesta & X & X & X & & & & \\
Cuestionario de la prueba pedagógica & X & X & X & & & & \\
\hline
\end{tabular}




\section{Anexo 5}

TÉCNICA: Entrevista Semiestructurada

Análisis cualitativo de las entrevistas a los docentes

CATEGORÍAS: Competencia comunicativa oral y Estrategia metodológica

PREGUNTA

1. ¿Al respecto podría comentar qué es para usted la competencia comunicativa oral?

2.¿Cuáles son los autores que abordan los fundamentos

teóricos de la

competencia

comunicativa oral?
RESPUESTA/ CITAS TEXTUALES

FRASES CODIFICADAS

\section{K1: Cuando hablamos de competencia} comunicativa oral estamos hablando de aquella

habilidad que desarrolla para poder expresar sus ideas dar un mensaje de acuerdo a un objetivo al propósito que quiere conocer a la persona que lo propósito que quiere conocer a la persona que habilidad que la persona tiene de expresarse en un idioma extranjero y utilizar expresiones un idioma extranjero y utilizar expresiones Vocabulario, la gramática, las expresiones desenvolviendo.

F2: La competencia comunicativa oral es el proceso por el cual el estudiante puede transmit sus ideas oralmente de una manera que el mensaje que traten de transmitir sea recibido de una manera en la que el receptor pueda entenderlo.

13: Es la capacidad de una persona para poder transmitir un mensaje y recibirlo de manera verbal.

B4: Es el resultado de las destrezas productiva en el marco oral como se expresa el usuario básicamente la gramática, el vocabulario,etc. K1: Podemos hablar de Chomsky, podemos hablar también... hay autores que tratan sobre Jeremy Hamer quien habla mucho sobre la competencia comunicativa ora.

B4: El fundamento del Input Output de Noam Chomsky quien impuso la Teoría de la Gramática Chomsky quien imuso la Teria de la Gramática Universa,pues propuso un nuevo paradigma D. $\mathrm{H}$ con la etnografía del habla. entenderlo mensaje y recibirlo de manera verbal

5. resultado de oral.
INSTRUMENTO: Guía de entrevista

\section{CATEGORIAS} ALTERNATIVAS

\section{ANALISIS CUALITATIVO}

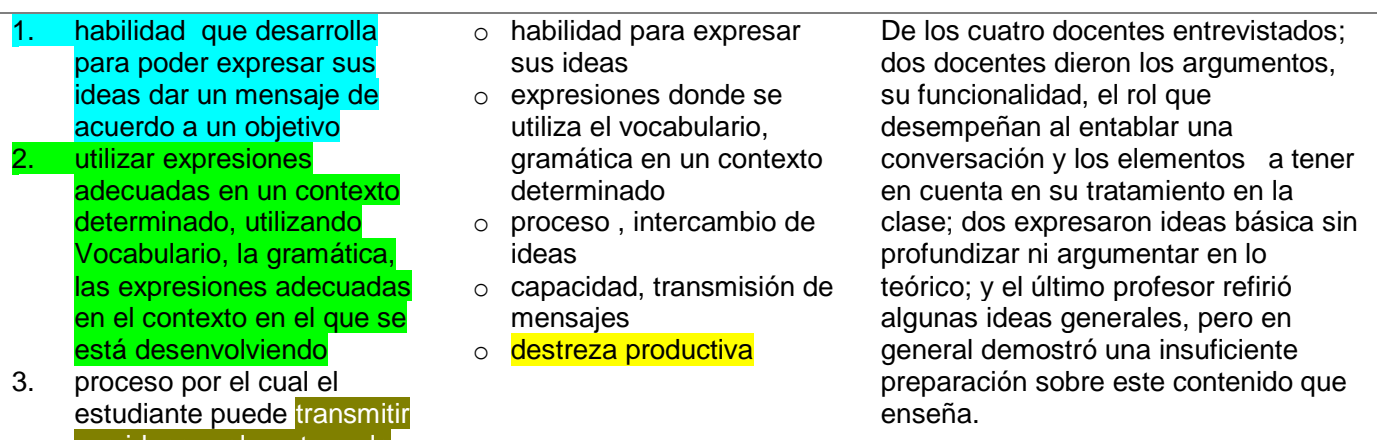

estudiante puede tran sus ideas oralmente en la que el receptor pueda

4. capacidad de una persona para poder transmitir un

resultado de las destrezas
productivas en el marco

1. Chomsky, Jeremy Hamer quien habla mucho sobre la Noam Chomsky competencia comunicativa

- Jeremy Hamer

2. Input Output de Noam Chomsky, Hymes, D. H con la etnografía del habla.
En cuanto a los teóricos de la competencia comunicativa oral, dos nombraron Chomsky y su posición teórica acerca de la gramatical universal y el aporte de Jeremy Hamer sobre los métodos comunicativos; uno se refirió a Dell Hymes sobre el desarrollo de la etnografía del habla; y desarrollo de la etnografia de
los dos restantes reflejaron desactualización y falta de preparación teórica, siendo un aspecto 


\begin{tabular}{|c|c|c|c|c|c|}
\hline $\begin{array}{l}\text { 3. ¿Qué } \\
\text { subcompetencias } \\
\text { abarca la competencia } \\
\text { comunicativa oral? }\end{array}$ & $\begin{array}{l}\text { K1: La fluidez, discourse managment (gestión del } \\
\text { discurso), entonación, pronunciación. } \\
\text { F2: Se puede distinguir la competencia léxica y } \\
\text { pragmático que a su vez se encuentran el factor } \\
\text { sociolingüístico y gramatical. } \\
\text { I3: Yo pienso que para adquirir la competencia } \\
\text { comunicativa oral hay que saber escuchar y } \\
\text { también saber elaborar un mensaje }\end{array}$ & $\begin{array}{l}\text { 1. La fluidez, discourse } \\
\text { managment (gestión del } \\
\text { discurso), } \\
\text { 2. la competencia léxica y } \\
\text { pragmático } \\
\text { el factor sociolingüístico y } \\
\text { gramatical } \\
\text { 3. Saber escuchar y elaborar } \\
\text { 4. un mensaje }\end{array}$ & & $\begin{array}{l}\text { La fluidez, gestión } \\
\text { del discurso } \\
\text { Factor pragmático y } \\
\text { sociolingüístico } \\
\text { Producción oral } \\
\text { Precisión y fluidez }\end{array}$ & $\begin{array}{l}\text { Acerca a esta pregunta, los cuatro } \\
\text { docentes concordaron en resaltar la } \\
\text { fluidez, entonación, pronunciación; } \\
\text { uno de ellos diferenció la competencia } \\
\text { léxica y la pragmática como factores } \\
\text { esenciales a nivel sociolingüístico y } \\
\text { gramatical en la activación del } \\
\text { pensamiento y la elaboración del } \\
\text { mensaje oral o escrito por el hablante. }\end{array}$ \\
\hline & B4: La precisión en el habla, fluidez básicamente. & & & & \\
\hline $\begin{array}{l}\text { 5. ¿Qué importancia } \\
\text { tiene para usted } \\
\text { atender la } \\
\text { comprensión como } \\
\text { parte de la } \\
\text { competencia oral? }\end{array}$ & $\begin{array}{l}\text { K1: Ah .. bueno es la parte principal de la parte } \\
\text { comunicativa... pues le permite al alumno que va } \\
\text { a decir , saber que va a decir en el acto } \\
\text { comunicativo. } \\
\text { F2: Es de suma importancia porque lo que busca } \\
\text { un docente es que el estudiante pueda transmitir } \\
\text { sus ideas de manera oral y sobretodo la } \\
\text { comprensión auditiva cumple un rol fundamental } \\
\text { en este proceso que no debe ser vertical por esa } \\
\text { razón los estudiantes deben hablar bien deben } \\
\text { transmitir su mensaje y entender el mensaje de los } \\
\text { demás. } \\
\text { B4: Muy importante pues a falta de esta no podrá } \\
\text { producir. }\end{array}$ & $\begin{array}{l}\text { 1. le permite al alumno que va } \\
\text { a decir, saber que va a } \\
\text { decir en el acto } \\
\text { comunicativo. } \\
\text { transmitir sus ideas, } \\
\text { 2. comprensión auditiva y } \\
\text { entender el mensaje de los } \\
\text { demás. } \\
\text { 3. Entendimiento del mensaje }\end{array}$ & & $\begin{array}{ll}\circ \quad \text { Argumentación del } \\
\text { discurso, ideas u } \\
\text { opiniones } \\
\text { Comprensión } \\
\text { auditiva, producción } \\
\text { oral, } \\
\text { Entender el mensaje }\end{array}$ & $\begin{array}{l}\text { En relación a esta pregunta, tres } \\
\text { docentes resaltaron su valor en el } \\
\text { dominio de la lengua, puesto que debe } \\
\text { establecer la relación entre el plano } \\
\text { sonoro y su representación léxico- } \\
\text { semántico para que entienda lo } \\
\text { escuchado y pueda producir sus } \\
\text { ideas; indican que si fueran orientados } \\
\text { bien, se motivarían, asimilarían y } \\
\text { aprenderían sin mucho esfuerzo al } \\
\text { enfatizarles en el qué hacer, cómo } \\
\text { escuchar, analizar, comprender el } \\
\text { sentido de las frases, las oraciones y } \\
\text { en general los mensajes construido; } \\
\text { los tres destacaron el peso que tiene } \\
\text { la comprensión auditiva en la } \\
\text { comprensión de las ideas poder } \\
\text { expresarse sobre el tema tratado en el } \\
\text { discurso. }\end{array}$ \\
\hline $\begin{array}{l}\text { 6. ¿Qué enfoques } \\
\text { teóricos y didácticas } \\
\text { conoce que estimulan } \\
\text { el desarrollo de la } \\
\text { competencia } \\
\text { comunicativa oral en } \\
\text { la enseñanza- } \\
\text { aprendizaje del Inglés } \\
\text { como segunda lengua } \\
\text { ? }\end{array}$ & $\begin{array}{l}\text { K1: EI CLL "Community language learning" } \\
\text { (Aprendizaje comunitario de idiomas) y el } \\
\text { communicative approach (Enfoque comunicativo). }\end{array}$ & $\begin{array}{l}\text { EI CLL "Community language } \\
\text { learning" y el communicative } \\
\text { approach }\end{array}$ & 0 & $\begin{array}{l}\text { Insuficiente actualización } \\
\text { teorica }\end{array}$ & $\begin{array}{l}\text { Solo un docente fundamentó } \\
\text { mencionando a Community language } \\
\text { learning (CLL) como el marco de } \\
\text { aprendizaje comunitario de idiomas a } \\
\text { la inversa; en general se constató } \\
\text { desconocimiento y desactualización } \\
\text { en los docentes al no aportar ninguna } \\
\text { idea. }\end{array}$ \\
\hline
\end{tabular}




\begin{tabular}{|c|c|c|c|c|c|c|}
\hline $\begin{array}{l}\text { 7. ¿ Cómo usted logra } \\
\text { interesar y motivar a } \\
\text { los estudiantes en las } \\
\text { clases para que se } \\
\text { comuniquen, den } \\
\text { opiniones, puntos de } \\
\text { vista, reflexionen, } \\
\text { critiquen y valoren en } \\
\text { la.... }\end{array}$ & $\begin{array}{l}\text { K1: Bueno es importante conocer al grupo } \\
\text { primero, hay grupos mucho más sencillo de llegar } \\
\text { y hay otros que no...pero hay que saber identificar } \\
\text { el punto de interés de los alumnos para tratar de } \\
\text { coger temas de su realidad de acuerdo a la edad } \\
\text { que tiene. también se puede coger por ejemplo } \\
\text { algunos recursos tales como canciones donde se } \\
\text { puede jalar el tema principal y de allí generar un } \\
\text { ejercicio o una actividad comunicativa. } \\
\text { F2: Obviamente tratando de hacer lo que es el } \\
\text { conflicto cognitivo que para nosotros es elaborar } \\
\text { una pregunta o generar una inquietud/ duda en el } \\
\text { alumno para que este empiece a tratar de } \\
\text { descubrir o conversar con los demás sobre cierto } \\
\text { punto o tema y luego profundizar como docentes } \\
\text { en el área donde estamos generando el conflicto } \\
\text { para que estos tengan un aprendizaje significativo } \\
\text { y que puedan utilizarlo comunicándose. } \\
\text { I3: Empezando por la comunicación en el mundo } \\
\text { de hoy ,ahora estamos hablando de la } \\
\text { comunicación verbal y la no verbal cuando } \\
\text { elaboramos un mensaje } 30 \% \text { de este es verbal y } \\
\text { el otro } 70 \% \text { es lenguaje corporal, es todo un } \\
\text { conjunto que emite un mensaje. Se les habla de la } \\
\text { importancia de saber comunicar o saber expresar } \\
\text { porque siempre estamos comunicando consciente } \\
\text { o inconscientemente y si lo hacemos de manera } \\
\text { consciente debemos que estar seguros de aquello } \\
\text { que realmente queremos transmitir. } \\
\text { B4: Mediante la sugestopedia para que se sientan } \\
\text { más cómodos, el trato con ellos, una buena } \\
\text { comunicación o un feeling con los estudiantes con } \\
\text { el fin de construir confianza al momento que se } \\
\text { comuniquen libremente porque generalmente ellos } \\
\text { están pendientes de los errores que puedan } \\
\text { cometer mas que producir pero siempre se debe } \\
\text { tener en cuenta los niveles de producción. }\end{array}$ & 1. & $\begin{array}{l}\text { conocer al grupo primero, } \\
\text { identificar el punto de } \\
\text { interés y generar una } \\
\text { actividad comunicativa. } \\
\text { Unir conflicto cognitivo para } \\
\text { generar aprendizaje } \\
\text { significativo (exteriorizarlo) } \\
\text { comunicándose. } \\
\text { comunicación verbal y la no } \\
\text { verbal } \\
\text { la sugestopedia una buena } \\
\text { comunicación o un feeling } \\
\text { con los estudiantes con el } \\
\text { fin de construir confianza }\end{array}$ & ० & $\begin{array}{l}\text { Conocer el grupo } \\
\text { estudiantil. } \\
\text { Aplicación de generar } \\
\text { conflicto cognitivo } \\
\text { Utilización de los } \\
\text { recursos lingüísticos } \\
\text { Empleo de método } \\
\text { acelerado en idiomas } \\
\text { construir confianza }\end{array}$ & $\begin{array}{l}\text { Respecto a esta pregunta, un docente } \\
\text { expresó que es necesario identificar } \\
\text { el punto de interés y generar las } \\
\text { actividades comunicativas variadas y } \\
\text { atractivas; dos puntualizaron desde } \\
\text { un enfoque funcional el aprendizaje } \\
\text { significativo empleando un sistema de } \\
\text { preguntas; y dos agregaron el papel la } \\
\text { sugestopedia a fin de estimular la } \\
\text { comunicación libre y conocer el nivel } \\
\text { de producción del estudiante. }\end{array}$ \\
\hline $\begin{array}{l}9 . ¿ \text { Cree usted que en } \\
\text { la enseñanza de } \\
\text { idiomas se deben } \\
\text { utilizar variados } \\
\text { medios audiovisuales? } \\
\text { Fundamente }\end{array}$ & $\begin{array}{l}\text { K1: La parte visual es muy importante para el } \\
\text { alumno, le ayuda a entender mucho mas lo que se } \\
\text { quiere expresar, le da aparte motivación, les da la } \\
\text { oportunidad de crear curiosidad haciéndoles } \\
\text { reflexionar que vayan mas alla del tema a tocar. }\end{array}$ & & $\begin{array}{l}\text { motivación, les da la } \\
\text { oportunidad } \\
\text { reflexionar } \\
\text { pronunciación, la } \\
\text { naturalidad, el ritmo, la } \\
\text { cadencia del receptor }\end{array}$ & & $\begin{array}{l}\text { Generar curiosidad/ } \\
\text { facilidad de capturar } \\
\text { el interés } \\
\text { Identificar los estilos } \\
\text { de aprendizaje }\end{array}$ & $\begin{array}{l}\text { Sobre esta pregunta, los cuatro } \\
\text { docentes concordaron sobre el rol } \\
\text { importantísimo que cumple los medios } \\
\text { audiovisuales en el proceso de } \\
\text { enseñanza aprendizaje puesto que se }\end{array}$ \\
\hline
\end{tabular}




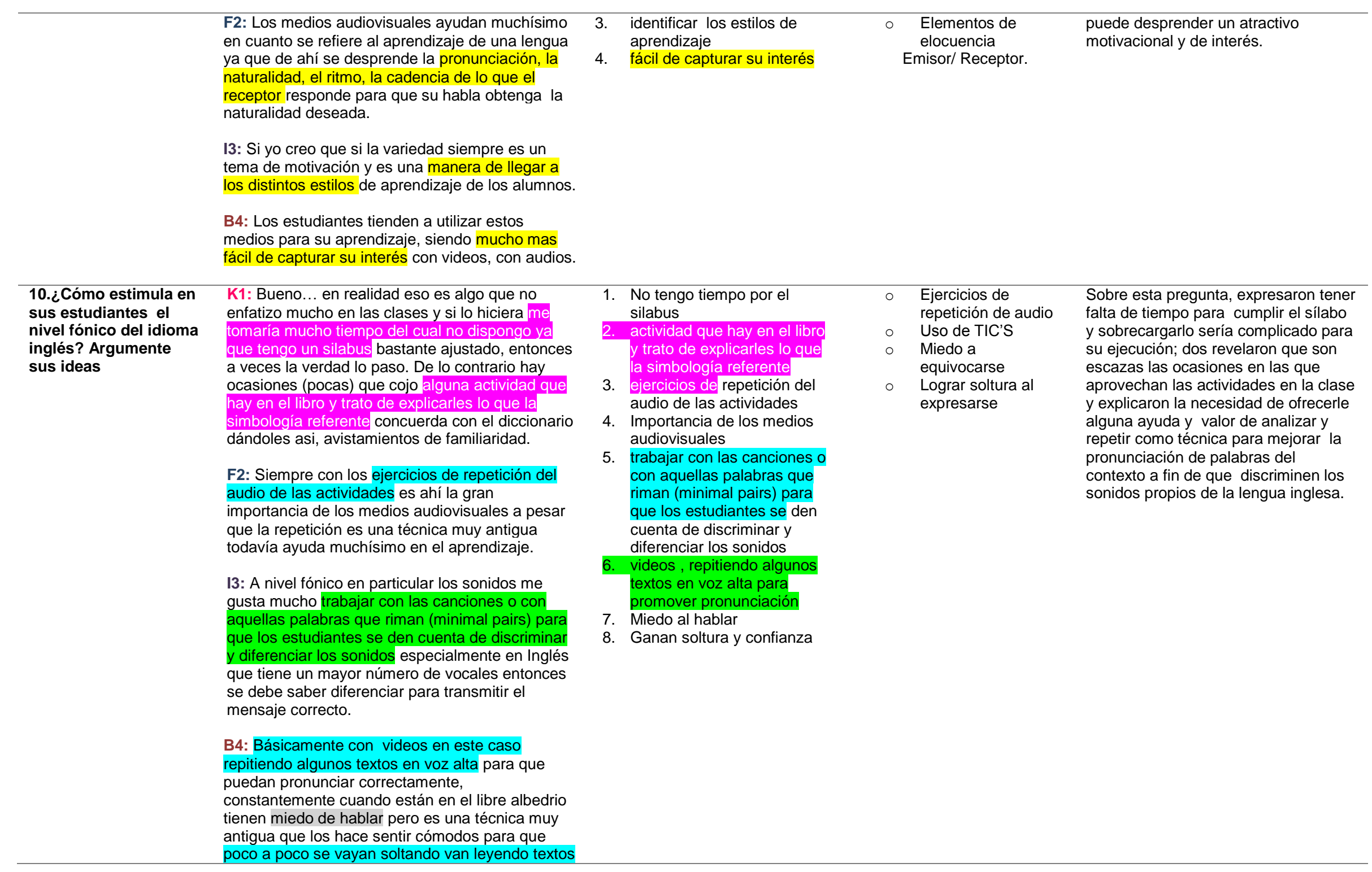


cortos en voz alta van agarrando confianza saben que sus compañeros van a prestar atención y si que sus companeros van a prestar atenci momento o duesués ya que se repiten de forma indirecta.

\section{1. ¿ Qué tratamiento le brinda usted a los estudiantes que presentan distintos niveles de desarrollo las habilidades comunicativas?}

\section{$\mathrm{K} 1:$ A ellos hay que darles material extra \\ escribirle lo que tiene que decir, de repente con \\ iguras o antes de la clase decirles que revisen \\ ección utilizando el método del Flipped \\ Classroom (Aula Invertida) con aquellos}

estudiantes que presentan un nivel de rendimiento bajo.
F2: Juntar a aquellos que presentan dificultades con algunos que ya han desarrollado esta competencia de manera satisfactoria para que competencia de manera salisfactoria para que estos puedan consultarles en lo posible con el fin de alcanzar lo requerido pero si noto que persiste la dificultad es ahi donde intervengo realizando actividades en donde puedan participar y practicar para que lleguen a cumplir el logro establecido en cada clase teniendo en cuenta las

recomendaciones previas ligadas a las asesorías o tutorías para mejorar la parte donde tienen falencias.

13: Creo que un tema muy importante es que el rse siendo asi de suma importancia la observación del docente pero la otra es poder promover la docente pero la otra es poder promover la con decirte "no estoy "ntendiendo lo que me estas comunicando" o "no logro comunicar lo que deseo" es un tema de confianza y sobre todo de motivación de lograr acercarse al alumno hacerle comprender que el proceso de

pero es a través de estos que vamos llegar al éxito que necesitamos y que el silencio no nos favorece en nada porque yo puedo asumir que sabe o que no sabe. Entonces es un tema de desarrollar

cierta empatía de acercarnos como docentes de ver como ellos captan ... algo que trato al menos her con ellos en cada inicio de ciclo es hacer con ello por si solos hagan una especie de autoevaluacion
1. darles material extra,

escribirle lo que tiene que

decir, de repente con

figuras método del Flipped

Juntar a aquellos que

presentan dificultades con

algunos que ya han

desarrollado esta

competencia

3. actividades en donde puedan participar y practicar para que lleguen a cumplir el logro

establecido

4. el alumno tenga confianza para comunicarse

5. la comunicación pu ede sufrir interferencias y errores

6. desarrollar cierta empatía

. Reconocin

aprendizaj

8. Ayuda al docente

conocerlos mas y evitar

percepción equivocada

9. confianza en construir vocabulario obtener nivel de comunicación

fros capture vision " $y$ puedan crear textos pequeños 0 artículos de internet
Respecto al tratamiento que dan a las habilidades comunicativas, un docente mencionó que las estrategias

utilizadas se basan en el

reforzamiento y la práctica, el empleo del método de Flipped Classroom (Aula invertida) es lo ideal en aquellos casos y el diálogo; mientras dos destacaron el aspecto emocional para lograr confianza para comunicarse con facilidad y evitar el silencio en su discurso.
Reconocer estilo de aprendizaje por

parte del estudiante

Construcción solida del léxico para

Evitar interferencias y errores 


\begin{tabular}{|c|c|c|c|c|c|}
\hline & $\begin{array}{l}\text { aprendizaje para poder expresarse, determinado } \\
\text { su porcentaje de auditivos, visuales, kinestésico } \\
\text { para que me ayuden a enfocar lo que quiero } \\
\text { transmitirles de acuerdo a sus intereses, } \\
\text { necesidades y sus características. Lo cual me } \\
\text { ayudado muchísimo en el tema de la } \\
\text { comunicación ya que ellos no solamente se } \\
\text { autoevalúan sino que se conocen mas y me } \\
\text { ayudan a conocerlos mucho mas rápido y en caso } \\
\text { tenga una percepción equivocada. } \\
\text { B4: Primero tener confianza en construir } \\
\text { vocabulario lo cual es fundamental para que } \\
\text { puedan tener cierto nivel de comunicación en el } \\
\text { aspecto gramático y estructural ... siempre en } \\
\text { clase lamentablemente porque ellos están en } \\
\text { constante contacto con su lengua materna, el } \\
\text { objetivo es que obtengan la confianza aun asi se } \\
\text { equivoquen ya sea viendo videos mediante el } \\
\text { sistema" fros capture vision "y puedan crear } \\
\text { textos pequeños o artículos de internet de sus } \\
\text { temas favoritos como tecnología, moda textos muy } \\
\text { breves }\end{array}$ & & & & \\
\hline $\begin{array}{l}\text { 12. - ¿ Qué importancia } \\
\text { tiene el método de } \\
\text { trabajo en grupo para } \\
\text { los estudiantes de } \\
\text { Inglés y por qué? }\end{array}$ & $\begin{array}{l}\text { 13: El trabajo en grupo tiende a desarrollar varias } \\
\text { habilidades primero tenemos el tema colaborativo } \\
\text { en específico la distribución de funciones, la } \\
\text { responsabilidad y secuencia no solo la parte } \\
\text { procedimental sino la actitudinal, que es en sí } \\
\text { como se mueve el mundo entonces si podemos } \\
\text { lograr que el alumno comprenda, entienda } \\
\text { aplicando ciertas estrategias para comunicarse y } \\
\text { aprenda de el y de los demás, estamos hablando } \\
\text { por ejemplo en una prueba a pequeña escala de } \\
\text { lo que se puede lograr en la comunidad para } \\
\text { hacer un efecto multiplicador que en nuestro país } \\
\text { necesita. Es por esa razón que la necesidad de } \\
\text { desarrollar esta habilidad comunicativa y el trabajo } \\
\text { colaborativo implica un tema de aceptación, } \\
\text { tolerancia, de valores que hace mucha falta. } \\
\text { B4: Es muy importante para que los estudiantes } \\
\text { puedan interactuar en el speaking utilizando los } \\
\text { trabajos en parejas o en grupo }\end{array}$ & $\begin{array}{ll}\text { 1. } & \text { tema colaborativo en } \\
\text { específico la distribución de } \\
\text { funciones, la } \\
\text { responsabilidad y secuencia } \\
\text { no solo la parte } \\
\text { procedimental sino la } \\
\text { actitudinal } \\
\text { 2. Lograr que el alumno } \\
\text { aplique estrategias } \\
\text { comunicativas } \\
\text { 3. } \quad \begin{array}{l}\text { el trabajo colaborativo } \\
\text { implica un tema de }\end{array} \\
\text { aceptación, tolerancia, de } \\
\text { valores los estudiantes } \\
\text { puedan interactuar en el } \\
\text { speaking utilizando los } \\
\text { trabajos en parejas o en } \\
\text { grupo }\end{array}$ & $\begin{array}{l}\circ \\
0 \\
\circ \\
\circ \\
\circ\end{array}$ & $\begin{array}{l}\text { Distribución de } \\
\text { funciones } \\
\text { Secuencia } \\
\text { procedimental y } \\
\text { actitudinal } \\
\text { Aplicación de } \\
\text { estrategias } \\
\text { comunicativas } \\
\text { Establecer valores } \\
\text { (aceptación, } \\
\text { tolerancia) } \\
\text { Lograr la interacción } \\
\text { genuina }\end{array}$ & $\begin{array}{l}\text { Al indagar sobre el rol del trabajo en } \\
\text { grupo, los entrevistados resaltaron un } \\
\text { gran valor para desarrollar habilidades } \\
\text { orales, de responsabilidad, actitudinal } \\
\text { siguiendo un tema y facilitando así la } \\
\text { comunicación oral y para aprenden de } \\
\text { sus compañeros; dos subrayaron la } \\
\text { función social en la interacción } \\
\text { continua que se alcanza en los } \\
\text { trabajos grupales manteniéndose la } \\
\text { aceptación, tolerancia y de valores. }\end{array}$ \\
\hline $\begin{array}{l}\text { 13. ¿Qué } \\
\text { características debe } \\
\text { tener la actividad de } \\
\text { aprendizaje para lograr }\end{array}$ & $\begin{array}{l}\text { K1: La actividad a realizar debe ser ni tan fácil ni } \\
\text { tan complicado debe ser challeging (desafiante), } \\
\text { es un poco ver la edad del alumno para que haya } \\
\text { un interés significativo conectando asi su }\end{array}$ & $\begin{array}{l}\text { 1. debe ser challeging } \\
\text { (desafiante } \\
\text { un interés significativo }\end{array}$ & & $\begin{array}{l}\text { Desafiante y de } \\
\text { interés significativo } \\
\text { Aprendizaje } \\
\text { significativo }\end{array}$ & $\begin{array}{l}\text { Al respecto solo un docente mencionó } \\
\text { que las estrategias utilizadas se basan } \\
\text { en el reforzamiento y la práctica, el } \\
\text { empleo del método de Flipped }\end{array}$ \\
\hline
\end{tabular}




\begin{tabular}{|c|c|c|c|c|c|}
\hline $\begin{array}{l}\text { interés en los } \\
\text { estudiantes por } \\
\text { aprender el contenido } \\
\text { y desarrollar las } \\
\text { habilidades orales en } \\
\text { la clase? }\end{array}$ & $\begin{array}{l}\text { aprendizaje con los temas que es de su gusto } \\
\text { para que pueda hacerles más sencillo encontrar } \\
\text { las palabras y finalmente expresarse } \\
\text { adecuadamente. }\end{array}$ & $\begin{array}{l}\text { 2. } \\
\text { lonectar su aprendizaje con } \\
\text { 3. Lograr con facilididad } \\
\text { expresarse adecuadamente }\end{array}$ & 0 & $\begin{array}{l}\text { Facilitar la expresión } \\
\text { oral }\end{array}$ & $\begin{array}{l}\text { Classroom (Aula invertida) es lo ideal } \\
\text { en aquellos casos y el diálogo; } \\
\text { mientras dos destacaron el aspecto } \\
\text { emocional para lograr confianza para } \\
\text { comunicarse con facilidad y evitar el } \\
\text { silencio en su discurso. }\end{array}$ \\
\hline $\begin{array}{l}\text { 14. ¿Qué estrategias } \\
\text { de aprendizaje } \\
\text { emplean sus } \\
\text { estudiantes para } \\
\text { iniciar y concluir la } \\
\text { exposición de un tema } \\
\text { en la clase? }\end{array}$ & $\begin{array}{l}\text { I3: Pero básicamente trabajamos en actividades } \\
\text { que van de carácter individual o de parejas } \\
\text { manteniéndose con una naturaleza más } \\
\text { comunicativa en una esfera más reducida por } \\
\text { cuestiones de tiempo. Volviendo a tu pregunta al } \\
\text { iniciar algún proyecto los estudiantes necesitan } \\
\text { haber desarrollado la confianza que ayuda mucho } \\
\text { para que se pregunten "como es que deben hacer } \\
\text { las cosas?" realmente estén seguros de lo que } \\
\text { esperamos de ellos y entiendan las rubricas de } \\
\text { evaluación a usar de inicio hasta el final de } \\
\text { trabajo, al momento de ello me agrada que traten } \\
\text { de cerciorarse o tratan de preguntar confirmando y } \\
\text { para eso está también la labor del maestro en } \\
\text { corroborar que se está cumpliendo el mensaje } \\
\text { correcto de lo que se espera del estudiante de un } \\
\text { inicio y al final el estudiante llega a consolidar la } \\
\text { importancia de la actividad ... no es que se } \\
\text { plantea la actividad porque se le ocurrió al } \\
\text { profesor o que está de moda, hay una razón } \\
\text { detrás de toda actividad siendo esta metodológica } \\
\text { que de repente se puede ver bastante lúdica o en } \\
\text { algún momento "chacotera" podemos llegar a ese } \\
\text { punto midiendo mucho con el fin de que el } \\
\text { estudiante se de cuente que todo tiene una } \\
\text { funcionalidad sabiendo cuando empieza, } \\
\text { 1. en donde esta y cuando ya va a terminar que } \\
\text { le ayude a medir su tiempo sin necesidad de } \\
\text { ver el tiempo } \\
\text { 2. se sienta motivado en un ambiente } \\
\text { familiarizado, relajado para desenvolverse y } \\
\text { fluyan las ideas distinguiendo un volumen } \\
\text { determinado en distintos casos ya se en la } \\
\text { timidez de un ss que debe elevar su voz en o } \\
\text { en el contexto en el que se maneje. } \\
\text { 3. La proyección de voz te die mucho del } \\
\text { mensaje que quieres transmitir. }\end{array}$ & $\begin{array}{l}\text { 1. estén seguros de lo } \\
\text { que esperamos de ellos } \\
2 . \quad \text { entiendan las rubricas } \\
\text { de evaluación a usar de inicio } \\
\text { hasta el final de trabajo } \\
\text { 3. el estudiante se de } \\
\text { cuente que las actividades } \\
\text { tiene una funcionalidad } \\
\text { |medir su tiempo } \\
\text { |desenvolverse y fluyan las } \\
\text { ideas distinguiendo un volumen } \\
\text { determinado } \\
\text { | proyección de voz }\end{array}$ & 0 & $\begin{array}{l}\text { Establecer los } \\
\text { objetivos planteados } \\
\text { Comprender su } \\
\text { evaluación } \\
\text { Funcionalidad de las } \\
\text { actividades } \\
\text { Elementos que } \\
\text { alimenten su } \\
\text { discurso }\end{array}$ & $\begin{array}{l}\text { Respecto a esta pregunta, dos } \\
\text { explicaron lo significativo que puede } \\
\text { ser para el ponente cuando termina la } \\
\text { presentación de la misma manera en } \\
\text { que la empezó, da firmeza durante el } \\
\text { discurso y ayuda al a entender la } \\
\text { exposición con su desenvolvimiento a } \\
\text { fin de influir en las ideas, proyección } \\
\text { de voz adecuada, aunque los } \\
\text { docentes restantes no contestaron de } \\
\text { forma concreta. }\end{array}$ \\
\hline $\begin{array}{l}\text { 15. ¿Cómo valora el } \\
\text { desarrollo del } \\
\text { vocabulario de sus } \\
\text { estudiantes y qué }\end{array}$ & $\begin{array}{l}\text { K1: Es muy importante el desarrollo del } \\
\text { vocabulario porque les da seguridad en el } \\
\text { momento de expresarse. Este tema en particular } \\
\text { es bastante delicado, se debe trabajar con juegos, }\end{array}$ & $\begin{array}{l}\text { 1. el desarrollo del vocabulario } \\
\text { porque les da seguridad en } \\
\text { el momento de expresarse } \\
\text { trabajar con juegos, }\end{array}$ & O & $\begin{array}{l}\text { Brinda seguridad al } \\
\text { estudiante } \\
\text { Interiorizar lo } \\
\text { aprendido }\end{array}$ & $\begin{array}{l}\text { De los cuatro entrevistados, dos } \\
\text { explicaron lo significativo que puede } \\
\text { ser para el ponente cuando termina la } \\
\text { presentación de la misma manera en }\end{array}$ \\
\hline
\end{tabular}


actividades realiza para su desarrollo?

dinámicas o también se puede utilizar plataformas como Kahoot, Pedlet, Mentimeter

generan divers

F2: Nosotros tenemos que ver que el alumno

produzca a nivel oral, y como docentes tenemos

que estar pendientes en el enriquecimiento de su

vocabulario clase tras clase, si el estudiante utiliza el léxico que se le provee significa que este

interiorizo lo aprendido.

16. ¿¿Cómo estimula la K1: Al finalizar cada clase usualmente les pongo metacognición y el

autocontrol en los estudiantes?

una figura que los hace reflexionar sobre el

proceso de aprendizaje en que se encuentran, enfatizo su lado kinestésico con el fin de que

evalúen su desempeño como preguntándose que

hicieron o que no hicieron para completar su

aprendizaje y mejorar ante esa situación.

F2:Al final de cada clase nosotros les tratamos de

hacer ver que es lo que han aprendido en la clase

formulándoles una pregunta que los lleve a

cuestionarse si pueden hacer esto, entonces ellos

están evaluando si han logrado formar las

oraciones o estructuras gramaticales ya

previamente previsto de las herramientas

facilitadas.

13: Desde que llegamos a la sesión de clase el logro esperado ya estamos hablando de metacognición porque el alumno tiene que darse cuenta que nivel esta y eso va detrás de las preguntas. Que es lo estábamos planteando al

inicio que es lo que me falta, en que camino estoy de 1 al 5 en donde te ubicas, y luego que le de 1 al 5 en donde te ubicas, y luego que le gustaría que el docente refuerce y su vez que realmente tu le estás hablando, pidiendo dando todo lo que necesita para aprender y cuando este no pone de su parte. Lo que se quiere como finalidad es lograr una autonomía por parte de ellos eso va por empezar a leer y seguir las indicaciones

B4: Se tiene que realizar un análisis por parte del docente si los estudiantes han comprendido no generalmente en una prueba sino se les cambia e dinámicas Kahoot, Pedlet, Mentimeter entre otros que generan diversión y significancia

2. produccion a nivel ora

enriquecimiento de su

interiorizar lo aprendido.

1. hace reflexionar sobre $\mathrm{e}$ proceso de aprendizaje

enfatizo su lado kinestésico

preguntándose que hicieron o que no hicieron

2. tratamos de hacer ver que han aprendido en la clase lleve a cuestionarse si pueden hacer esto

.

el logro esperado darse

cuenta el nivel planteando

al inicio que es lo que me falta, en que

camino estoy

4. reforzar al ss y lograr una autonomía de ellos

5. creando una situación

cotidiana para obtener una respuesta automática y espontanea
- Producción certera

de su nivel oral

Enriquecimiento lexico

efectiva

Lograr autonomía

de estudiantes

Reconocimien

- Obtener respuesta

espontanea y

automática

contexto que la empezó, da firmeza durante el discurso y ayuda al a entender la

exposición con su desenvolvimiento a fin de influir en las ideas, proyección de voz adecuada, aunque los

docentes restantes no contestaron de forma concreta.

Respecto a esta pregunta, los entrevistados nombraron diversas técnicas para realizarlo, ayudan aprendizaje, hacen preguntarse para saber qué lograron y qué necesitan saber que lograron y qué necesitan puedan intar puedan interactuar en una situación comunicativa cotidiana y asi conseguir una respuesta espontanea que ayuda al desarrollo de la oralidad. 
tema e indirectamente les voy preguntando cosas que estén asociadas a tema que hemos tratado como por ejemplo creando una situación cotidiana para obtener una respuesta automática y

\section{7. - ¿ Cómo lleva a cabo el proceso de evaluación de los conocimientos, las habilidades orales de los estudiantes en la clase?}

K1: En la universidad en este nivel utilizamos el KET (Key English Test) entonces con ellos se maneja sus promedios basados en este examen.

F2: Aquí tenemos diversos tipos de evaluación basados en instrumentos de la universidad de Cambridge que son probados a nive internacional.

13: Explico las rubricas dando ejemplos, también utilizo la retroalimentación, si bien es cierto llego una escala de evaluación pero tengo indicadores mientras voy monitoreando sin interferir y sin meterme dentro de su conversación o trabajo meterme dentro de su conversación o trabajo lo observo y de manera muy general hablarles y decirles los errores que cometieron sin nombrar a alguien en específico porque si no hablan no hay manera que sepa de a situación actual del grupo. Yo siempre enfatizo la frase si quieres que te ayude comunícate, habla, exprésate y

fundamentalmente equivócate.

B4: La institución utiliza las pruebas predeterminadas con formato estandarizado por universidades internacionales pero aparte uso rubricas con sus respectivos indicadores y lo detenidamente su producción individual detenidamente su producción individual y lamentablemente este último no ingresa en e puntaje.
1. KET (Key English Test)

evaluación basados en

instrumentos de la

universidad de Cambridge

3. las rubricas ,

retroalimentación

escala de evaluación pero

tengo indicadores

4. monitorea sin interferir y $\sin$ meterme de manera muy general hablarles y decirles general hablarles y decirles
los errores

5. los errores

indicadores y lo siguiente es circular con ellas

escuchando detenidamente su producción individual y evaluando la interacción con los demás

6. pruebas predeterminadas con formato estandarizad por universidades

internacionales

7. Interacción no ingresa en la evaluación
- pruebas

predeterminadas

con formato

estandarizado por

universidades internacionales

- Utilización de

rubricas

- Monitoreo individual

Escala de

evaluación
Respecto a esta pregunta, los

docentes coincidieron en menciona sobre tipo de evaluación con

instrumentos probados y certificados por la universidad de Cambridge, lo cual revela la validez en el proceso porque usan las rúbricas con sus respectivos indicadores y

seguidamente la explicación de estas 'por los alumnos, pero no precisaron nada de la evaluación integral. 


\section{Anexo 6}

Resultados del análisis de la encuesta a los estudiantes

Tabla 8 ¿Consideras importante el contenido de la asignatura de Inglés para ti?

\begin{tabular}{|c|c|c|c|c|c|}
\hline & \multirow{3}{*}{$\begin{array}{l}\text { A veces } \\
\text { Siempre }\end{array}$} & Frecuencia & Porcentaje & $\begin{array}{c}\text { Porcentaje } \\
\text { válido }\end{array}$ & $\begin{array}{l}\text { Porcentaje } \\
\text { acumulado }\end{array}$ \\
\hline \multirow[t]{3}{*}{ Válido } & & $\begin{array}{r}1 \\
\end{array}$ & 6,7 & 6,7 & 6,7 \\
\hline & & 14 & 93,3 & 93,3 & 100,0 \\
\hline & Total & 15 & 100,0 & 100,0 & \\
\hline
\end{tabular}

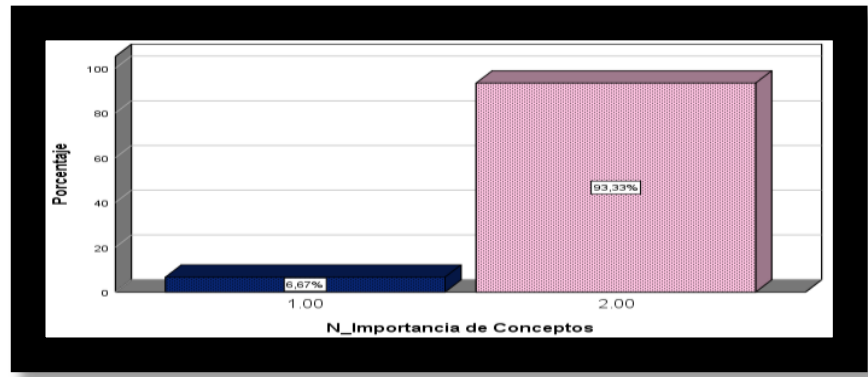

Tabla 9

Fuente: elaboración propia

¿En la clase se fomenta la participación a través de preguntas, diálogos, lecturas y comentarios sobre el contenido?

\begin{tabular}{lll|l|l|l} 
& & & & & \\
& & Frecuencia & Porcentaje & $\begin{array}{l}\text { Porcentaje } \\
\text { acumulado }\end{array}$ \\
\hline Válido & & 1 & 6,7 & 6,7 & 6,7 \\
\cline { 2 - 6 } & válido & 13,3 & 20,0 \\
\cline { 2 - 6 } & A veces & 2 & 13,3 & 80,0 & 100,0 \\
\hline & Siempre & 12 & 80,0 & 100,0 & \\
\hline
\end{tabular}

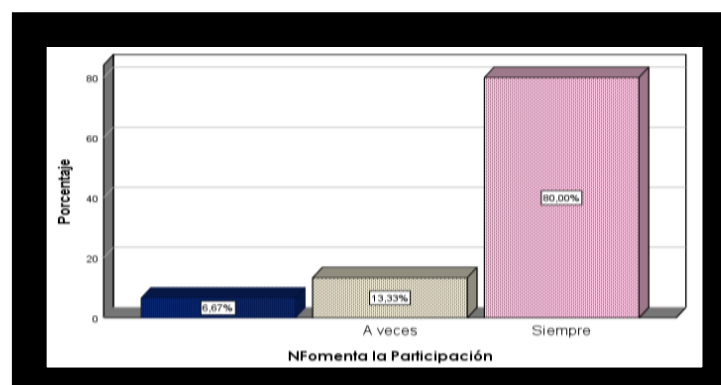

Tabla 10

Fuente: elaboración propia

¿Al realizar las actividades prácticas; el profesor orienta en el qué hacer, cómo, para qué y cómo seré evaluado?

\begin{tabular}{|c|c|c|c|c|c|}
\hline & & Frecuencia & Porcentaje & $\begin{array}{l}\text { Porcentaje } \\
\text { válido }\end{array}$ & $\begin{array}{l}\text { Porcentaje } \\
\text { acumulado }\end{array}$ \\
\hline \multirow[t]{2}{*}{ Válido } & & 4 & 26,7 & 26,7 & 26,7 \\
\hline & A veces & 1 & 6,7 & 6,7 & 33,3 \\
\hline
\end{tabular}




\begin{tabular}{l|l|l|l|l}
\hline Siempre & 10 & 66,7 & 66,7 & 100,0 \\
\hline Total & 15 & 100,0 & 100,0 & \\
\hline
\end{tabular}

Tabla 11

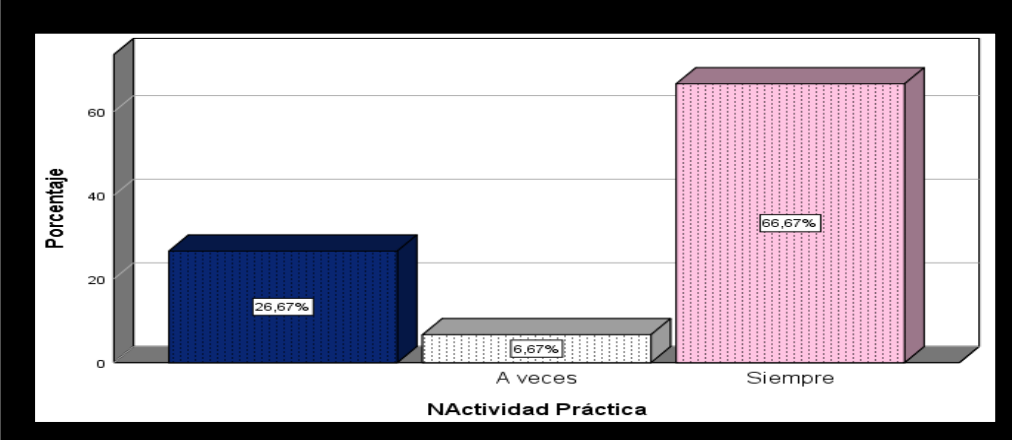

Fuente: elaboración propia.

¿Empleas técnicas para iniciar, mantener y terminar un diálogo o una conversación breve?

\begin{tabular}{|c|c|c|c|c|c|}
\hline & & Frecuencia & Porcentaje & $\begin{array}{l}\text { Porcentaje } \\
\text { válido }\end{array}$ & $\begin{array}{l}\text { Porcentaje } \\
\text { acumulado }\end{array}$ \\
\hline \multirow[t]{4}{*}{ Válido } & Casi nunca & 2 & 13,3 & 13,3 & 13,3 \\
\hline & A veces & 1 & 6,7 & 6,7 & 20,0 \\
\hline & Siempre & 12 & 80,0 & 80,0 & 100,0 \\
\hline & Total & 15 & 100,0 & 100,0 & \\
\hline
\end{tabular}

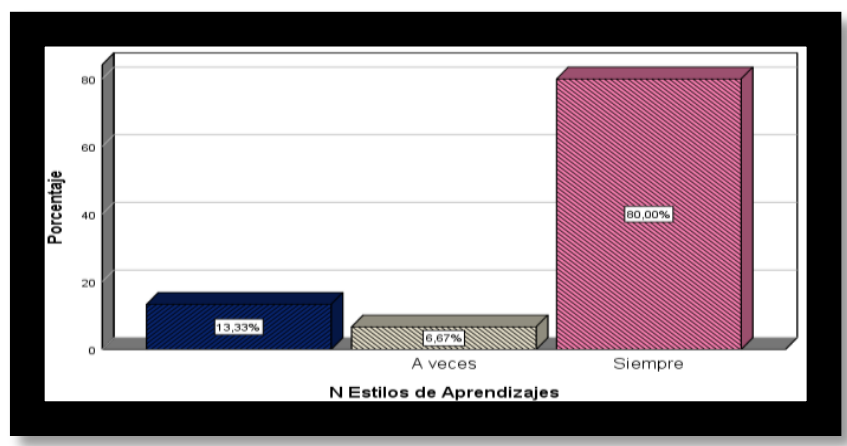

Fuente: elaboración propia

Tabla 12

¿El docente aplica diferentes tipos de evaluación?

\begin{tabular}{|c|c|c|c|c|c|}
\hline & & Frecuencia & Porcentaje & $\begin{array}{c}\text { Porcentaje } \\
\text { válido }\end{array}$ & $\begin{array}{l}\text { Porcentaje } \\
\text { acumulado }\end{array}$ \\
\hline \multirow[t]{4}{*}{ Válido } & & 5 & 33,3 & 33,3 & 33,3 \\
\hline & A veces & 1 & 6,7 & 6,7 & 40,0 \\
\hline & Siempre & 9 & 60,0 & 60,0 & 100,0 \\
\hline & Total & 15 & 100,0 & 100,0 & \\
\hline
\end{tabular}




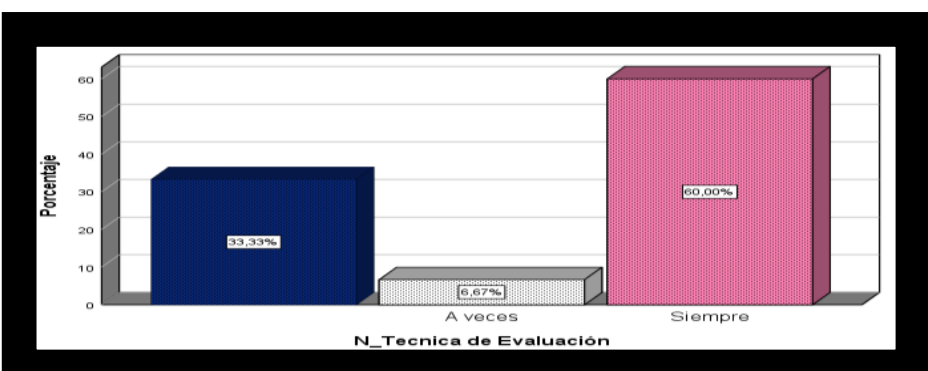

Fuente: elaboración propia

Tabla 13

¿El profesor emplea en la clase videos, películas y otros medios para demostrar cómo escuchar, pronunciar y realizar diálogos orales?

\begin{tabular}{lll|l|l|l} 
& & Frecuencia & Porcentaje & $\begin{array}{l}\text { Porcentaje } \\
\text { válido }\end{array}$ & $\begin{array}{l}\text { Porcentaje } \\
\text { acumulado }\end{array}$ \\
\hline Válido & 1 & 6,7 & 6,7 & 6,7 \\
\cline { 2 - 6 } & A veces & 4 & 26,7 & 26,7 & 33,3 \\
\cline { 2 - 6 } & Siempre & 10 & 66,7 & 66,7 & 100,0 \\
\cline { 2 - 6 } & Total & 15 & 100,0 & 100,0 & \\
\hline
\end{tabular}

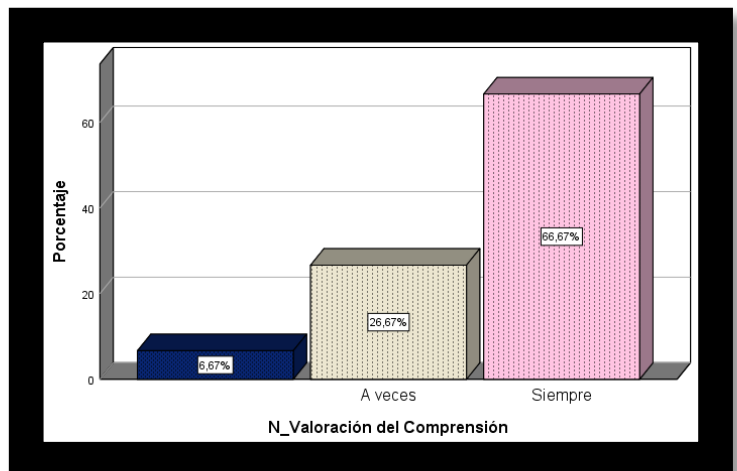

Fuente: elaboración propia.

Anexo 7

Resultados del análisis de la prueba pedagógica

Tabla 14

Destrezas Lingüísticas

\begin{tabular}{|c|c|c|c|c|c|}
\hline & & Frecuencia & Porcentaje & $\begin{array}{l}\text { Porcentaje } \\
\text { válido }\end{array}$ & $\begin{array}{l}\text { Porcentaje } \\
\text { acumulado }\end{array}$ \\
\hline \multirow[t]{4}{*}{ Válido } & Pobre & 2 & 14,3 & 14,3 & 14,3 \\
\hline & Insuficiente & 10 & 71,4 & 71,4 & 85,7 \\
\hline & Aceptable & 2 & 14,3 & 14,3 & 100,0 \\
\hline & Total & 14 & 100,0 & 100,0 & \\
\hline
\end{tabular}




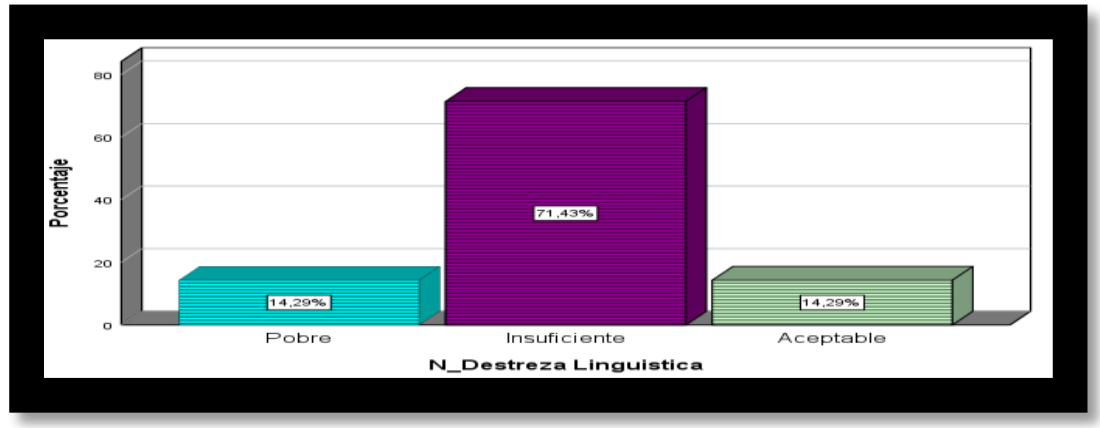

Fuente: elaboración propia

Tabla 15

Destrezas Funcionales

\begin{tabular}{|c|c|c|c|c|c|}
\hline & & Frecuencia & Porcentaje & $\begin{array}{l}\text { Porcentaje } \\
\text { válido }\end{array}$ & $\begin{array}{l}\text { Porcentaje } \\
\text { acumulado }\end{array}$ \\
\hline \multirow[t]{4}{*}{ Válido } & Pobre & 4 & 28,6 & 28,6 & 28,6 \\
\hline & Insuficiente & 8 & 57,1 & 57,1 & 85,7 \\
\hline & Aceptable & 2 & 14,3 & 14,3 & 100,0 \\
\hline & Total & 14 & 100,0 & 100,0 & \\
\hline
\end{tabular}

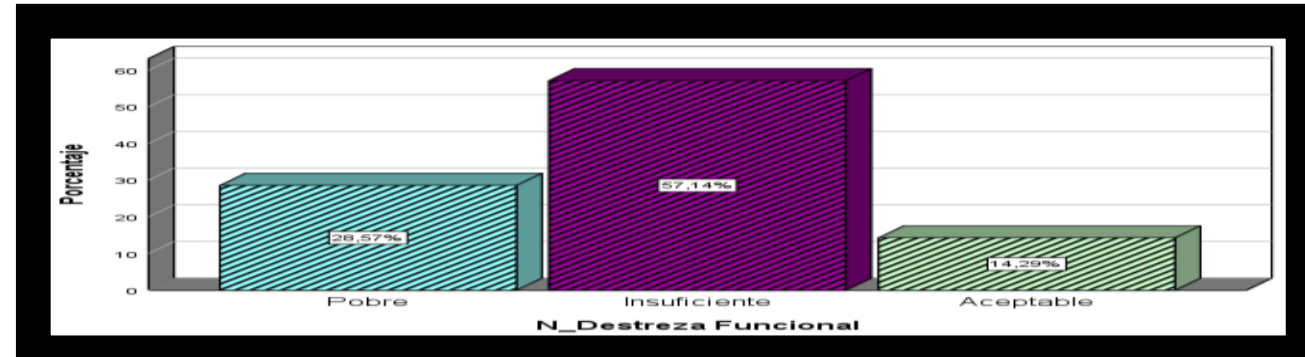

Fuente: elaboración propia 


\section{Anexo 8}

\section{Sesiones de Aprendizaje 1}

\begin{tabular}{|c|c|c|c|}
\hline \begin{tabular}{l|l} 
Escuela: Negocios Internacionales \\
Docente: & Asignatura: Inglés 2 \\
Susan Cubas & \\
\end{tabular} & Año I & Unidad No.: 01 & Fecha: \\
\hline \multicolumn{4}{|c|}{ Tema: El día a día } \\
\hline \multicolumn{4}{|c|}{$\begin{array}{l}\text { Competencia } \\
\text { Comunica de forma oral y escrita actividades y rutinas, propias o de otras culturas, en tiempo presente con coherencia y cohesión; siendo un emisor y receptor } \\
\text { respetuoso; y actuando de forma pertinente. }\end{array}$} \\
\hline \multicolumn{4}{|c|}{$\begin{array}{l}\text { Capacidades } \\
\text { - Adecúa, organiza y desarrolla la información, en presente simple, para expresarse de forma oral o escrita sobre actividades y rutinas, con corrección lingüística, } \\
\text { coherencia y cohesión. } \\
\text { - Interactúa estratégicamente con distintos interlocutores, haciendo uso de gestos, movimientos corporales y contacto visual para enfatizar lo que dice. }\end{array}$} \\
\hline \multicolumn{4}{|c|}{$\begin{array}{l}\text { Indicadores de logro } \\
\text { - Redacta con corrección gramatical, coherencia y coherencia; se expresa con buena pronunciación y entonación en presente simple, empleando diferentes } \\
\text { estrategias para hacerse entender si es el caso y participando con entusiasmo. }\end{array}$} \\
\hline $\begin{array}{l}\text { - Expositivo-explicativo } \\
\text { - Conversacional } \\
\text { - Basado en el trabajo de los estudiantes }\end{array}$ & $\begin{array}{l}\text { Estrategias de comunicación } \\
\text { - Estrategias de expresión } \\
\text { - Estrategias de comprensión } \\
\text { - Estrategias de interacción } \\
\text { Estrategias de enseñanza-aprendizaje: } \\
\text { - Lluvia de ideas } \\
\text { - Preguntas exploratorias } \\
\text { - Organizador visual } \\
\text { - Cuadro sinóptico }\end{array}$ & \multicolumn{2}{|c|}{$\begin{array}{l}\text { Recursos } \\
\text { - Textos seleccionados } \\
\text { - Videos } \\
\text { - Computadora/software/medios de proyección }\end{array}$} \\
\hline \multicolumn{4}{|l|}{ Secuencia didáctica } \\
\hline 1. Motivación $\left(12^{\prime}\right)$ & 2. Conocimientos previos (5') & \multicolumn{2}{|c|}{ 3. Situación problémica (2’) } \\
\hline $\begin{array}{l}\text { Observan un video donde una o más personas } \\
\text { realizan diferentes actividades durante el día. } \\
\text { Luego, se realizan algunas preguntas } \\
\text { exploratorias: } \\
\text { ¿Dónde están? ¿Hacia dónde van? } \\
\text { ¿Qué hacen? }\end{array}$ & $\begin{array}{l}\text { Se pregunta a los estudiantes que hacen } \\
\text { ellos durante el día y responden a través de } \\
\text { una lluvia de ideas. }\end{array}$ & \multicolumn{2}{|c|}{$\begin{array}{l}\text { Se les pide que imaginen que están casados y con hijos y luego } \\
\text { redactan un texto respondiendo a la pregunta ¿cuál es mi rutina o } \\
\text { actividad diaria? }\end{array}$} \\
\hline \multirow{2}{*}{$\begin{array}{l}\text { 4. Construcción de significados (10') } \\
\text { A través de un organizador visual se pregunta } \\
\text { y explica ¿qué es una rutina? ¿con qué } \\
\text { frecuencia una actividad se considera rutina? }\end{array}$} & 5. Organización del conocimiento. (30’) & \multicolumn{2}{|c|}{ 6. Aplicación de los conocimientos (40’) } \\
\hline & $\begin{array}{l}\text { A través de un cuadro sinóptico se explica: } \\
\text { Una rutina: involucra acciones como } \\
\text { levantarse, vestirse, entre otro. }\end{array}$ & $\begin{array}{l}\text { 1. Redactan su } \\
\text { palabras) } \\
\text { 2. Se desplazan } \\
\text { sobre su rutina }\end{array}$ & $\begin{array}{l}\text { uación problémica. (mínimo } 50 \\
\text { gen a un compañero y le preguntan }\end{array}$ \\
\hline
\end{tabular}




\begin{tabular}{|c|c|c|}
\hline $\begin{array}{l}\text { ¿qué tiempo verbal se debe utilizar en estos } \\
\text { casos? }\end{array}$ & $\begin{array}{l}\text { Una rutina. Emplea el tiempo presente } \\
\text { simple: } \\
\text { - I get up, She gets up, etc. } \\
\text { - Verbos Auxiliares Do/Does para preguntas. } \\
\text { - Verbos auxiliares para hacer oraciones } \\
\text { negativas Don't/Doesn't. } \\
\text { - Adverbios de frecuencia: sometimes, } \\
\text { never, usually, often, always. } \\
\text { Pronunciación } \\
\text { - Diferenciación de los sonidos fonéticos /s/, } \\
\text { /z/, /Iz/, /ð/, /@/ } \\
\text { Redacción } \\
\text { - Uso de conectores: and, or, first, then, after, } \\
\text { finally, para dar cohesión al texto } \\
\text { Durante este proceso, se realiza una } \\
\text { constante constatación de la comprensión de } \\
\text { la explicación a través de preguntas o } \\
\text { aclaraciones que parten del docente o de los } \\
\text { estudiantes. }\end{array}$ & $\begin{array}{l}\text { 3. Apoyándose en sus notas, informan de manera oral a todos tus } \\
\text { compañeros su rutina; luego, mencionan la rutina de su compañero y } \\
\text { preguntan de quién está hablando, los demás tienen que adivinar. } \\
\text { 4. En parejas, organizan un diálogo sobre el tema, dándole un } \\
\text { contexto y lo presentan delante de sus compañeros. Se les recuerda } \\
\text { utilizar el lenguaje no verbal para demostrar satisfacción, molestia, y } \\
\text { otras emociones y sentimientos. } \\
\text { Durante este proceso, el docente se moviliza constantemente por el } \\
\text { aula para absolver dudas o hacer aclaraciones. }\end{array}$ \\
\hline 7. Evaluación (40’) & 8. Tarea & Observaciones \\
\hline $\begin{array}{l}\text { 1. Durante la aplicación de los conocimientos, } \\
\text { se realizan evaluaciones orales individuales o } \\
\text { en pareja a través de una Lista de cotejo. } \\
\text { 2. Al final de la sesión se tomará una Prueba } \\
\text { escrita objetiva sobre los conocimientos y } \\
\text { habilidades adquiridas. } \\
\text { 3. Las redacción escrita durante el proceso se } \\
\text { evaluará con una Rúbrica } \\
\text { 4. Ficha de autoevaluación, al término de la } \\
\text { sesión para que evalúen su desempeño } \\
\text { 5. Ficha de coevaluación, aplicada después del } \\
\text { trabajo en parejas } \\
\text { Metacognición: } \\
\text { 1. Ficha de metacognición que incluye las } \\
\text { preguntas: ¿qué aprendí? ¿para qué lo } \\
\text { aprendí? ¿cómo lo aprendí? } \\
\text { En base a las respuestas, se les hace } \\
\text { reflexionar sobre propios procesos de } \\
\text { aprendizaje. } \\
\text { Retroalimentación: }\end{array}$ & $\begin{array}{l}\text { Para la próxima clase, redactan, como } \\
\text { familia, qué rutinas realizan.(Máx. } 50 \\
\text { palabras) }\end{array}$ & \\
\hline
\end{tabular}




\section{Sesión de aprendizaje Nro. 2}

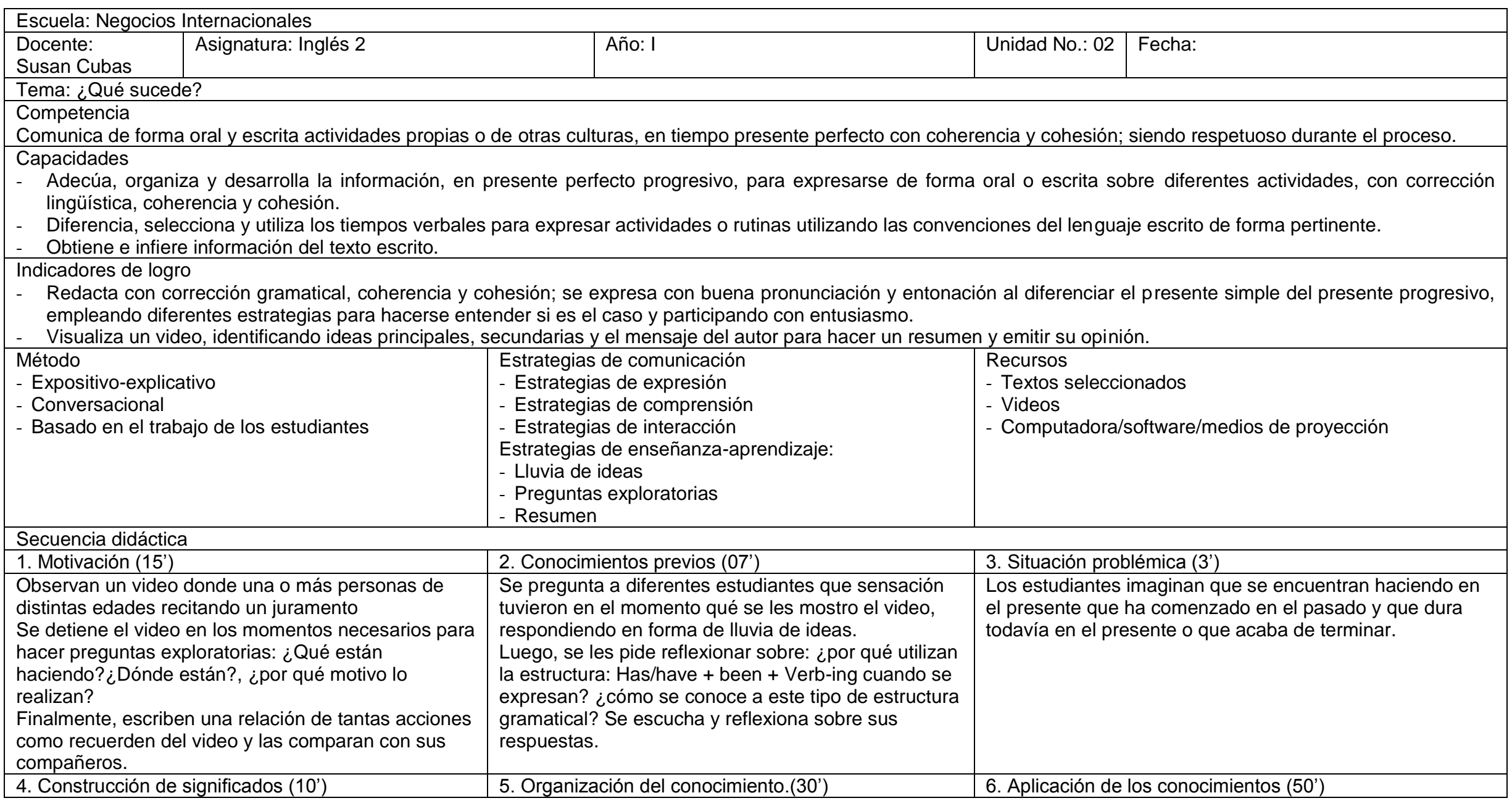




\begin{tabular}{|c|c|c|}
\hline $\begin{array}{l}\text { A través de diferentes ejemplos, se les pide a los } \\
\text { estudiantes de forma oral que seleccionen la } \\
\text { estructura correcta que debe emplearse: Presente } \\
\text { perfecto o Presente perfecto progresivo, expresando } \\
\text { oralmente la razón de su elección. }\end{array}$ & $\begin{array}{l}\text { A través de cuadro sinóptico, se les pide a los } \\
\text { estudiantes que mencionen cuándo se utiliza el } \\
\text { presente perfecto progresivo (se agrega la } \\
\text { información que ellos no conozcan), cuál es su } \\
\text { estructura y expresiones de tiempo, brindando los } \\
\text { ejemplos a su misma vez. } \\
\text { A través de un cuadro comparativo se les pide hacer } \\
\text { una comparación entre el presente perfecto y el } \\
\text { presente perfecto progresivo, con sus ejemplos. } \\
\text { Pronunciación } \\
\text { - Diferenciación de los sonidos fonéticos: -ing ending; } \\
\text { lai/, /ei/ } \\
\text { Redacción } \\
\text { - Uso de conectores: and, or, while, because para dar } \\
\text { cohesión al texto } \\
\text { Durante este proceso, se realiza la constatación de la } \\
\text { comprensión de la explicación a través de preguntas } \\
\text { que parten del docente o de los estudiantes. }\end{array}$ & $\begin{array}{l}\text { 1. De forma grupal analizaran el juramento mostrado con el } \\
\text { fin de realizar uno propio } \\
\text { 2. Apoyándose en sus notas, informan de manera oral a } \\
\text { todos sus compañeros sus ideas; luego, mencionan y } \\
\text { organizan el contexto de estos y lo presentan delante de } \\
\text { sus compañeros. Se les recuerda utilizar el lenguaje no } \\
\text { verbal para demostrar satisfacción, molestia, y otras } \\
\text { emociones y sentimientos. } \\
\text { 3. Cada grupo recitará el juramento creado. } \\
\text { Durante este proceso, el docente se moviliza } \\
\text { constantemente por el aula para absolver dudas o hacer } \\
\text { aclaraciones. }\end{array}$ \\
\hline 7. Evaluación (40’) & 8. Tarea & Observaciones \\
\hline
\end{tabular}


1. Durante la aplicación de los conocimientos, se realizan evaluaciones orales individuales o en

pareja/tríos a través de una Lista de cotejo.

2. Al final de la sesión se tomará una Prueba escrita

objetiva sobre los conocimientos y habilidades

adquiridas.

3. Las redacción escrita durante el proceso se

evaluará con una Rúbrica

4. Ficha de autoevaluación, al término de la sesión

para que evalúen su desempeño en clase.

5. Ficha de coevaluación, aplicada después del trabajo en parejas

Metacognición:

1. Ficha de metacognición que incluye las preguntas: ¿qué aprendí? ¿para qué lo aprendí? ¿cómo lo

aprendí?

En base a las respuestas, se les hace reflexionar sobre propios procesos de aprendizaje.

Retroalimentación

Observaciones por parte del docente hechas en

relación al desarrollo de la clase y sugerencias sobre

qué requieren mejorar los estudiantes.
En grupos, crear un discurso compromiso de lealtad

frente a la familia, amigos, equipo deportivo, grupo de música... 


\section{Anexo 9}

\section{Ficha de validación de la propuesta metodológica}

\section{Datos generales.}

1.1. Apellidos y nombres del especialista:

1.2. Grado de estudios alcanzado

1.3. Resultado científico en valoración:

1.4. Autor del resultado científico :

II. Aspectos a observar VALIDACIÓN INTERNA

\begin{tabular}{|c|c|c|c|c|c|c|c|c|}
\hline \multirow{3}{*}{ Indicadores } & \multirow{2}{*}{\multicolumn{5}{|c|}{$\begin{array}{l}\text { Escala de } \\
\text { valoración }\end{array}$}} & \multicolumn{3}{|c|}{ Aspectos } \\
\hline & & & & & & \multirow{2}{*}{$\begin{array}{l}\text { Positi } \\
\text { vos }\end{array}$} & \multirow{2}{*}{$\begin{array}{l}\text { Negati } \\
\text { vos }\end{array}$} & \multirow{2}{*}{$\begin{array}{l}\text { Suger } \\
\text { encias }\end{array}$} \\
\hline & 1 & 2 & 3 & 4 & 5 & & & \\
\hline Factibilidad de aplicación del resultado que se presenta. & & & & & & & & \\
\hline Claridad de la propuesta para ser aplicado por otros & & & & & & & & \\
\hline $\begin{array}{l}\text { Posibilidad de la propuesta de extensión a otros } \\
\text { contextos semejantes }\end{array}$ & & & & & & & & \\
\hline $\begin{array}{l}\text { Correspondencia con las necesidades sociales e } \\
\text { individuales actuales }\end{array}$ & & & & & & & & \\
\hline $\begin{array}{l}\text { Congruencia entre el resultado propuesto y el objetivo } \\
\text { fijado. }\end{array}$ & & & & & & & & \\
\hline $\begin{array}{l}\text { Novedad en el uso de conceptos y procedimientos de la } \\
\text { propuesta. }\end{array}$ & & & & & & & & \\
\hline $\begin{array}{l}\text { La modelación contiene propósitos basados en los } \\
\text { fundamentos educativos, curriculares y pedagógicos. } \\
\text { detallado, preciso y efectivo }\end{array}$ & & & & & & & & \\
\hline $\begin{array}{l}\text { La propuesta está contextualizada a la realidad en } \\
\text { estudio }\end{array}$ & & & & & & & & \\
\hline $\begin{array}{l}\text { Presenta objetivos claros, coherentes y posibles de } \\
\text { alcanzar }\end{array}$ & & & & & & & & \\
\hline Contiene un plan de acción de lo general a lo particular & & & & & & & & \\
\hline
\end{tabular}

FICHA DE VALIDACIÓN EXTERNA (FORMA)

\begin{tabular}{|c|c|c|c|c|c|c|c|c|c|}
\hline \multirow{4}{*}{ Indicadore } & & \multirow{2}{*}{\multicolumn{5}{|c|}{$\begin{array}{l}\text { Escala de } \\
\text { valoración }\end{array}$}} & \multicolumn{3}{|c|}{ Aspectos } \\
\hline & & & & & & \multirow{3}{*}{\multicolumn{2}{|c|}{\begin{tabular}{|l} 
\\
Positiv \\
os
\end{tabular}}} & \multirow{3}{*}{$\begin{array}{l}\text { Negativ } \\
\text { os }\end{array}$} & \multirow{3}{*}{$\begin{array}{l}\text { Sugere } \\
\text { ncias }\end{array}$} \\
\hline & & \multirow{2}{*}{1} & \multirow[b]{2}{*}{2} & \multirow{2}{*}{\multicolumn{2}{|c|}{\begin{tabular}{l|l}
3 & 4 \\
\end{tabular}}} & & & & \\
\hline & & & & & 4 & 5 & & & \\
\hline Claridad & $\begin{array}{l}\text { Es formulado con lenguaje } \\
\text { apropiado }\end{array}$ & & & & & & & & \\
\hline
\end{tabular}




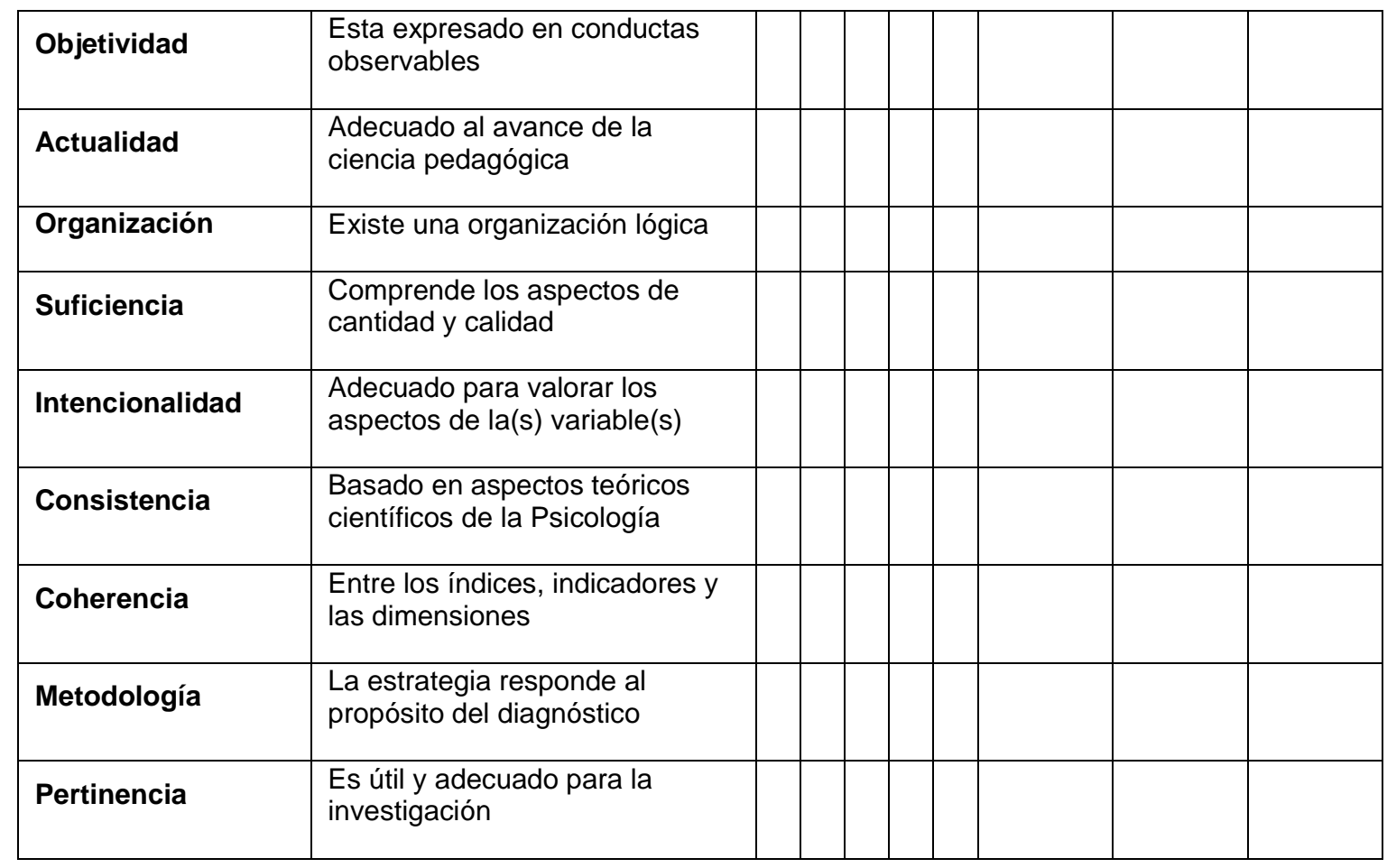

I. Aportes o sugerencias para el perfeccionamiento del resultado científico:

\section{Opinión de aplicabilidad.}

III. RESULTADOS

PROMEDIO DE VALORACIÓN INTERNA: (50\%) (50\%) + PUNTAJE DE VALORACIÓN EXTERNA:

RESULTADO DE VALORACIÓN:

Tabla de Valoración

Deficiente $0-25$

Baja $25-50$

Regular

$51-70$

Buena

$71-85$

Muy Buena

$86-100$
1. Deficiente ( )
2. Baja
3. Regular
4. Buena
5. Muy buena ( )

OPINIÓN DE APLICABILIDAD:
a) Deficiente ( )
b) Baja
c) Regular ( )
d) Buena ( )
e) Muy Buena ( )

\begin{tabular}{|l|l|l|l|}
\hline Nombres y Apellidos & & DNI Na & \\
\hline Dirección domiciliaria & & Teléfono / Celular & \\
\hline
\end{tabular}




\begin{tabular}{|l|l|}
\hline Título profesional / Especialidad & \\
\hline Grado Académico & \\
\hline Mención & \\
\hline
\end{tabular}

\section{Firma}

Lugar y fecha:

Ficha de validación de la propuesta metodológica

Datos generales.

Apellidos y nombres de especialista: ....Flores Valdiviezo. Hernán

Grado de estudios aleanzado: ... Magster.

Resultado científico en valoración: Estrategia metodológica para desarrollar

competencia comunicativa oral en los estudiantes de Inglés de Negocios Internacionales

Autor del resultado cientifico: Bachiller Susan Jannina Cubas Cruz

Aspectos a observar

\begin{tabular}{|c|c|c|c|c|c|}
\hline \multirow{3}{*}{ indicadores } & erna & & & & \\
\hline & \multirow{2}{*}{\multicolumn{2}{|c|}{$\begin{array}{l}\text { Escale de } \\
\text { valoración }\end{array}$}} & \multicolumn{3}{|l|}{ Aspectos } \\
\hline & & & Positivos & Negativos & Sugerencias \\
\hline Factibilidad de aplicación del resultado que se presenta. & \multicolumn{2}{|c|}{\begin{tabular}{l|l|l|l|l|l}
1 & 2 & 3 & -4 & 5 \\
\end{tabular}} & & & \\
\hline Claridad de la propuesta para ser aplicado por otros & & 7 & & & \\
\hline $\begin{array}{l}\text { Posibilidad de la propuesta de extensión a otros } \\
\text { contextos semejantes }\end{array}$ & & $\sqrt{ }$ & & & \\
\hline $\begin{array}{l}\text { Correspondencia con las necesidades sociales e } \\
\text { individuales actuales }\end{array}$ & & $\mathcal{D}$ & & & \\
\hline $\begin{array}{l}\text { Congruencia entre el resultado propuesto y el objetivo } \\
\text { fijado. }\end{array}$ & & $\checkmark$ & & & \\
\hline $\begin{array}{l}\text { Novedad en el uso de conceptos y procedimientos de la } \\
\text { propuesta. }\end{array}$ & & $\sqrt{ }$ & & & \\
\hline $\begin{array}{l}\text { La modelación contiene propósitos basados en los } \\
\text { fundamentos educativos. curriculares y pedagógicos. } \\
\text { detallado, preciso y efectivo }\end{array}$ & & d & & & \\
\hline $\begin{array}{l}\text { La propuesta está contextualizada a la realidad en } \\
\text { estudio. }\end{array}$ & & $d$ & & & \\
\hline $\begin{array}{l}\text { Presenta objetivos claros, coherentes y posibles de } \\
\text { alcanzar. }\end{array}$ & & $\sqrt{ }$ & & & \\
\hline Contiene un plan de ácción de lo general a lo particu & & 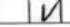 & & & \\
\hline
\end{tabular}

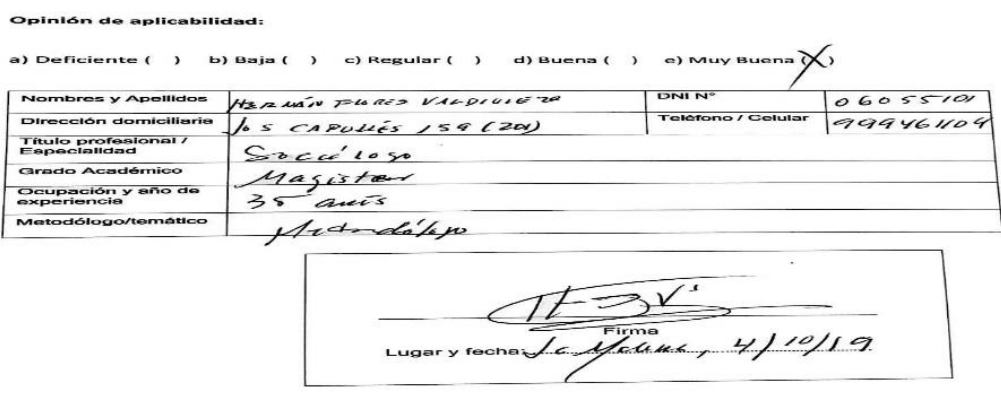




\begin{tabular}{|c|c|c|c|c|c|c|c|c|}
\hline \multicolumn{2}{|l|}{ Indicadores } & \multicolumn{4}{|c|}{$\begin{array}{l}\text { Escala de } \\
\text { valoración }\end{array}$} & \multicolumn{3}{|l|}{ Aspectos } \\
\hline & & & & & & \multirow[t]{2}{*}{ Positivos } & \multirow[t]{2}{*}{ Negativos } & \multirow[t]{2}{*}{ Sugerencias } \\
\hline & & 1 & 2 & \begin{tabular}{l|l|}
3 & 4
\end{tabular} & 5 & & & \\
\hline Claridad & $\begin{array}{l}\text { Es formulado con lenguaje } \\
\text { apropiado. }\end{array}$ & & & & V & & & \\
\hline Objetividad & $\begin{array}{l}\text { Está expresado en conductas } \\
\text { observables }\end{array}$ & & & & $\sqrt{ }$ & & & \\
\hline Actualidad & $\begin{array}{l}\text { Adecuado al avance de la } \\
\text { ciencia pedagógica. }\end{array}$ & & & & $\sqrt{ }$ & & & \\
\hline Organización & Existe una organización lógica. & & & & $\sqrt{ }$ & & & \\
\hline Suficiencia & $\begin{array}{l}\text { Comprende los aspectos de } \\
\text { cantidad y calidad }\end{array}$ & & & & 1 & & & \\
\hline Intencionalidad & $\begin{array}{l}\text { Adecuado para valorar los } \\
\text { aspectos de las categorias. }\end{array}$ & & & & $\sqrt{ }$ & & & \\
\hline Consistencia & $\begin{array}{l}\text { Basado en aspectos teóricos } \\
\text { científicos de la educación. }\end{array}$ & & & & $\checkmark$ & & & \\
\hline Coherencia & $\begin{array}{l}\text { Entre el propósito, diseño y la. } \\
\text { implementación de la propuesta. }\end{array}$ & & & & $\sqrt{ }$ & & & \\
\hline Metodologia & $\begin{array}{l}\text { La estrategia responde al } \\
\text { propósito de la investigación }\end{array}$ & & & & $\sqrt{1}$ & & & \\
\hline Pertinencia & $\begin{array}{l}\text { Es útil y adecuado para la } \\
\text { investigación }\end{array}$ & & & & $\sqrt{ }$ & & & \\
\hline
\end{tabular}
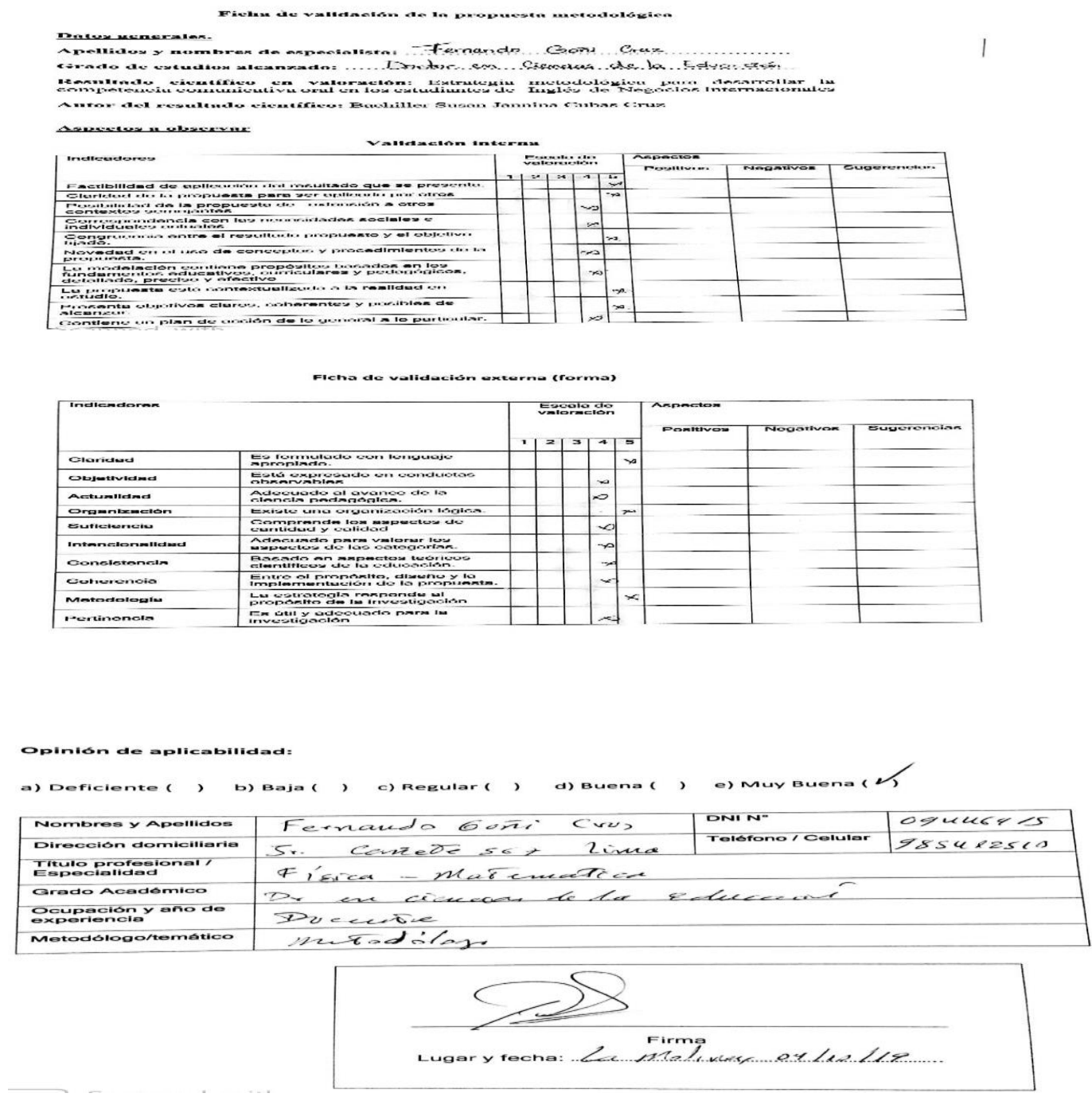
Datos generales.

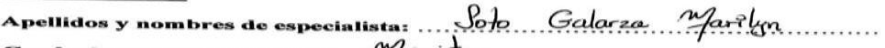

Grado de estudios alcanzado: .... Magiester.

Resultado ciemtifico en valoración: Estrategia metodológica para desarrollar la
competenóa comunicativa oral en los estudiantes de Inglés de Nogocios

Autor del resultado cientifico: Bachiller Susan Jannina Cubas Cruz

Aspectos a observar

\begin{tabular}{|c|c|c|c|c|c|}
\hline \multirow{3}{*}{ indicadores } & \\
\hline & \multirow{2}{*}{\multicolumn{2}{|c|}{\begin{tabular}{l|l} 
Eacala des \\
vaioración
\end{tabular}}} & \multirow{2}{*}{\begin{tabular}{|l} 
Aspectios \\
Postivos
\end{tabular}} & \multirow[b]{2}{*}{ Negativos } & \multirow[b]{2}{*}{ Sugerencias } \\
\hline & & & & & \\
\hline Factibilidad de aplicación del resultado que se presents. & & & & & \\
\hline Claridad de ia propuesta para ser aplicado por otros & $x$ & & & & \\
\hline $\begin{array}{l}\text { Posibilidad de le propuesta de extensión a otros } \\
\text { contentos semejantes }\end{array}$ & & $x$ & & & \\
\hline $\begin{array}{l}\text { Gorrespondencia con las necesidados sociales a } \\
\text { individusies actules }\end{array}$ & & L & & & \\
\hline $\begin{array}{l}\text { Congruencia entre el resultado propuesto y el objetivo } \\
\text { riado. }\end{array}$ & & $x$ & & & \\
\hline $\begin{array}{l}\text { Novedad en al uso de conceptos y procedimientos de la } \\
\text { propuesta. }\end{array}$ & $x$ & & & & \\
\hline 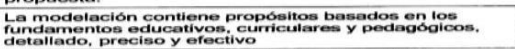 & & $x$ & & & \\
\hline $\begin{array}{l}\text { La propuesta está contextualizada a la realidad en } \\
\text { estuduaio. }\end{array}$ & & $x$ & & & \\
\hline Presenta objetivos elaros, coherentes y posibles de & & $x$ & & & \\
\hline 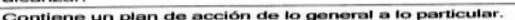 & & $\mid x$ & & & \\
\hline
\end{tabular}

Promedio de valoracion - Valoración internatrataracion extarna

resultado de valoración: 10.5

Escala de valoracion

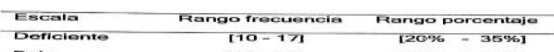

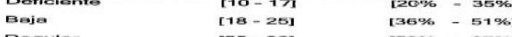

$\begin{array}{lll}\text { Regutar } & 126-39] & 852 \%=67 \% \\ \text { Buena } & {[34-41]} & {[68 \%-83 \%,}\end{array}$

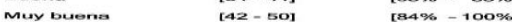

Opinion de aplicabilidad:

a) Deficiente (, b) Baja (, c) Regutar (, d) Buena $\chi$, e) Muy Buena ( ,

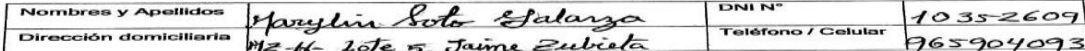

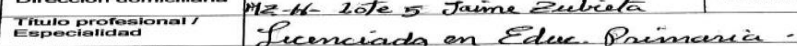

Especiandad $\quad$ Lecenciads an Edwer.

arado Acadímico

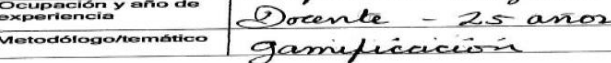

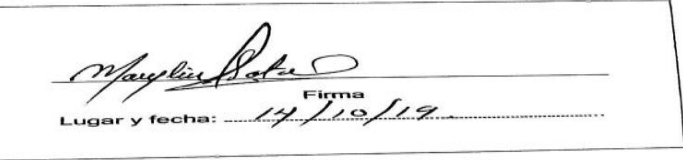

